THIAGO ALEXANDRE ALVES DE ASSUMPÇÃO

DESENVOLVIMENTO DE TÉCNICA PARA NUCLEAÇÃO DE NANOPARTÍCULAS METÁLICAS EM VIDROS DE GERMANATO DOPADOS COM ÍONS DE TÚLIO PARA APLICAÇÕES EM DISPOSITIVOS FOTÔNICOS 
THIAGO ALEXANDRE ALVES DE ASSUMPÇÃO

\section{DESENVOLVIMENTO DE TÉCNICA PARA NUCLEAÇÃO DE NANOPARTÍCULAS METÁLICAS EM VIDROS DE GERMANATO DOPADOS COM ÍONS DE TÚLIO PARA APLICAÇÕES EM DISPOSITIVOS FOTÔNICOS}

Dissertação de Mestrado apresentada à Escola Politécnica da Universidade de São Paulo para obtenção do título de Mestre em Engenharia. 
THIAGO ALEXANDRE ALVES DE ASSUMPÇÃO

\section{DESENVOLVIMENTO DE TÉCNICA PARA NUCLEAÇÃO DE NANOPARTÍCULAS METÁLICAS EM VIDROS DE GERMANATO DOPADOS COM ÍONS DE TÚLIO PARA APLICAÇÕES EM DISPOSITIVOS FOTÔNICOS}

Dissertação de Mestrado apresentada à Escola Politécnica da Universidade de São Paulo para obtenção do título de Mestre em Engenharia.

Área de Concentração: Microeletrônica

Orientador:

Prof. Dra. Luciana Reyes Pires Kassab 
Dedico este trabalho aos meus pais e minhas irmãs que sempre estiveram presente em minhas experiências, me ajudaram $e$ incentivaram a continuar minha jornada. 


\section{AGRADECIMENTOS}

À Profa. Dra. Luciana Reyes Pires Kassab, pela orientação, amizade, confiança e pela oportunidade em desenvolver esta pesquisa.

À FATEC-SP, por ter cedido o Laboratório de Vidros e Datação para o desenvolvimento deste trabalho.

Ao Prof. Dr. Pedro Kyohara, do Laboratório de Microscopia Eletrônica do IFUSP, pelo uso do equipamento para as medidas de Microscopia Eletrônica de Transmissão, e à Simone Perche de Toledo por realizar e analisar as medidas de Microscopia Eletrônica de Transmissão.

Aos Profs. Dr. Cid B. Araújo e Dr. Anderson S. L. Gomes, do Departamento de Física da UFPE, pela colaboração, auxílio e participação em eventos e publicações.

Ao Prof. Dr. Shigueu Watanabe, do Laboratório de Cristais lônicos, Vidros Especiais e Datação Arqueológica (IFUSP), pela colaboração nas medidas de absorção óptica.

Ao Prof. Dr. Niklaus Ursus Wetter do Centro de Lasers e Aplicações do IPENSP, pelo uso de equipamentos na realização de medidas de luminescência no visível.

Aos amigos que ainda estão e aos que passaram pelo laboratório: Vanessa, Davinson, Renata, Ricardo, Diego, Carlos, José, Fabio, Francisco, Leonardo, Juan, Katia, Flávia, René e Windson, pela amizade e apoio em todos os momentos.

Ao CNPq, pela bolsa de mestrado e pelo apoio financeiro através da Rede Nanofoton, para a compra de materiais de consumo, equipamentos e auxílio em congressos.

A minha namorada que em muitos momentos, durante o desenvolvimento deste trabalho, teve paciência nas horas difíceis, foi compreensiva e atenciosa, me incentivou e colaborou quando precisei de ajuda, e pelo amor e carinho incondicional.

A todos que de alguma forma contribuíram para o desenvolvimento deste trabalho, os meus sinceros agradecimentos.

Agradeço também a Deus, pela vida e pelos caminhos abençoados! 
"Bom mesmo é ir à luta com determinação, abraçar a vida e viver com paixão, perder com classe e viver com ousadia. Pois o triunfo pertence a quem se atreve, e a vida é muito bela para ser insignificante." 


\section{RESUMO}

Neste trabalho são apresentadas a preparação, a metodologia adotada para a nucleação de nanopartículas (NPs) de prata e a investigação das propriedades luminescentes do sistema vítreo $\mathrm{GeO}_{2}$ - $\mathrm{PbO}$ dopado com íons de túlio e codopado com íons de túlio e itérbio, na presença de NPs de prata, visando aplicação em dispositivos fotônicos. Este sistema vítreo apresenta uma larga janela de transmissão (400 - $4500 \mathrm{~nm}$ ) quando comparado aos silicatos, boratos e fosfatos, alto índice de refração $(\approx 2,0)$, baixas energia de fônon $\left(700 \mathrm{~cm}^{-1}\right)$, alta resistência mecânica e durabilidade química. Com a finalidade de se obter maior controle sobre o processo de nucleação das NPs, realizaram-se tratamentos térmicos de várias formas, variando-se principalmente as grandezas tempo e temperatura. A partir da Microscopia Eletrônica de Transmissão (MET), a presença das NPs no material vítreo pôde ser confirmada, e pelas análises de Espectroscopia de Energia Dispersiva (EDS - Energy Dispersive Spectroscopy), determinamos que as NPs possuem em sua composição prata, podendo elas serem puramente metálicas, e em alguns casos, compostas de prata e elementos da matriz. As medidas de absorção evidenciaram a incorporação dos íons $\mathrm{Tm}^{3+}$ e $\mathrm{Yb}^{3+}$ na forma trivalente, e a presença das bandas de absorção associadas à Ressonância dos Plasmons Superficiais (RPS) da prata, localizadas no intervalo de 420 a $550 \mathrm{~nm}$. Foram medidas as bandas associadas à conversão ascendente $(\mathrm{CA})$ do $\mathrm{Tm}^{3+}$ em 480, 650 e $800 \mathrm{~nm}$, devidas às transições ${ }^{1} \mathrm{G}_{4} \rightarrow{ }^{3} \mathrm{H}_{6},{ }^{1} \mathrm{G}_{4} \rightarrow{ }^{3} \mathrm{~F}_{4},{ }^{3} \mathrm{H}_{4} \rightarrow{ }^{3} \mathrm{H}_{6}$, respectivamente. Nas amostras contendo NPs de prata, tratadas a $420^{\circ} \mathrm{C}$, não foi observada a banda de RPS da prata. Entretanto, um aumento na luminescência foi verificado, assim como a presença das NPs por MET. No caso das amostras tratadas por intervalos de tempo contínuos e não-contínuos, observamos a tendência de formação de NPs menores, maiores e agregados, e maior tendência de aumento da luminescência para o segundo caso; no caso da variação da temperatura, observamos a formação da banda de RPS da prata para tratamentos superiores a $500{ }^{\circ} \mathrm{C}$ realizados em curto intervalo de tempo, e um aumento considerável da luminescência. As variações no processo de nucleação das NPs foram relacionadas às formas de tratamento adotadas. O estudo da variação da intensidade de luminescência em função da potência do laser de excitação mostrou que as NPs não interferem nos 
processos de CA dos íons $\mathrm{Tm}^{3+}$. Desta forma, o aumento da luminescência foi atribuído ao aumento do campo local nas proximidades dos íons de terras-raras (TRs). Portanto, o desenvolvimento de um método adequado de tratamento térmico desempenha um papel fundamental no processo de nucleação das NPs, e pode permitir um aumento considerável da luminescência proveniente dos íons de TRs, e conferir novas propriedades aos materiais e aplicações em dispositivos fotônicos.

Palavras-chave: Nanopartículas metálicas, conversão ascendente, íons de terrasraras, túlio, itérbio, vidros. 


\section{ABSTRACT}

This work presents the preparation and the methodology used for the nucleation of silver nanoparticles (NPs), and the investigation of the luminescent properties of $\mathrm{PbO}-\mathrm{GeO}_{2}$ glass system doped with thulium ions and codoped with thulium and ytterbium ions, in the presence of NPs silver, for application in photonic devices. This glass system presents a large transmission window (400 - $4500 \mathrm{~nm}$ ) when compared to silicates, borates and phosphates, high refractive index $(\approx 2.0)$, low phonon energy $\left(700 \mathrm{~cm}^{-1}\right)$, high mechanical strength and chemical durability. In order to obtain greater control over the process of nucleation of NPs, different processes were used for the heat-treatment, varying mainly the time and the temperature. From the transmission electron microscopy (TEM), the presence of NPs in the glassy material could be confirmed, and from Energy Dispersive Spectroscopy (EDS) analysis, it was determined that the NPs have silver in their composition. The NPs may be purely metallic and, in some cases, composed by silver and elements of the matrix glass. Optical Absorption measurements showed the incorporation of $\mathrm{Tm}^{3+}$ and $\mathrm{Yb}^{3+}$ ions in the trivalent form, and the presence of absorption bands related to the Surface Plasmon Resonance (SPR) of silver, located in the range of 420 to 550 $\mathrm{nm}$. Bands associated to $\mathrm{Tm}^{3+}$ upconversion (UPC) frequency centered around 480, 650 and $800 \mathrm{~nm}$ were observed due to transitions ${ }^{1} \mathrm{G}_{4} \rightarrow{ }^{3} \mathrm{H}_{6},{ }^{1} \mathrm{G}_{4} \rightarrow{ }^{3} \mathrm{~F}_{4},{ }^{3} \mathrm{H}_{4} \rightarrow{ }^{3} \mathrm{H}_{6}$, respectively. The SPR of silver NPs were not observed for the samples heat-treated at $420^{\circ} \mathrm{C}$, which contained silver NPs in their composition. However, an increase in the luminescence was observed and the presence of NPs was confirmed by TEM analyses. For the samples heat-treated by continuous and non-continuous time intervals, we observed the tendency of the formation of smaller, larger and aggregated NPs, and a higher tendency of enhancement of the luminescence for the second case. For the samples heat-treated at different temperatures in short time interval, we observed the formation of the SPR band for temperatures higher than $500{ }^{\circ} \mathrm{C}$, and a considerable increase in the luminescence. Variations in the process of NPs nucleation were related to the different heat-treatments adopted. The study of the luminescence intensity variation as function of the laser power excitation showed that the NPs do not interfere in the $\mathrm{Tm}^{3+}$ UPC luminescence processes. Thus, the enhancement in the luminescence was attributed to local field enhancement in the 
proximities of rare-earth ions (REIs). Therefore, the development of an appropriate method of heat-treatment plays an important role in the process of NPs nucleation, and enables a considerable increase in the luminescence from the REIs, and gives new properties to materials which are of great interest for applications in photonic devices.

Keywords: Metallic nanoparticles, upconversion, rare-earth ions, thulium, ytterbium, glasses. 


\section{LISTA DE ILUSTRAÇÕES}

Figura 1.1 - Taça de Lycurgus (IV d.C.) [3]

22

Figura 2.1 - Analogia bidimensional esquemática, segundo Zachariasen, ilustrando a estrutura de um (a) cristal e de um (b) material amorfo, de mesma composição [22].

Figura 2.2 - Processo de formação de vidros e cristais [17] .............................27

Figura 2.3 - Níveis de energia da configuração $4 f$ dos íons $\operatorname{TR}^{3+}[34]$.................... 34

Figura 2.4 - Exemplos de processos de conversão ascendente (CA). (a) CA por AEE; (b) CA por AEE através da TE entre íons; (c) CA por EC.

Figura 2.5 - Diagrama simplificado dos níveis de energia dos íons $\mathrm{Tm}^{3+} \mathrm{com}$ a representação das emissões possíveis no visível.

Figura 2.6 - Diagrama simplificado dos níveis de energia (a) do íon $\mathrm{Tm}^{3+}$ com a representação dos processos de CA por AEE e RC e (b) dos íons $\mathrm{Tm}^{3+}$ e $\mathrm{Yb}^{3+}$ com a representação dos processos de CA por AEE através da TE. 40

Figura 2.7 - Esquema para a oscilação plasmônica de uma esfera, mostrando o deslocamento da nuvem dos elétrons livres em relação ao núcleo. 42

Figura 2.8 - Representação das distâncias entre NPs e íons de TRs.

Figura 2.9 - Espectro de absorção de NPs de ouro com diferentes tamanhos [20].

Figura 2.10 - Espectro de absorção de NPs de ouro em suspensão, mostrando a formação de banda de plasmon em 650nm, decorrente da aglomeração das NPs [55].

Figura 2.11 - Interferência da forma das nanopartículas de prata na posição das bandas de absorção dos PS em colóides com nanopartículas de prata [58] ....48 Figura 2.12 - Comparação de bandas de plasmon de NPs de prata em vidros de sílica [59].

Figura 2.13 - Representação esquemática da nucleação das NPs de prata.

Figura 2.14 - Espectros de absorção (à esquerda) e emissão (à direita) de amostras de germanato dopadas com $\mathrm{Pr}^{3+}$ e NPs de prata [80]. 
Figura 2.15 - Espectros de absorção (à esq.) e de emissão (à dir.) de amostra de germanatos dopadas com $\mathrm{Er}^{3+}$. As transições indicadas na figura são referentes aos íons de $\mathrm{Er}^{3+}[20,81]$.

Figura 2.16 - Espectro de absorção de filmes finos de germanato contendo NPs de cobre e de $\mathrm{Cu}_{2} \mathrm{O}$. LGF-7 corresponde ao filme fino tratado por 7 horas e LGF-17, ao filme tratado por 17 horas [82]

Figura 2.17 - Espectro de emissão das amostras de germanato codopadas com $\mathrm{Er}_{2} \mathrm{O}_{3}$ e $\mathrm{Yb}_{2} \mathrm{O}_{3}$ contendo NPs de prata. As transições identificadas por I, II e III são, respectivamente, ${ }^{2} \mathrm{H}_{11} \rightarrow{ }^{4} \mathrm{I}_{15 / 2}(525 \mathrm{~nm}),{ }^{4} \mathrm{~S}_{3 / 2} \rightarrow{ }^{4} \mathrm{I}_{15 / 2}(550 \mathrm{~nm})$ e ${ }^{4} \mathrm{~F}_{9 / 2} \rightarrow{ }^{4} \mathrm{I}_{15 / 2}(662 \mathrm{~nm})$, e correspondem aos íons de $\mathrm{Er}^{3+}$ [85].

Figura 2.18 - Espectros de (a) absorção e de (b) emissão das amostra de germanato dopadas com $\mathrm{Eu}_{2} \mathrm{O}_{3}$ e $\mathrm{Au}_{2} \mathrm{O}_{3}$, tratadas termicamente de 1 a 72 horas. As transições identificadas nos espectros correspondem aos íons de $\mathrm{Eu}^{3+}$, e a larga banda de absorção centrada em $\approx 500 \mathrm{~nm}$ corresponde à RPS do ouro [87]

Figura 2.19 - Gravação em amostra de telureto.

Figura 2.20 - Evaporadora PV 300 Prest Vácuo. À esquerda, a câmara de vácuo, onde se situa a amostra vítrea e o substrato. À direita, o painel de controle do sistema de vácuo e geração de rádio freqüência. 57

Figura 2.21 - Plasma de argônio gerado durante a deposição de filmes finos. 58

Figura 3.1 - Espectro de absorção na região do visível e infravermelho próximo (esquerda) e transmitância no infravermelho (direita) da matriz vítrea estudada......59 Figura 3.2 - Etapas utilizadas na confecção das amostras vítreas. 62 Figura 3.3 - Diagrama das etapas de produção do vidro e nucleação das NPs metálicas.

Figura 3.4 - Diagrama das etapas utilizadas para nuclear as NPs variando-se os tempos de tratamento.

Figura 3.5 - Diagrama das etapas utilizadas para a nucleação das NPs em diferentes temperaturas.

Figura 3.6 - Espectrofotômetro Cary 500 usado nas medidas de absorção óptica. 66

Figura 3.7 - Arranjo experimental para as medidas de absorção óptica [26]. 
Figura 3.8 - Foto do arranjo experimental das medidas de emissão realizadas nas amostras codopadas com $\mathrm{Tm}_{2} \mathrm{O}_{3}$ e $\mathrm{Yb}_{2} \mathrm{O}_{3}$.

Figura 3.9 - Arranjo experimental das medidas de emissão realizadas nas amostras.

Figura 3.10 - Imagens do (a) ambiente gráfico e da (b) programação visual utilizadas no desenvolvimento do software empregado nas medidas de luminescência.

Figura 4.1 - Amostras do sistema GP codopadas com $0,5 \% \mathrm{Tm}_{2} \mathrm{O}_{3}$ e diferentes concentrações de $\mathrm{Yb}_{2} \mathrm{O}_{3}$.

Figura 4.2 - Espectro de absorção das amostras do sistema GP codopadas com $0,5 \% \mathrm{Tm}_{2} \mathrm{O}_{3}$ e diferentes concentrações de $\mathrm{Yb}_{2} \mathrm{O}_{3}$.

Figura 4.3 - Espectro de emissão das amostras do sistema GP codopadas com $0,5 \% \mathrm{Tm}_{2} \mathrm{O}_{3}$ e diferentes concentrações de $\mathrm{Yb}_{2} \mathrm{O}_{3}$.

Figura 4.4 - Intensidades de luminescência dos íons de $\mathrm{Tm}^{3+}$ em função da concentração dos íons $\mathrm{Yb}^{3+}$.

Figura 4.5 - Amostras do sistema GP - T2Y1A, tratadas por diferentes intervalos de tempo.

Figura 4.6 - Amostras do sistema GP - T2Y3A, tratadas por diferentes intervalos de tempo.

Figura 4.7 - Amostras do sistema GP - T3Y3A, tratadas por diferentes intervalos de tempo.

Figura 4.8 - Espectro de absorção das amostras T2Y1A, tratada por diferentes intervalos de tempo.

Figura 4.9 - Espectro de absorção das amostras T2Y3A, tratada por diferentes intervalos de tempo.

Figura 4.10 - Espectro de absorção das amostras T3Y3A, tratada por diferentes intervalos de tempo.

Figura 4.11 - Micrografias das amostras T2Y3A, tratadas por (a) 24, (b) 30 e (c) 60 horas.

Figura 4.12 - Histogramas das amostras T2Y3A, tratadas por (a) 24 e (b) 30 horas.

Figura 4.13 - Histogramas das amostras T2Y3A, tratada por 60 horas. 80

Figura 4.14 - Espectros de EDS das amostras T2Y3A, tratadas por 24 horas (à esquerda) e 30 horas (à direita). 
Figura 4.15 - Espectros de EDS das amostras T2Y3A, tratadas por 60 horas.

Figura 4.16 - Micrografias das amostras T3Y3A, tratadas por (a) 24 horas e (b) 30 horas.

Figura 4.17 - Espectros de EDS das amostras T3Y3A, tratadas por 24 horas (a esq.) e 30 horas (à dir.).

Figura 4.18 - Espectro de emissão das amostras T2Y1A, tratadas por diferentes intervalos de tempo.

Figura 4.19 - Espectro de emissão das amostras T2Y3A, tratadas por diferentes intervalos de tempo.

Figura 4.20 - Espectro de emissão das amostras T3Y3A, tratada por diferentes intervalos de tempo.

Figura 4.21 - Espectro de emissão das amostras com as maiores intensidades luminescentes.

Figura 4.22 - Intensidade de luminescência em função da potência do laser para a amostra T2Y3A (60h - 420).

Figura 4.23 - Amostras do sistema GP - T5A, tratadas por diferentes intervalos de tempo: tratamentos contínuos e não-contínuos.

Figura 4.24 - Espectro de absorção das amostras T5A, tratadas por diferentes intervalos de tempo: tratamentos contínuos e não-contínuos.

Figura 4.25 - Micrografias das amostras T5A, tratadas por (a) 12 horas, (b) 24 horas não-contínuas e por (c) 24 horas contínuas. 89

Figura 4.26 - Histogramas das amostras T5A, tratadas por (a) 12 horas, (b) 24 horas não-contínuas e por (c) 24 horas contínuas.

Figura 4.27 - Espectros de EDS das amostras T5A, tratadas por (a) 12 horas,

(b) 24 horas não-contínuas e por (c) 24 horas contínuas.

Figura 4.28 - Micrografias das amostras T5A, tratadas por (a) 48 horas nãocontínuas e (b) 48 horas contínuas.

Figura 4.29 - Micrografias das amostras T5A, tratadas por (a) 72 horas nãocontínuas e (b) 72 horas contínuas.

Figura 4.30 - Histogramas das amostras T5A, tratadas por (a) 48 horas nãocontínuas e (b) 48 horas contínuas.

Figura 4.31 - Histogramas das amostras T5A, tratadas por 72 horas nãocontínuas. 
Figura 4.32 - Espectros de EDS das amostras T5A, tratadas por (à esq.) 48 horas não-contínuas e (à dir.) 48 horas contínuas.

Figura 4.33 - Espectros de EDS das amostras T5A, tratadas por (à esq.) 72 horas não-contínuas e (à dir.) 72 horas contínuas.

Figura 4.34 - Espectro de emissão na região do visível das amostras T5A, tratadas por diferentes intervalos de tempo: tratamentos contínuos e nãocontínuos.

Figura 4.35 - Intensidade de luminescência em função da potência do laser para a amostra T5A $(24 \mathrm{~h}-420)$.

Figura 4.36 - Amostras T2Y3A produzidas em cadinho de alumina pura e tratadas em diferentes temperaturas para nucleação das NPs.

Figura 4.37 - Efeito da banda de RPS das NPs de prata na amostra tratada por

6 horas à $500^{\circ} \mathrm{C}$ (à esq.) e à $540^{\circ} \mathrm{C}$ (à dir.).

Figura 4.38 - Espectro de absorção das amostras T2Y3A, tratadas em diferentes temperaturas.

Figura 4.39 - Micrografia e histograma da amostra T2Y3A $(6 \mathrm{~h}-480) \ldots \ldots \ldots \ldots \ldots \ldots . . . . . .17$

Figura 4.40 - Espectro de EDS da amostra T2Y3A $(6 \mathrm{~h}-480) \ldots \ldots \ldots \ldots \ldots \ldots \ldots \ldots \ldots . . . \ldots 8$

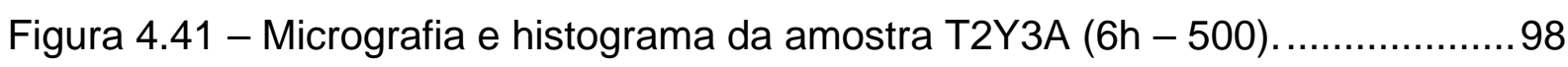

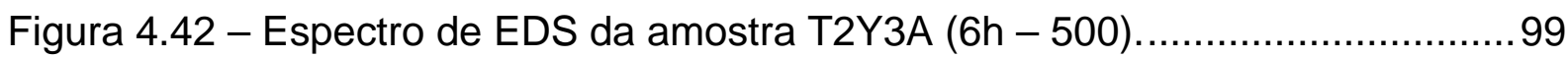

Figura 4.43 - Micrografia e histograma da amostra T2Y3A $(6 \mathrm{~h}-540) \ldots \ldots \ldots \ldots \ldots \ldots . . . . . .99$

Figura 4.44 - Espectro de EDS da amostra T2Y3A $(6 \mathrm{~h}$ - 540).........................100

Figura 4.45 - Micrografia e histograma da amostra T2Y3A $(6 \mathrm{~h}-570) \ldots \ldots \ldots \ldots \ldots \ldots . . .100$

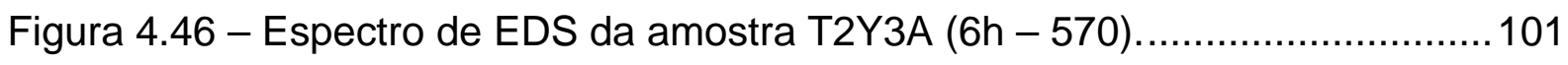

Figura 4.47 - Micrografias das amostra T2Y3A (12h - 540) (à esq.) e T2Y3A (6h - 570) (à dir.), onde foram observadas NPs de chumbo-germânio e chumbo.

Figura 4.48 - Espectro de EDS das amostra T2Y3A (12h - 540) (à esq.) e T2Y3A (6h - 570) (à dir.), onde foram observadas NPs de chumbo-germânio e chumbo.

Figura 4.49 - Espectro de emissão das amostras T2Y3A, tratadas em diferentes temperaturas.

Figura 4.50 - Intensidade de luminescência em função da potência do laser para a amostra T2Y3A $(6 h-570)$. 
Figura 4.51 - Espectro de emissão comparando as amostras produzidas em cadinho de $\mathrm{Al}_{2} \mathrm{O}_{3}-\mathrm{SiO}_{2}$ e em cadinho de $\mathrm{Al}_{2} \mathrm{O}_{3}$, tratadas por diferentes tempos e temperaturas. 


\section{LISTA DE TABELAS}

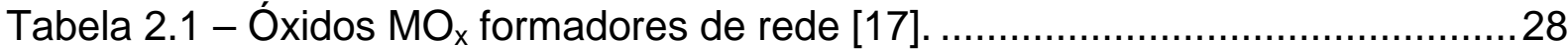

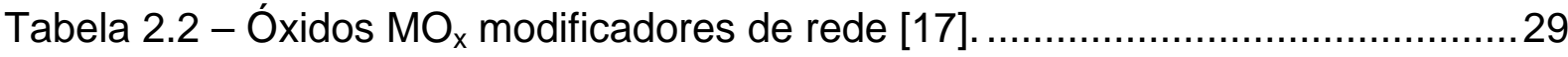

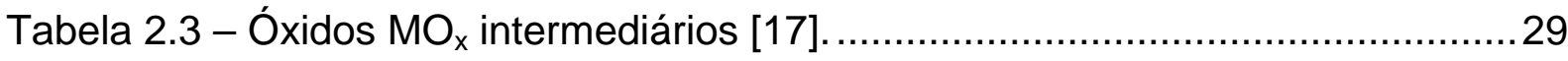

Tabela 2.4 - Óxidos formadores de rede [29]............................................ 31

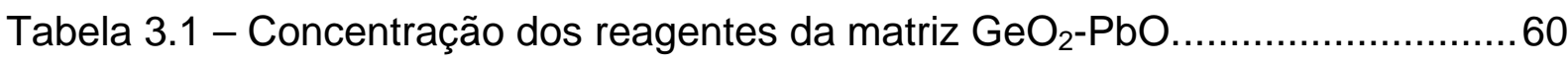

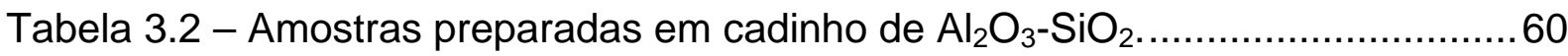

Tabela 3.3 - Amostras preparadas em cadinho de alumina pura. .........................60

Tabela 3.4 - Amostras estudadas neste trabalho e respectivos códigos de identificação.

Tabela 4.1 - Resumo dos resultados referentes a determinação do número de fótons absorvidos ( $n$ ) nas emissões relativas ao processo de conversão ascendente das amostras estudas neste trabalho. 


\section{LISTA DE ABREVIATURAS E SIGLAS}

a.C. Antes de Cristo

AEE Absorção de estado excitado

ATD Análise Térmica Diferencial

CA Conversão Ascendente

CCD Charge-Coupled Device

CNPq Conselho Nacional de Desenvolvimento Científico e Tecnológico

CVD Chemical Vapor Deposition

d.C. Depois de Cristo

EC Emissão Cooperativa

EDS Energy Dispersive Spectroscopy

FATEC-SP Faculdade de Tecnologia de São Paulo

$\mathrm{GP} \quad \mathrm{GeO}_{2}-\mathrm{PbO}$

IFUSP Instituto de Física da USP

IPEN Instituto de Pesquisas Energéticas e Nucleares

IV Infravermelho

LED Light Emitting Diode

LVD Laboratório de Vidros e Datação

MET Microscopia eletrônica de transmissão

NP Nanopartícula

PS Plasmons superficiais ou plasmons de superfície

RC Relaxação Cruzada

RPS Ressonância dos Plasmons superficiais

SC Sensibilização Cooperativa

TE Transferência de energia

TR Terra-rara

UFPE Universidade Federal de Pernambuco

USP Universidade de São Paulo

UV Ultravioleta 


\section{LISTA DE SÍMBOLOS}

$2 R$ Distâncias de pontos e/ou anéis da figura de difração

$2 \lambda L \quad$ Constante característica do feixe de elétrons do microscópio.

$A^{+} \quad$ Ion aceitador

$\mathrm{C}_{Y b}{ }^{3+}$ Concentração de ions $\mathrm{Yb}^{3+}$

$D^{+} \quad$ lon doador

$d_{h k l} \quad$ Distâncias interplanares características de cada elemento

$l_{\text {exc }} \quad$ Intensidade de excitação

$I_{F} \quad$ Intensidade de Fluorescência

$T_{a} \quad$ Temperatura Ambiente

$T_{c} \quad$ Temperatura de Cristalização

$T_{f} \quad$ Temperatura de Fusão

$T_{g} \quad$ Temperatura de Transição Vítrea

$T_{T} \quad$ Temperatura de Tratamento Térmico

$\sigma_{a b s} \quad$ Secção de choque de absorção

$\sigma_{\text {esp }} \quad$ Secção de choque de espalhamento

$\sigma_{\text {ext }} \quad$ Secção de choque de extinção 


\section{SUMÁRIO}

RESUMO

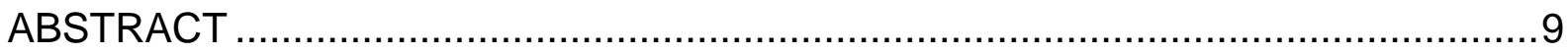

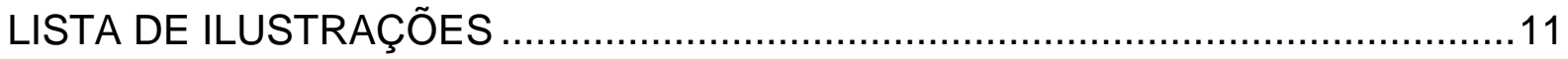

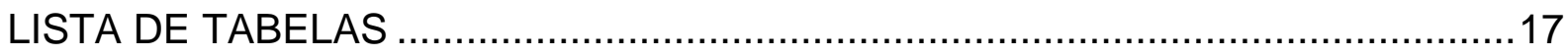

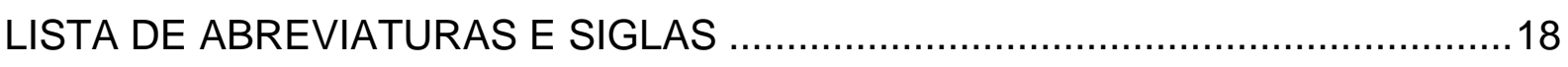

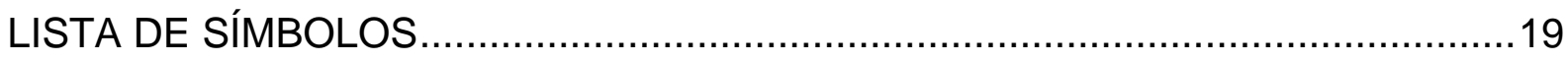

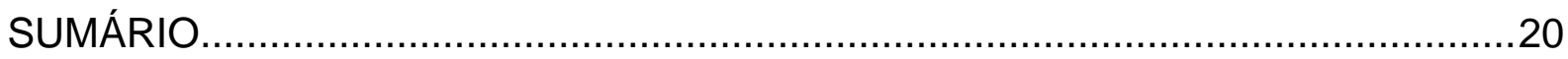

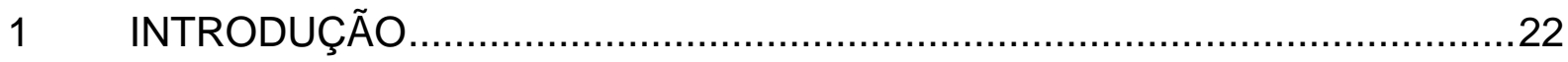

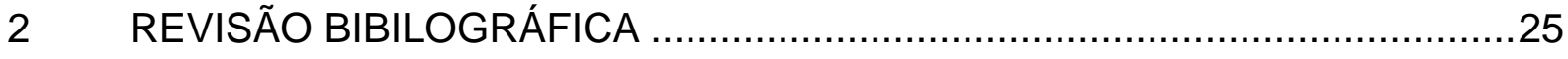

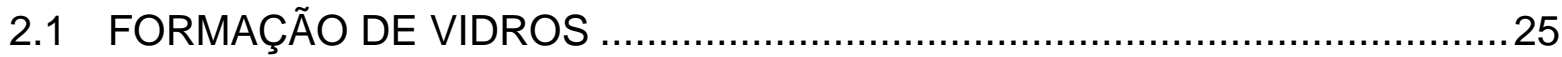

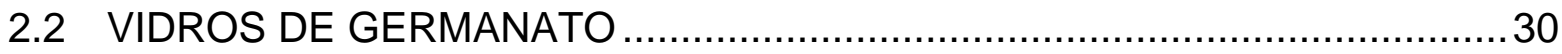

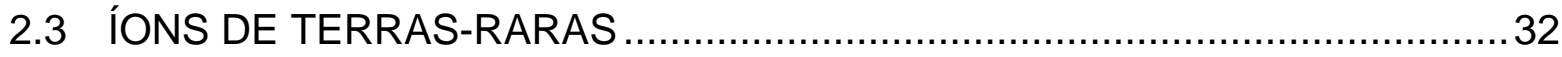

2.3.1 Processos de Transferência de Energia e Conversão Ascendente ........35

2.3.2 Processo de Conversão Ascendente dos íons $\mathrm{Tm}^{3+}$ e de

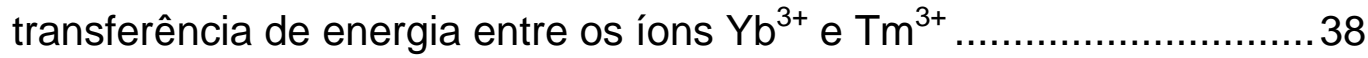

2.4 NANOPARTÍCULAS METÁLICAS E PLASMÔNICA ...................................42

2.4.1 Ressonância dos Plamons Superficiais e a Nucleação das Nanopartículas de Prata............................................................... 48

2.4.2 Metodologias de Nucleação de Nanopartículas ………........................50

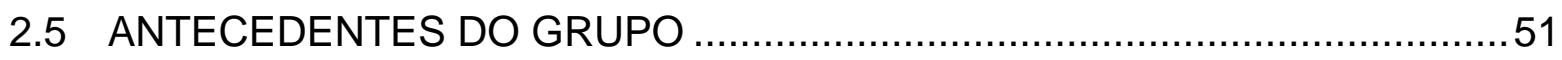

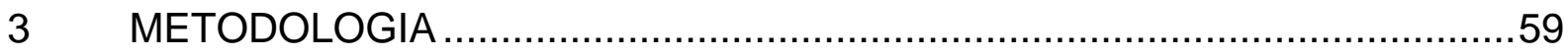

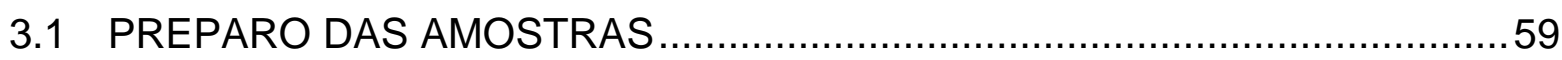

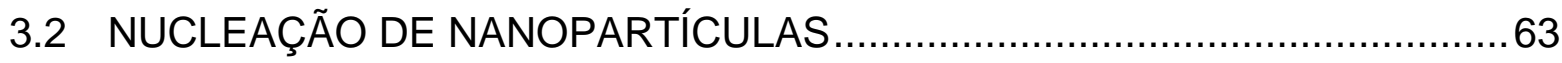

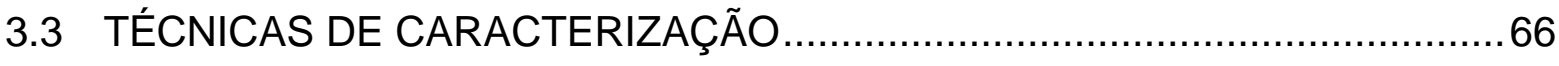

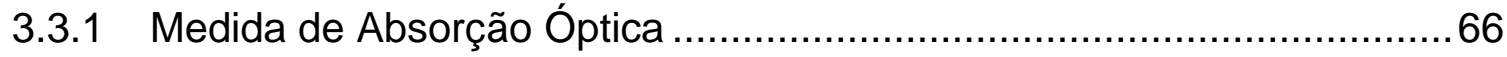

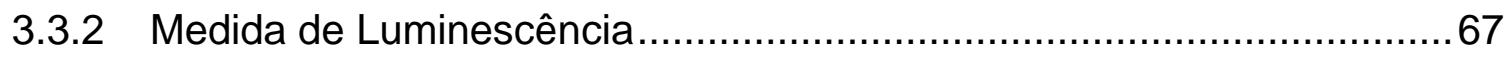


3.3.3 Microscopia Eletrônica de Transmissão e Espectroscopia de Energia

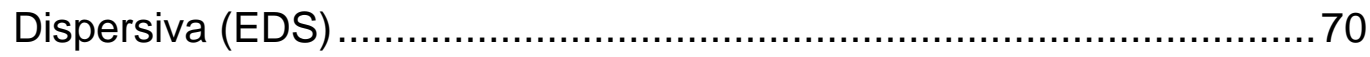

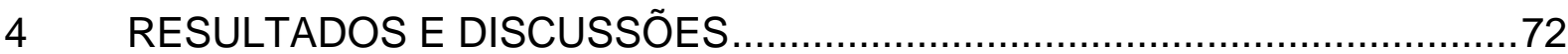

4.1 VIDROS CODOPADOS COM $\mathrm{Tm}_{2} \mathrm{O}_{3} \quad \mathrm{E} \quad \mathrm{Yb}_{2} \mathrm{O}_{3}$ PRODUZIDOS EM CADINHO DE ALUMINA-SILICATO .......................................................... 72

4.1.1 Medidas de Absorção Óptica .............................................................

4.1.2 Medidas de Luminescência ................................................................. 74

4.2 VIDROS CODOPADOS COM $\mathrm{Tm}_{2} \mathrm{O}_{3} \mathrm{E} \mathrm{Yb}_{2} \mathrm{O}_{3}$ CONTENDO NPS DE PRATA PRODUZIDOS EM CADINHO DE ALUMINA-SILICATO ...................76

4.2.1 Medidas de Absorção Óptica ........................................................... 77

4.2.2 Microscopia Eletrônica de Transmissão e EDS......................................78

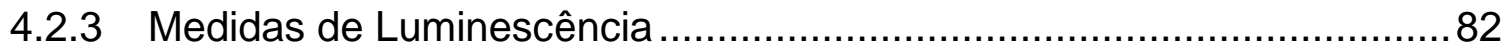

4.3 VIDROS DOPADOS COM $\mathrm{Tm}_{2} \mathrm{O}_{3}$ CONTENDO NPS DE PRATA PRODUZIDOS EM CADINHO DE ALUMINA PURA ....................................8 87

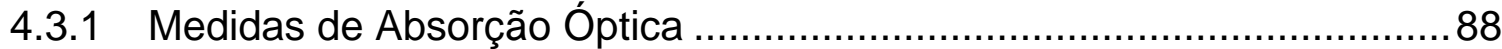

4.3.2 Microscopia Eletrônica de Transmissão e EDS........................................ 89

4.3.3 Medidas de Luminescência ...................................................................93

4.4 VIDROS CODOPADOS COM $\mathrm{Tm}_{2} \mathrm{O}_{3}$ e $\mathrm{Yb}_{2} \mathrm{O}_{3}$ CONTENDO NPS DE PRATA PRODUZIDOS EM CADINHO DE ALUMINA PURA ….....................95

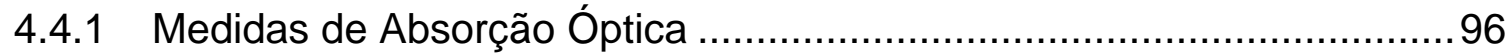

4.4.2 Microscopia Eletrônica de Transmissão e EDS......................................97

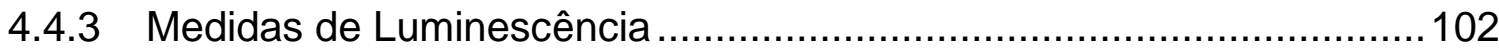

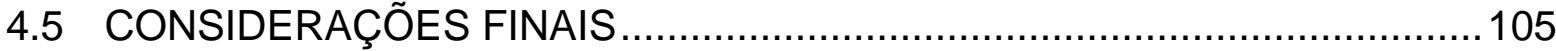

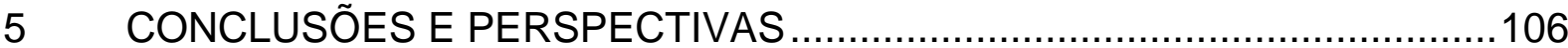

6 SUGESTÕES PARA TRABALHOS FUTUROS ......................................108

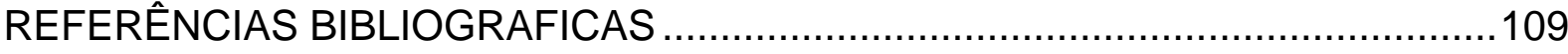

APÊNDICE A - PARTICIPAÇÕES EM CONFERÊNCIAS E PUBLICAÇÕES ........114 


\section{INTRODUÇÃO}

A confecção de novos materiais contendo nanopartículas (NPs) metálicas tem atraído muita atenção dos pesquisadores no mundo todo, dada a possibilidade de modificar as propriedades físicas e químicas dos materiais. Essas modificações são causadas em suma pela presença das NPs e pela forma e distribuição de tamanho das mesmas [1]. Independente de NPs puramente metálicas ou não, as áreas de aplicação são bem amplas. Atualmente a obtenção de materiais contendo NPs distribuídas de forma homogênea e que proporcionem os efeitos desejáveis já é uma realidade. Apesar da grande variedade de estudos que envolvem esta área, na antiguidade já se produziam vidros contendo NPs, sem mesmo que seus fabricantes soubessem das suas propriedades [2].

Os vitrais das grandes e antigas catedrais espalhadas pela Europa, entre outros artefatos, apresentam vidros que produzem efeitos diferentes quando interagem com a luz. Um exemplo é a taça de Lycurgus, fabricada pelos romanos no século IV d. C., que ao interagir com a luz visível, espalha e absorve luz verde e azul, devido à presença de NPs de ouro. Quando observada com uma fonte de luz externa, ou seja, onde ocorre reflexão da luz, a taça assume a coloração esverdeada. Entretanto, quando a fonte de luz é disposta internamente à taça, ou seja, a luz é transmitida, a taça apresenta regiões esverdeadas e avermelhadas. Este efeito ocorre, pois a absorção de luz pelas NPs é maior na região azul-verde do espectro visível que na região vermelha, adquirindo, assim, tonalidades diferentes em cada região, como podemos observar na Figura 1.1 [3].
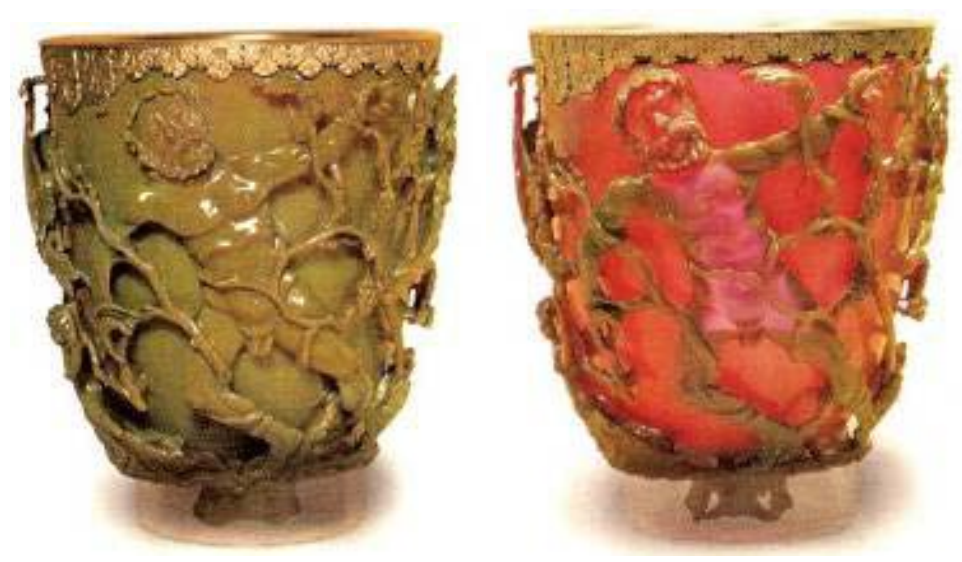

Figura 1.1 - Taça de Lycurgus (IV d.C.) [3]. 
Vidros de Germanato apresentam uma boa estabilidade química e vítrea, alta resistência mecânica, baixa energia de fônon $\left(\approx 700 \mathrm{~cm}^{-1}\right)$ e larga janela de transmissão (400 - $4500 \mathrm{~nm}$ ), quando comparados com os silicatos, boratos e fosfatos, e alto índice de refração $(\geq 2,0)$ linear e não-linear. No caso da matriz estudada, $\mathrm{GeO}_{2}-\mathrm{PbO}$, suas características são bastante conhecidas e muitos trabalhos já foram publicados pelo grupo [4], assim como outros com diferentes concentrações de cada óxido [5-7]. O alto índice de refração e a baixa energia de fônon os tornam grandes candidatos a utilização como fibras de vidros em telecomunicações, como dispositivos fotônicos e optoeletrônicos [4].

Os materiais dopados com $\mathrm{Tm}^{3+}$ têm atraído grande interesse dos pesquisadores devido as suas aplicações em dispositivos como laser de estado sólido, LEDs, displays e dispositivos de armazenamento de dados [4,8-12], devido à sua intensa emissão de luz azul, em torno de $480 \mathrm{~nm}$, quando utilizado em sistemas que envolvem codopagem com $\mathrm{Yb}^{3+}$, além da área médica que utiliza a região do infravermelho [13]. Os vidros de germanato dopados com vários íons de terras-raras (TRs) se mostraram bastantes eficientes no processo de conversão ascendente (CA). Na presença de NPs, um aumento considerável da luminescência já foi observado em vários trabalhos realizados pelo grupo. Entretanto, não se encontra na literatura estudos que envolvam a interação das NPs com sistemas dopados com $\mathrm{Tm}^{3+}$ e codopados com $\mathrm{Yb}^{3+} / \mathrm{Tm}^{3+}$, o que caracteriza o ineditismo deste trabalho. Cabe acrescentar que existem apenas três trabalhos publicados que tratam da interação entre as NPs e íons de TRs, em sistemas codopados, os quais foram realizados pelo grupo [14-16].

Propriedades ópticas, elétricas e magnéticas, e suscetibilidade óptica nãolinear em vidros são algumas das características que sofrem alteração com a presença de NPs metálicas no meio vítreo [1].

Este projeto tem como objetivo desenvolver metodologias de tratamento térmico adequadas à nucleação de nanopartículas (NPs) metálicas de prata em vidros de germanato dopados com íons de TRs $\left(\mathrm{Tm}^{3+}\right)$ e codopadas com $\mathrm{Yb}^{3+} \mathrm{e}$ $\mathrm{Tm}^{3+}$, visando obter maior controle sobre o processo. A partir da variação dos parâmetros do referido processo, tais como temperatura e tempo de tratamento, são observadas as variações na distribuição de tamanho das NPs e alterações nos espectros de absorção e de emissão. 
O objetivo do controle da variação da forma e do tamanho das NPs consiste em obter maior domínio sobre a luminescência dos íons de $\mathrm{Tm}^{3+}$ na região do visível. A referida luminescência é normalmente obtida através do processo de CA. Sabe-se que as NPs de prata na ordem de poucos nanômetros possuem ressonância plasmônica de superfície (RPS) na região compreendida entre 0 ultravioleta (UV) e o verde do espectro, e à medida que se tornam maiores, a RPS se desloca em direção ao infravermelho [1].

Neste trabalho são estudadas as influências dos diferentes processos de nucleação das NPs nas emissões dos íons de $\mathrm{Tm}^{3+}$, na região do visível, sobretudo na região do azul. A interferência da nucleação das NPs no processo de transferência de energia entre os íons $\mathrm{Tm}^{3+}$ e $\mathrm{Yb}^{3+}$ também é abordada.

Dentre as técnicas de caracterização utilizadas, temos as medidas ópticas de absorção e emissão, a Microscopia Eletrônica de Transmissão (MET) e a Espectroscopia de Energia Dispersiva (EDS - Energy Dispersive Spectroscopy). As medidas ópticas têm como intuito verificar a incorporação dos íons de TRs, a nucleação das NPs e os efeitos causados na luminescência das TRs devido aos diferentes processos de nucleação. Através da MET verifica-se a presença, a distribuição de tamanho e a forma das NPs, e através do EDS confirma-se a composição das NPs presentes nas amostras produzidas.

No Capítulo 2, serão apresentados os fundamentos teóricos para o entendimento do presente trabalho, abordando tópicos como formação de vidros, processos de transferência de energia (TE) entre íons de terra rara e a interação da luz com as NPs, dando enfoque à variação do processo de tratamento térmico como meio de obtenção destas NPs, objetivo do trabalho em questão.

O Capítulo 3 apresenta um detalhamento das etapas de produção dos materiais vítreos, a metodologia adotada para a nucleação das NPs e as técnicas de caracterização utilizadas para o estudo das propriedades destes vidros.

No Capítulo 4 são apresentados os resultados obtidos e as discussões, e por fim, as conclusões são apresentadas no Capítulo 5.

Algumas propostas de continuidade da pesquisa são apresentadas no Capítulo 6. 


\section{REVISÃO BIBILOGRÁFICA}

\subsection{FORMAÇÃO DE VIDROS}

Dentre os elementos ópticos utilizados atualmente, o vidro é considerado o de menor custo, pois a grande maioria das matrizes vítreas pode ser produzida por várias técnicas, tais como, a fusão seguida do resfriamento rápido, o sol-gel, o sputtering, a deposição química a vapor (chemical vapor deposition - CVD), o processamento por microondas, entre outras [17-19]. Algumas delas podem ser de alto custo, mas a complexidade da produção de um material cristalino de alta qualidade óptica e transparência torna o custo ainda mais alto, dado que as técnicas envolvidas são a fusão zonal e a Czochralski. Na Antigüidade, os vidros eram utilizados como objetos decorativos e o conhecimento da sua produção vem desde 3000 a.C., na Mesopotâmia. Atualmente, ele apresenta um papel fundamental na ciência e tecnologia [20].

Dentre as técnicas apresentadas, a mais utilizada é a fusão dos reagentes seguida do resfriamento rápido da massa fundida, originando assim, um material que possui uma estrutura similar a dos líquidos, porém mais compacta [21]. resultado final é o vidro, um sólido amorfo, que não apresenta organização atômica de longo alcance.

Em 1932, Zachariasen publicou um artigo intitulado The Atomic Arragement in Glass (O Arranjo Atômico em Vidros), que afirmava que a base estrutural para a formação dos vidros por fusão/resfriamento gera um arranjo atômico caracterizado por uma rede tridimensional estendida, a qual apresentava ausência de simetria e periodicidade. Para ilustrar a diferença entre a estrutura ordenada de um cristal e a estrutura caótica de um vidro de mesma composição, uma analogia bidimensional foi feita por Zachariasen, como mostrado na Figura 2.1 [22]. 


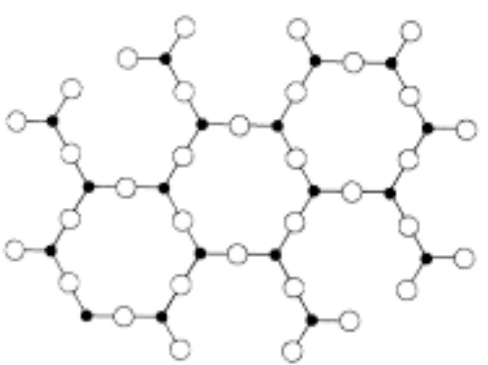

(a)

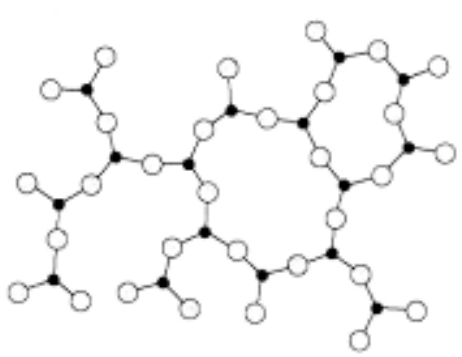

(b)

Figura 2.1 - Analogia bidimensional esquemática, segundo Zachariasen, ilustrando a estrutura de um (a) cristal e de um (b) material amorfo, de mesma composição [22].

Para a formação de um material puramente vítreo, um líquido deve ser superresfriado de forma que não ocorra a formação de cristais. Durante o processo de resfriamento do líquido, a temperatura e o volume devem decrescer quase que continuamente. Caso ocorra descontinuidade na queda da temperatura, como mostrado na Figura 2.2 na região da temperatura de cristalização $\left(T_{c}\right)$, a formação de um material parcialmente ou totalmente cristalino pode ocorrer. Esta temperatura varia de acordo com a composição do material fundido, podendo existir mais de uma $T_{c}$. Entretanto, a temperatura de transição vítrea $\left(T_{g}\right)$ pode variar com a composição e com a taxa de resfriamento, ou seja, quanto maior for esta taxa, maior será a $T_{g}$, representado por $T_{g 1}$ e $T_{g 2}$ na Figura 2.2 [17]. Um material é considerado vítreo para temperaturas abaixo da $T_{g}$, onde este sofre mudanças nas taxas de variação das propriedades físicas e termodinâmicas, por exemplo, uma redução na taxa de compressão volumétrica em função da temperatura (Figura 2.2).

O conhecimento da $T_{g}$ se faz necessário para que um tratamento térmico possa ser realizado em temperatura adequada, ou seja, menor que a $T_{g}$, pois a finalidade do tratamento é aliviar as tensões internas do material, tornando-o menos susceptível a fratura [19]; temperaturas maiores que a $T_{g}$ podem proporcionar a formação de cristais, dependendo da diferença entre $T_{g}$ e $T_{c}$. Cabe acrescentar que o material vítreo se encontra num estado metaestável, logo, a tendência é caminhar para um estado estável quando fornecemos energia suficiente para que o efeito ocorra. 


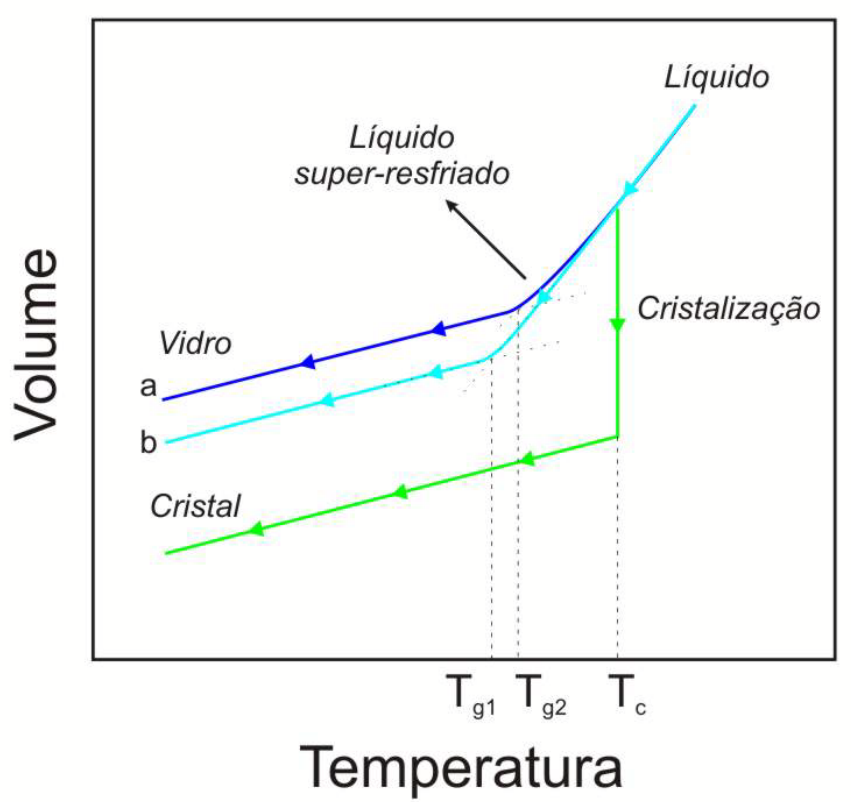

Figura 2.2 - Processo de formação de vidros e cristais [17].

Para entender melhor a formação dos vidros, critérios foram estabelecidos ao longo dos anos. Em 1929, Goldschmit propôs o primeiro critério para interpretar o fenômeno de vitrificação de forma cristaloquímica, onde dizia que a razão entre o raio do ânion e o raio do cátion ao qual está coordenado deveria estar entre 0,2 e 0,4 . Esta razão caracteriza o intervalo correspondente às coordenações triangulares e tetraédricas [23]. Contudo, existem exceções, como é o caso do óxido de berílio $\left(\mathrm{Be}_{2} \mathrm{O}_{3}\right)$ que não forma vidro, mas possui razão entre ânion e cátion dentro do intervalo determinado; e de outros óxidos que apresentam razão inferior a 0,2, mas formam vidros.

Assim, Plumat sugeriu um segundo critério, onde levava em consideração também a valência dos íons, permitindo classificar simultaneamente os óxidos, os halogênios, os sulfatos, entre outros. Foi em 1932, por Zachariasen, que surgiram as regras que utilizamos até hoje para classificar os óxidos em formadores de rede, modificadores e intermediários [22]. Em seu artigo, Zachariasen determinou que para um material de composição química $A_{m} B_{n} O$ formar vidro, é necessário que:

- Uma grande porcentagem da amostra seja formada por cátions rodeados de triângulos ou tetraedros de oxigênios; 
- Esses triângulos ou tetraedros compartilhem apenas seus vértices entre si, e não arestas ou faces (no caso dos tetraedros);

- E os oxigênios estejam ligados a apenas dois cátions, e não formem mais ligações com nenhum outro cátion;

- O cátion A deve ser grande e possuir uma carga baixa, e o cátion B deve possuir carga 3, 4 ou 5.

Onde $m$ e $n$ representam a quantidade de cátions $A$ e $B$, respectivamente, por unidade de oxigênio. Acrescentou ainda que os poliedros devam ter pelo menos 3 de seus vértices compartilhados com outros poliedros.

Considerando estas regras, os óxidos foram separados em 3 categorias e são mostrados nas tabelas que seguem:

- Formadores de rede, capazes de produzirem vidros na ausência de outros reagentes;

- Modificadores de rede, que não formam vidros sozinhos, mas podem entrar nos espaços vazios do reticulado;

- Intermediários, que podem entrar no reticulado do vidro.

Tabela 2.1 - Óxidos $\mathrm{MO}_{x}$ formadores de rede [17].

\begin{tabular}{ccc}
\hline Óxidos & Valência & $\begin{array}{c}\text { No }^{o} \text { coordenação } \\
\text { dos Cátions }\end{array}$ \\
\hline $\mathrm{B}$ & +3 & 3 e 4 \\
$\mathrm{Al}$ & +3 & 4 \\
$\mathrm{Si}$ & +4 & 4 \\
$\mathrm{Ge}$ & +4 & 4 \\
$\mathrm{~B}$ & +4 & 4 \\
$\mathrm{P}$ & +5 & 4 \\
$\mathrm{~V}$ & +5 & 4 \\
$\mathrm{As}$ & +5 & 4 \\
$\mathrm{Sb}$ & +5 & 4 \\
$\mathrm{Zr}$ & +4 & 6 \\
\hline
\end{tabular}


Tabela 2.2 - Óxidos $\mathrm{MO}_{\mathrm{x}}$ modificadores de rede [17].

\begin{tabular}{|c|c|c|}
\hline Óxidos & Valência & $\begin{array}{c}\text { No de coordenação } \\
\text { dos Cátions }\end{array}$ \\
\hline $\mathrm{Li}$ & +1 & 4 \\
\hline $\mathrm{Pb}$ & +2 & 4 \\
\hline $\mathrm{Zn}$ & +2 & 4 \\
\hline $\mathrm{Cd}$ & +2 & 4 \\
\hline $\mathrm{Na}$ & +1 & 6 \\
\hline $\mathrm{Cd}$ & +2 & 6 \\
\hline $\mathrm{Hg}$ & +2 & 6 \\
\hline $\mathrm{Mg}$ & +2 & 6 \\
\hline Sc & +3 & 6 \\
\hline $\mathrm{Ga}$ & +3 & 6 \\
\hline In & +3 & 6 \\
\hline $\mathrm{Pb}$ & +4 & 6 \\
\hline Sn & +4 & 6 \\
\hline $\mathrm{La}$ & +3 & 7 \\
\hline $\mathrm{Ba}$ & +2 & 8 \\
\hline $\mathrm{Ca}$ & +2 & 8 \\
\hline $\mathrm{Sr}$ & +2 & 8 \\
\hline$Y$ & +3 & 8 \\
\hline $\mathrm{K}$ & +1 & 9 \\
\hline $\mathrm{Rb}$ & +1 & 10 \\
\hline Cs & +1 & 12 \\
\hline Th & +4 & 12 \\
\hline
\end{tabular}

Tabela 2.3 - Óxidos $\mathrm{MO}_{\mathrm{x}}$ intermediários [17].

\begin{tabular}{ccc}
\hline Óxidos & Valência & $\begin{array}{c}\mathrm{N}^{\circ} \text { de coordenação } \\
\text { dos Cátions }\end{array}$ \\
\hline $\mathrm{Zn}$ & +2 & 2 \\
$\mathrm{~Pb}$ & +2 & 2 \\
$\mathrm{Cd}$ & +2 & 2 \\
$\mathrm{Be}$ & +2 & 4 \\
$\mathrm{Al}$ & +3 & 6 \\
$\mathrm{Ti}$ & +4 & 6 \\
$\mathrm{Th}$ & +4 & 8 \\
$\mathrm{Zr}$ & +4 & 8 \\
\hline
\end{tabular}




\subsection{VIDROS DE GERMANATO}

Vidros de óxido de germânio $\left(\mathrm{GeO}_{2}\right)$ foram elaborados pela primeira vez em 1926, por Dennis e Laubengayer [7], mas estudos detalhados a respeito da estrutura e do comportamento de matriz vítrea com a inclusão de outros óxidos têm sido realizados apenas nas últimas décadas.

Estes vidros tendem a apresentar uma estrutura similar a dos vidros de óxido de silício $\left(\mathrm{SiO}_{2}\right)$, pois a disposição dos oxigênios ao redor do átomo de germânio assumem a forma de um tetraedro $\left(\mathrm{GeO}_{4}\right)$, assim como nos vidros de $\mathrm{SiO}_{2}$. Apesar disso, a dinâmica de formação dos vidros de germanato não procede da mesma forma como a dos silicatos, pois eles podem apresentar também estruturas octaédricas $\left(\mathrm{GeO}_{6}\right)$ [17].

Contudo, ao incluirmos $\mathrm{Al}_{2} \mathrm{O}_{3}$ à composição do vidro, a formação dos octaedros é suprimida. O mesmo efeito ocorre para outros óxidos. No caso da matriz estudada neste trabalho $\left(\mathrm{GeO}_{2}-\mathrm{PbO}\right)$, a medida que se aumenta a concentração de $\mathrm{PbO}, \mathrm{a}$ coordenação do $\mathrm{GeO}_{2}$ muda de 4 para 6. Essa mudança afeta diretamente as propriedades do vidro (temperatura de transição vítrea, viscosidade, coeficiente de expansão térmica, densidade, condutividade elétrica, etc.). Este fenômeno é conhecido como "Anomalia do Germanato", e ocorre geralmente em vidros de composição $\mathrm{X}_{2} \mathrm{O}-\mathrm{GeO}_{2}$, onde $X$ é um metal alcalino [17]. Estudos recentes mostram que na verdade as coordenações 4 e 6 são assumidas pelo $\mathrm{GeO}_{2}$ até uma dada concentração de $\mathrm{PbO}$, e a partir deste ponto a coordenação tende a ser apenas 4 [5].

A inclusão do $\mathrm{PbO}$ aos vidros de germanato, assim como outros óxidos de metais pesados, conferem a estes vidros propriedades bastante interessantes e de ampla aplicação. Dentre as propriedades, podemos citar:

- Aumento no índice de refração linear e não-linear do vidro;

- Janelas de transmissão mais amplas, desde o visível até o infravermelho médio.

- Aumento na densidade do material, na resistência mecânica e na estabilidade química; 
- Diminuição das temperaturas de transformação (entre 250 e $450{ }^{\circ} \mathrm{C}$ para a temperatura de transição vítrea, e entre 350 e $550{ }^{\circ} \mathrm{C}$ para a temperatura de cristalização) e de fusão;

- Aumento da expansão térmica.

Essas propriedades estão relacionadas aos altos valores de massa, baixa energia de ligação e alta polarizabilidade dos metais pesados [24].

A alta não-linearidade que os vidros de óxidos de metais pesados podem apresentar, os tornam bastantes susceptíveis à construção de dispositivos fotônicos, tais como limitadores ópticos e chaves ópticas [20]. Outras aplicações podem ser citadas também, como a supercondutividade [25,26], janelas de blindagem de radiação e cintiladores [24]. Assim, vidros de germanato associados a óxidos de metais pesados são de grande interesse e bastante estudados atualmente.

Piasecki et al. $[27,28]$ reportam que a sensibilidade da não-linearidade óptica de segunda ordem é extremamente alta para temperaturas próximas a transição vítrea nos vidros de $\mathrm{GeO}_{2}-\mathrm{PbO}$, o que torna possível a detecção da transição de fase desses vidros.

Outra característica bastante importante é a baixa energia de fônon destes vidros, o que indica baixas perdas por processos não-radiativos, quando comparados aos silicatos, boratos e fosfatos, como podemos ver na Tabela 2.4.

Tabela 2.4 - Óxidos formadores de rede [29].

\begin{tabular}{cc}
\hline Vidros & Energia de fônon $\left(\mathrm{cm}^{-1}\right)$ \\
\hline Silicato & $1000-1100$ \\
Borato & $1350-1480$ \\
Fosfato & $1100-1350$ \\
Telureto & $600-850$ \\
Fluoreto & $500-600$ \\
Calcogeneto & $200-300$ \\
Gemanato & $700-900$ \\
\hline
\end{tabular}

Cabe acrescentar que fenômenos de CA são também facilmente observados em vidros de germanato e de grande interesse para a comunidade científica. 
Destarte dadas às características apresentadas, muitos trabalhos envolvendo a luminescência de íons terras-raras (TRs) em vidros de germanato de várias composições já foram publicados. No Capitulo 2, na subseção Antecedentes do Grupo são apresentados alguns trabalhos baseados em matrizes vítreas de germanato e de teluretos dopadas com íons de TRs e também na presença de nanopartículas (NPs) metálicas, que foram realizados no Laboratório de Vidros e Datação (LVD) nos últimos anos.

\section{3 ÍONS DE TERRAS-RARAS}

Os químicos da Grécia Clássica classificavam como "terra" toda substância que não pudesse ser separada pelos métodos de fusão disponíveis na época. Essa definição se manteve até o século XVIII [30].

Em 1794, um químico Finlandês chamado Johan Gadolin descobriu um mineral raro que acreditava ser constituído de um novo elemento, ao qual classificou como sendo uma "terra rara" e nomeou de Ytterbia, pois este mineral foi encontrado na aldeia de Ytterby, próximo a Stockholm, Suécia. Este mesmo mineral, em 1803, resultou em uma nova terra-rara (TR) que ficou conhecida como Céria, nomeada em função do asteróide descoberto em 1801, o Ceres [30]. Em 1808, Humphrey Davy demonstrou que na verdade as "terras" eram formadas de óxidos de elementos metálicos. Assim, com o passar dos anos, no mineral encontrado por Gadolin (que em homenagem a ele foi chamado de Gadolinite) descobriu-se a existência de muitos outros óxidos. Os químicos da época perceberam então que os óxidos de TRs poderiam estar presentes também em muitos outros minérios [31].

Em 1859, com a introdução da espectroscopia no estudo das TRs, ocorreu um grande avanço na classificação e separação destas. Padrões de absorção e luminescência para cada elemento foram catalogados e se tornaram uma ferramenta essencial no fracionamento destes elementos. Entre 1843 e 1939 muitos óxidos foram obtidos e novos elementos foram adicionados à tabela periódica. $\mathrm{O}$ fracionamento era realizado a partir das diferenças de solubilidade e peso molecular de cada óxido. No total são 17 elementos considerados TRs [32]. Estes são o Escândio (Sc), o Ítrio (Y), e os elementos da sua série do Lantânio (La-Lu). 
Apesar do nome "terras raras", sabemos que não são elementos raros como imaginavam os químicos do passado, dada a abundancia deles na crosta terrestre. O túlio (Tm) que é considerado o mais raro, por exemplo, é mais abundante que a prata, o ouro, o cádmio, entre outros elementos. Atualmente, as TRs são comercializadas na forma de óxidos de grande pureza (99,99\%).

Em 1885 surgiu uma das primeiras aplicações, a lâmpada à gás Welbash, e em 1903, o isqueiro [31]. Com o avanço da ciência, surgiram estudos voltados para a confecção de novos materiais com possíveis aplicações nas áreas da medicina, telecominações, armazenamento de dados, displays de equipamentos (televisores, celulares, etc.), entre outras. Mais recentemente podemos incluir estudos no desenvolvimento de lasers e de dispositivos fotônicos e optoeletrônicos.

Dos 17 elementos considerados TRs, apenas 13 apresentam propriedades luminescentes quando inseridos em algum material. Isto se deve ao fato que o Escândio, o Ítrio, o Lantânio e o Lutécio são opticamente inativos, ou seja, para o caso do Escândio e do Ítrio, as subcamadas incompletas são, respectivamente, a 3d e a 4d que podem eventualmente fazer parte das ligações químicas, já que são camadas externas; já o Lantânio não possui elétrons $4 f$ e o Lutécio possui a subcamada $4 \mathrm{f}$ totalmente preenchida. No entanto todos os outros apresentam níveis $4 \mathrm{f}$ desocupados; os elétrons presentes nesta subcamada podem ser promovidos à estes níveis por absorção de radiação eletromagnética.

Assim, as transições mencionadas geram os espectros de absorção e emissão destes elementos, conferindo-lhes propriedades luminescentes com fluorescências que compreendem a região do ultravioleta (UV) ao infravermelho (IV) próximo do espectro eletromagnético. Os íons de TRs são normalmente incorporados nos materiais na forma iônica trivalente, porém, em condições especiais eles podem se apresentar na forma bivalente ou tetravalente, assim, apresentando espectros diferentes.

Sabendo que entre os íons $\mathrm{TR}^{3+}$ e o ambiente químico ocorre baixa interação, pois a subcamada $4 f$ é interna as subcamadas $5 \mathrm{~s}$ e $5 p$, que se encontram completamente preenchidas e opticamente inativas, dizemos que os elétrons $4 \mathrm{f}$ se encontram "blindados". Lembrando da regra de Laporte [33], verificamos que as transições 4f-4f são proibidas por paridade. Portanto, as transições que ocorrem são caracterizadas por serem estreitas, de baixa intensidade e longo tempo de vida, e os níveis energéticos por serem "fixos" independente do material utilizado como 
hospedeiro para os íons de $\mathrm{TR}^{3+}$. A Figura 2.3 apresenta os níveis energéticos originados da configuração 4f [34].

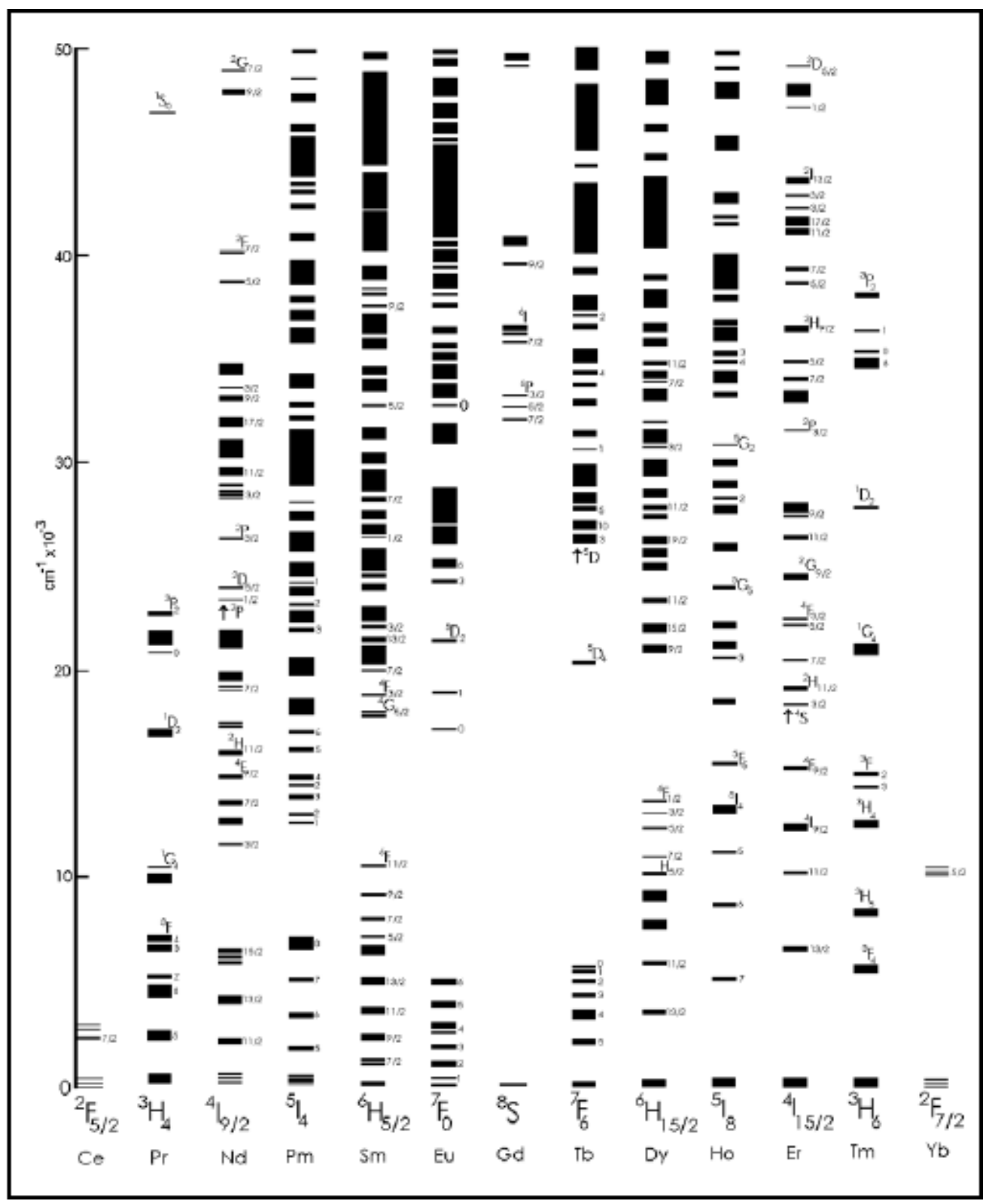

Figura 2.3 - Níveis de energia da configuração 4 f dos íons $\operatorname{TR}^{3+}$ [34].

A nomenclatura dos níveis de energia utiliza a seguinte simbologia:

$$
{ }^{2 S+1} L_{J}
$$

- Os números quânticos orbitais totais $L=0,1,2,3,4,5 \ldots$, são representados pelas letras maiúsculas $S, P, D, F, G, H$ etc.; 
- O valor $(2 S+1)$ é a multiplicidade do nível de energia devido às possíveis orientações do spin resultante $S$. Logo, em um sistema de um elétron $(S=1 / 2)$ a multiplicidade é 2 ;

- $\mathrm{J}$ é o momento angular total $(J=L+S)$.

A seguir serão descritos alguns processos de luminescência nos íons de TRs, as aplicações em vidros dopados com a TR túlio, e codopados com túlio e itérbio.

\subsubsection{Processos de Transferência de Energia e Conversão Ascendente}

As emissões dos vários comprimentos de onda que se pode obter a partir das TRs se dão por diferentes processos de transferência de energia (TE). Estes podem ocorrer entre íons de mesma natureza ou íons diferentes. Quando forem diferentes, um dos íons deverá se comportar como íon doador $\left(D^{+}\right)$e o outro como íon aceitador $\left(\mathrm{A}^{+}\right)$. Os processos de TE entre íons podem ser divididos basicamente em quatro [35]:

1.1. Transferência radiativa ressonante: um íon $\mathrm{D}^{+}$emite um fóton que é absorvido por um íon $\mathrm{A}^{+}$. A transferência é dada como ressonante, pois a energia fornecida pelo $D^{+}$é totalmente absorvida pelo $A^{+}$, podendo ocorrer entre íons iguais ou diferentes;

1.2. Transferência não radiativa ressonante: interação eletromagnética não radiativa entre os estados do íon $\mathrm{D}^{+}$e do íon $\mathrm{A}^{+}$, onde a energia fornecida pelo íon $\mathrm{D}^{+}$é ressonante a diferença entre níveis energéticos do íon $\mathrm{A}^{+}$.

1.3. Transferência não radiativa assistida por fônons: processo não radiativo e não ressonante que também ocorre através da interação eletromagnética, contudo, entre íons diferentes. Ela é considerada não ressonante, pois ocorre a liberação de fônons quando a energia fornecida pelo íon $\mathrm{D}^{+}$é maior que a necessária para excitar o íon $\mathrm{A}^{+}$, ou a absorção de fônons quando a energia transferida é menor que a necessária para excitar o íon $\mathrm{A}^{+}$, mantendo desta forma, o equilíbrio entre energia emitida pelo $\mathrm{D}^{+}$e a absorvida pelo $\mathrm{A}^{+}$. 
1.4. Transferência não radiativa por relaxação cruzada (RC): um íon $D^{+}$em estado excitado transfere parte da sua energia para o íon $A^{+}$, ficando ambos os íons em estados excitados intermediários. Esta transferência também é dada pela interação eletromagnética entre os íons, e ocorre apenas entre íons de mesma natureza.

Alguns materiais não são totalmente adequados para que os processos de TE sejam bem sucedidos. Dependendo da concentração dos dopantes, alguns defeitos podem ser gerados e a energia pode ser transferida para estes defeitos, além de íons de $\mathrm{OH}^{-}$, entre outras impurezas. Assim, a luminescência proveniente dos íons pode ser comprometida. Esta energia é perdida na forma de fônons e a esse efeito chamamos de "quenching".

Emissões na região do visível podem ocorrer através de um mecanismo chamado conversão ascendente (CA), que se caracteriza pela emissão de fótons com maior energia (menor comprimento de onda) que a utilizada pela fonte de bombeio (excitação), ou a proveniente de íons $\mathrm{D}^{+}$no caso das amostras contendo mais de um dopante. Assim, torna-se possível a utilização de lasers de diodo operando na região do infravermelho (IV) e vermelho como fontes de excitação [11].

Este mecanismo pode ser obtido de várias maneiras; os mais importantes para a emissão no visível são a absorção de estado excitado (AEE), a sensibilização cooperativa (SC) e emissão cooperativa (EC). O modo de contribuição de cada um depende de vários fatores como o comprimento de onda de bombeio, a intensidade do laser, a energia de fônon do sistema, entre outros [11].

No processo de AEE, um íon em estado fundamental é excitado a um nível intermediário pela absorção de um fóton com energia ressonante à diferença entre dois níveis energéticos. A partir deste, a absorção de outro fóton leva este íon a um nível de maior energia que o intermediário, e ao decair deste nível para o fundamental emite um fóton de menor comprimento de onda, logo, maior energia. Este processo ocorre a partir da absorção de fótons provenientes da fonte de bombeio (Figura 2.4a) ou de outros íons excitados (Figura 2.4b), neste caso os íons $\mathrm{D}^{+}$. Quando a AEE ocorre entre íons, os processos de TE são os descritos anteriormente, devendo os íons $\mathrm{D}^{+}$estarem em maior concentração que os íons $\mathrm{A}^{+}$, garantindo que a TE seja efetiva e que mais fótons possam interagir com os íons $A^{+}$. 
Na SC, dois íons em estado intermediário, ao decaírem, transferem energia a um íon diferente, levando-o do estado fundamental a um estado de maior energia que o intermediário, e na EC, dois íons em estado excitado decaem simultaneamente, emitindo um único fóton a partir de um nível virtual com o dobro da energia da transição que realizaram (Figura 2.4c). Este último processo ocorre através da interação Coulombiana entre os íons e depende fortemente da distância interiônica.

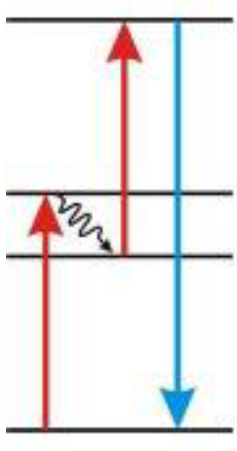

(a)

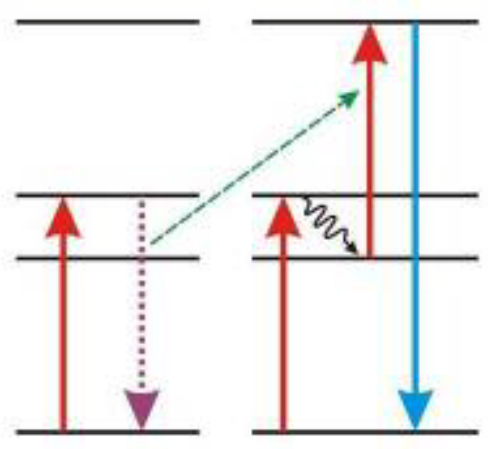

(b)

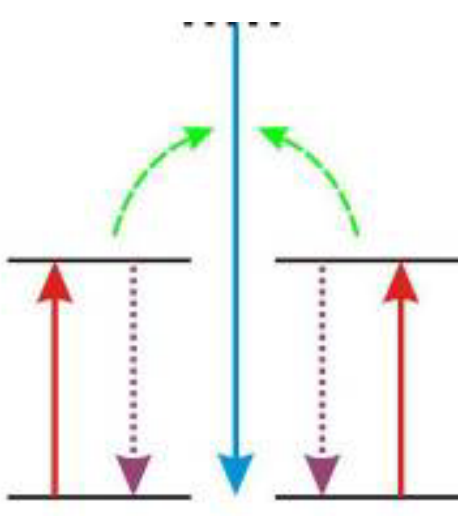

(c)

Figura 2.4 - Exemplos de processos de conversão ascendente (CA). (a) CA por AEE; (b) CA por AEE através da TE entre íons; (c) CA por EC.

Para um mecanismo de CA que ainda não atingiu o estado de saturação da emissão, a intensidade da fluorescência $\left(I_{F}\right)$ é diretamente proporcional a uma potencia $n$ da intensidade de excitação $\left(l_{\text {exc }}\right)$, tal que:

$$
I_{F} \propto I_{\text {exc }}^{n}
$$

onde $n=1,2,3,4 \ldots$ equivale ao numero de fótons absorvidos para a emissão de um fótons no processo de CA [36-38].

Experimentalmente, mede-se a intensidade de emissão da CA para diferentes potencias de excitação. Os dados são colocados em um gráfico em escala logarítmica para ambas as grandezas $\left(\log \left[I_{F}\right] \times \log \left[I_{\text {exc }}\right]\right)$. O valor de $n$ é então obtido através do ajuste de uma reta, onde o coeficiente angular desta corresponde ao número de fótons absorvidos para a emissão por CA. O valor pode sofrer desvio, apresentando número fracionado, devido aos processos de TE assistidos por fônon e efeitos de saturação. 
O fenômeno da CA é de grande interesse da comunidade cientifica, devido às diversas aplicações possíveis, como conversores de luz do IV para o visível, armazenamento de dados, displays coloridos, dispositivos fotônicos e optoeletrônicos, entre outros [39].

2.3.2 Processo de Conversão Ascendente dos íons $\mathrm{Tm}^{3+}$ e de transferência de energia entre os íons $\mathrm{Yb}^{3+}$ e $\mathrm{Tm}^{3+}$

O túlio foi separado pela primeira vez na forma de óxido em 1879, por Per Teodor Cleve, como sendo uma das impurezas encontradas na TR já conhecida como érbio, de onde foi encontrada também a TR hólmio. A sua forma metálica foi obtida nos primórdios a partir do aquecimento de seu óxido misturado com 0 lantânio, entretanto, nos dias atuais ele é obtido a partir do aquecimento do fluoreto de túlio com cálcio, devido o alto custo do processo. Por ser uma das TRs menos abundante e mais difícil de obter, no passado era considerada de baixo interesse e poucas eram as aplicações. As primeiras aplicações foram o dosímetro de radiação e os equipamentos de raios $X$ portáteis para uso na medicina [40].

Com o avanço da ciência, novas aplicações para os íons de TRs foram surgindo à medida que os métodos de produção dos materiais, de obtenção dos reagentes e as técnicas de caracterização foram evoluindo. Da mesma forma, o túlio passou a ser mais empregado e investigado. O interesse surgiu quando foram observadas novas possibilidades de aplicação, tais como, telecomunicações, sensoriamento químico, gravação óptica de dados, displays [8-12,41], laser de estado sólido no visível $[42,43]$ e fibras dopadas com $\mathrm{Tm}^{3+}$ que emitem em 2,3 $\mu \mathrm{m}$ e são aplicadas em procedimentos cirúrgicos [13].

Dentre as emissões apresentadas pelos íons $\mathrm{Tm}^{3+}$ estamos interessados nas que se encontram na região visível do espectro eletromagnético. Na Figura 2.5 são apresentadas as emissões e respectivas transições na região do visível, mas que dependem da matriz hospedeira devido à energia de fônon, da janela de transmissão, entre outras características do material. É apresentada também uma emissão no IV, em torno de $800 \mathrm{~nm}$. 


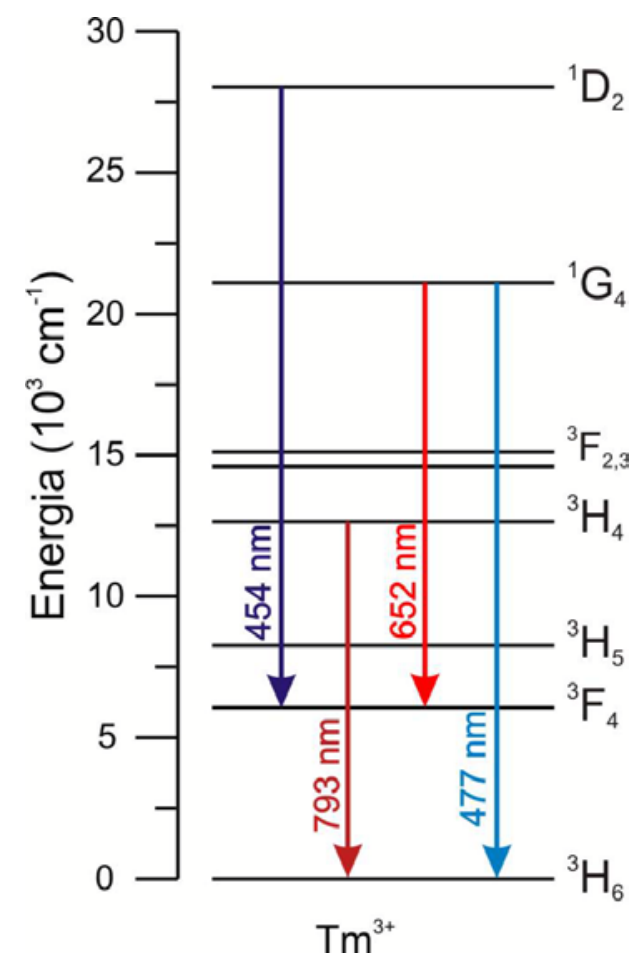

Figura 2.5 - Diagrama simplificado dos níveis de energia dos íons $\mathrm{Tm}^{3+}$ com a representação das emissões possíveis no visível.

Cabe acrescentar que todas as emissões apresentadas na Figura 2.5 foram medidas no trabalho em questão.

$\mathrm{Na}$ Figura 2.6a são apresentados os processos de CA por AEE e RC observados nos íons $\mathrm{Tm}^{3+}$ quando bombeados por radiação de $\approx 1050 \mathrm{~nm}$. Outra forma de se obter as emissões provenientes do $\mathrm{Tm}^{3+}$ é a utilização de outra TR que se comporte como um íon $\mathrm{D}^{+}$(doador). Em sistemas com mais de um dopante, devemos levar em consideração vários fatores, dentre eles as concentrações idéias de cada um, para que a emissão desejada seja a predominante, além dos processos de TE possíveis e as limitações de incorporação do dopante no hospedeiro. Dentre os vários íons de TR que se comportam como doadores de energia, temos o $\mathrm{Nd}^{3+} \mathrm{e}$ o $\mathrm{Yb}^{3+}$, já consagrados na literatura como doadores eficientes, inclusive para o $\mathrm{Tm}^{3+}$. $\mathrm{Na}$ iniciação científica ambos foram estudados, e no caso dos vidros de germanato, o mais eficiente foi o $\mathrm{Yb}^{3+}$. Na Figura 2.6b são apresentados os processos de CA por AEE através da TE assistida por fônon entre os íons de $\mathrm{Yb}^{3+}$ e $\mathrm{Tm}^{3+}$. Cabe acrescentar que a AEE é predominante em amostras com baixa concentração de dopante [20]. 

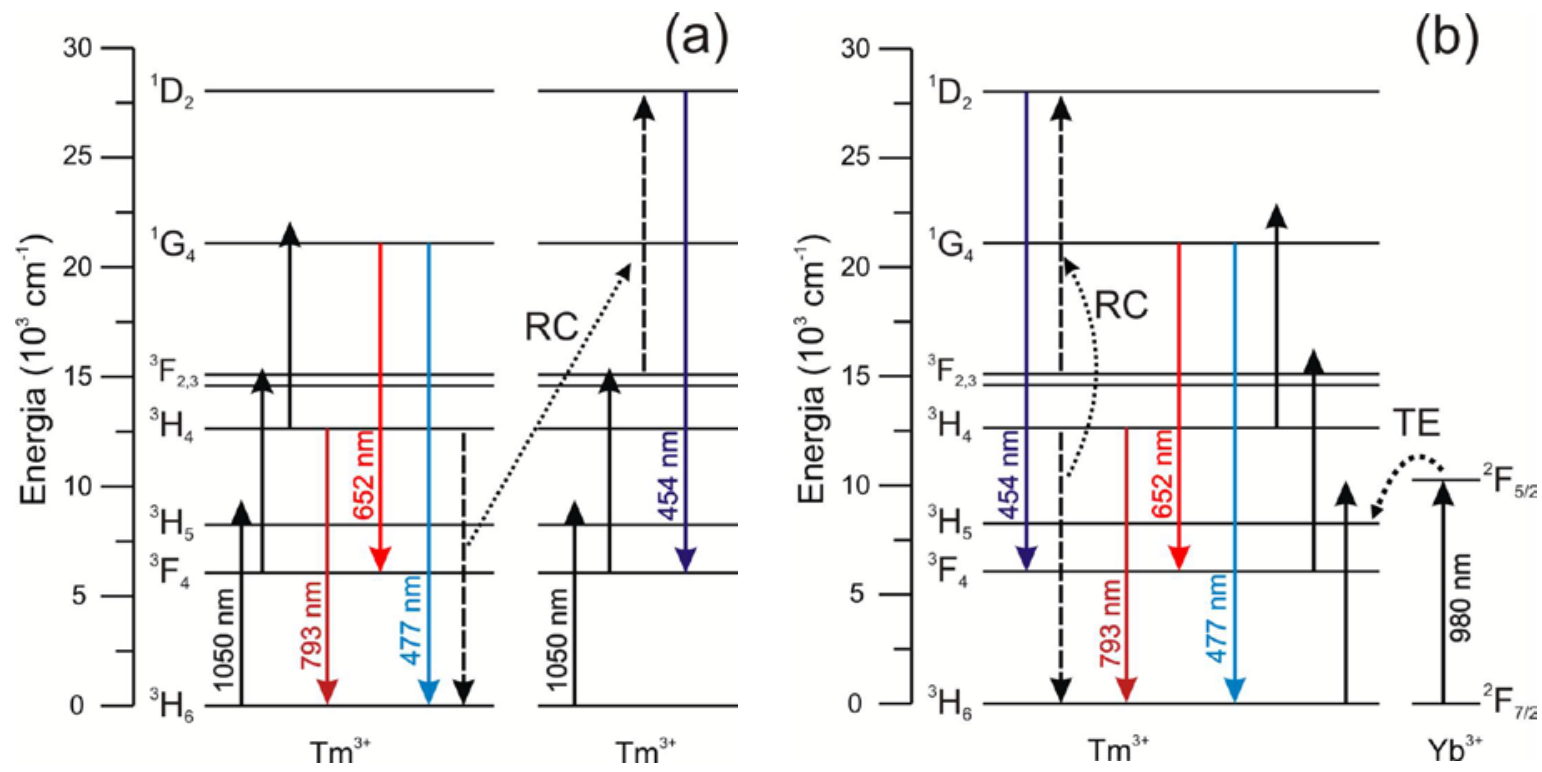

Figura 2.6 - Diagrama simplificado dos níveis de energia (a) do íon $\mathrm{Tm}^{3+}$ com a representação dos processos de CA por AEE e RC e (b) dos íons $\mathrm{Tm}^{3+}$ e $\mathrm{Yb}^{3+}$ com a representação dos processos de CA por AEE através da TE.

Quando excitamos as amostras dopadas apenas com $\mathrm{Tm}^{3+}$, verificamos uma baixa intensidade de emissão no visível. Isto ocorre, pois a TE entre estes íons é baixa, dado que o tempo de vida do nível ${ }^{3} \mathrm{H}_{5}$ é curto. Assim, a probabilidade dos íons se manterem no estado excitado é menor, e a transição ${ }^{3} \mathrm{~F}_{4} \rightarrow{ }^{3} \mathrm{H}_{6}(\approx 2,0 \mu \mathrm{m})$ acaba ocorrendo com maior frequência que as emissões no visível [44]. Além deste fator, há também a dependência da fluorescência com a potência do laser, a janela de transmissão do hospedeiro e o comprimento de onda de bombeio, que neste caso não é ressonante.

No caso da interação $\mathrm{Yb}^{3+}$ e $\mathrm{Tm}^{3+}$, a emissão no visível se torna eficiente à medida que aumentamos a concentração dos íons $\mathrm{Yb}^{3+}$, confirmando a dependência da quantidade de fótons que interagem com um único íon $\mathrm{Tm}^{3+}$. Para verificar a relação existente entre a concentração de $\mathrm{Yb}^{3+}$ e a intensidade das fluorescências observadas, realizou-se um estudo a partir da relação:

$$
I_{F} \propto C_{Y b^{3+}}^{n}
$$

onde $n=1,2,3,4 \ldots$ representa o número de íons de $\mathrm{Yb}^{3+}$ que interagem com um único íon de $\mathrm{Tm}^{3+}$ no processo de emissão para cada transição observada.

Experimentalmente, mede-se a intensidade de emissão da CA para diferentes concentrações de $\mathrm{Yb}^{3+}$. Os dados são colocados em um gráfico em escala logarítmica para ambas as grandezas $\left(\log \left[I_{F}\right] \times \log \left[C_{Y b}{ }^{3+}\right]\right)$. O valor de $n$ é então 
obtido através do ajuste de uma reta, onde o coeficiente angular desta corresponde ao número de íons $\mathrm{Yb}^{3+}$ que fornecem fótons em cada emissão observada. O valor pode sofrer desvio, apresentando número fracionado, devido aos processos de TE assistidos por fônon e efeitos de saturação, já que a relação se baseia na intensidade de emissão dos íons $\mathrm{Tm}^{3+}$.

Nas transições ${ }^{1} \mathrm{G}_{4} \rightarrow{ }^{3} \mathrm{H}_{6}(\approx 477 \mathrm{~nm})$ e ${ }^{1} \mathrm{G}_{4} \rightarrow{ }^{3} \mathrm{~F}_{4}(652 \mathrm{~nm})$, de ambos os casos, observamos a absorção de 3 fótons, o que caracteriza uma dependência cúbica com a intensidade do laser.

No caso da transição ${ }^{1} \mathrm{D}_{2} \rightarrow{ }^{3} \mathrm{~F}_{4}(454 \mathrm{~nm})$, observamos a absorção de 2 fótons, seguido de um processo de RC [16]. Neste processo a interação entre dois íons $\mathrm{Tm}^{3+}$ se faz necessária, em vista da existência de apenas um nível de excitação nos íons $\mathrm{Yb}^{3+}$. Esta transição não pode ser caracterizada pela absorção de 4 fótons por um único íon, uma vez que a diferença energética entre o fóton e a transição ${ }^{1} \mathrm{G}_{4}$ $\rightarrow{ }^{1} D_{2}$ é muito grande. Contudo, ao analisarmos quantos fótons participam da transição, obtemos o valor quatro. Isto se deve ao fato de que dois íons de $\mathrm{Tm}^{3+}$ absorvem 2 fótons cada um, e a RC não é contabilizada, pois a resultante da TE é nula. Esta emissão é de baixa intensidade, pois se encontra fora da janela de transmissão do vidro, o que possibilita a reabsorção da fluorescência pela matriz.

A transição ${ }^{3} \mathrm{H}_{4} \rightarrow{ }^{3} \mathrm{H}_{6}$ (793 nm) se caracteriza pela absorção de 2 fótons, revelando uma dependência quadrática com a intensidade do laser. A intensidade desta fluorescência pode variar, já que corresponde a mesma transição realizada na $\mathrm{RC}$, que se caracteriza por ser uma TE não radiativa. Esta variação depende diretamente da concentração dos íons $\mathrm{Tm}^{3+}$, logo, da distância entre eles.

Em todos os processos de CA dos íons $\mathrm{Tm}^{3+}$, a AEE é assistida por fônon, pois não há ressonância entre a fonte de excitação (laser ou íons $\mathrm{Yb}^{3+}$ ) e os íons $\mathrm{Tm}^{3+}$. Nos processos que envolvem a TE entre $\mathrm{Yb}^{3+}$ e $\mathrm{Tm}^{3+}$, a fonte de excitação é ressonante aos íons de $\mathrm{Yb}^{3+}$. 


\subsection{NANOPARTÍCULAS METÁLICAS E PLASMÔNICA}

Surgiu, nos últimos anos, um considerável interesse atrelado ao estudo dos fenômenos associados à interação da luz com as NPs metálicas. Neste trabalho, estamos interessados nos efeitos causados pela absorção de luz das NPs metálicas, que é descrita por uma oscilação coerente dos elétrons, induzida por interação com o campo eletromagnético $[1,45]$. Tais efeitos podem alterar as propriedades elétricas, ópticas e magnéticas dos materiais que contenham NPs, e alguns deles já se encontram na literatura [46-49]. Nos vidros, além das propriedades mencionadas, a suscetibilidade óptica não-linear tem sido de grande interesse devido às aplicações como dispositivos fotônicos [50,51].

A interação do campo elétrico da radiação eletromagnética com as NPs metálicas provoca oscilações coletivas nos elétrons livres (Figura 2.7). A estas oscilações dá-se o nome de plasmons superficiais (PS). Quando a frequência da luz for a mesma da oscilação dos PS, observa-se o aparecimento de uma banda de absorção devido à ressonância $[1,45,52]$. Esta frequência de ressonância de plasmons superficiais (RPS) depende de várias características:

- Tipo de material (tipicamente prata, ouro, platina, cobre etc.);

- Distribuição de tamanho das NPs;

- Formato das NPs;

- Ambiente químico do hospedeiro onde as NPs estão inseridas;

- Inicio da janela de transmissão do hospedeiro, em vista que as bandas de absorção da RPS variam do UV ao IV [20].

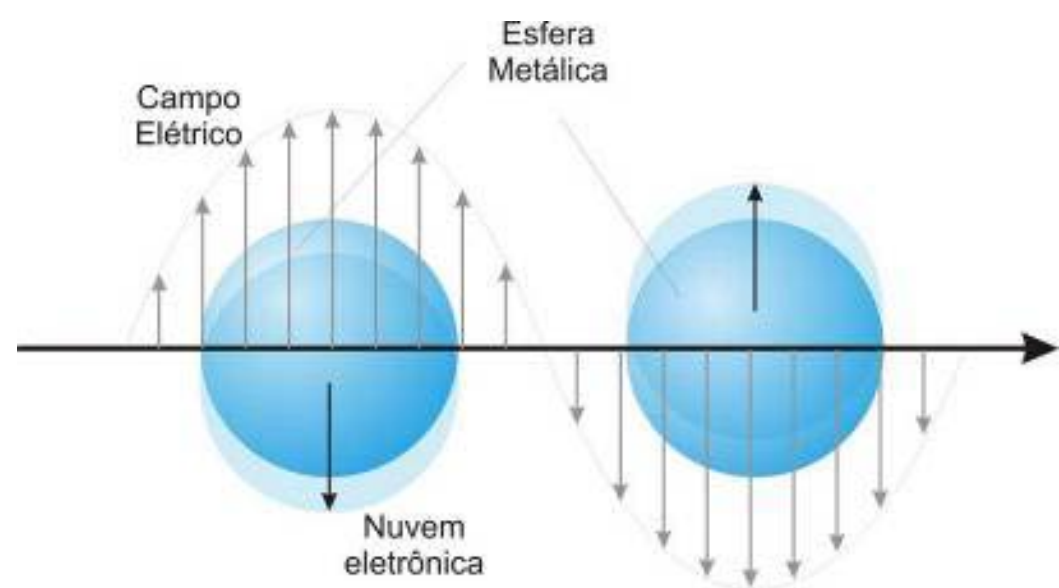

Figura 2.7 - Esquema para a oscilação plasmônica de uma esfera, mostrando o deslocamento da nuvem dos elétrons livres em relação ao núcleo. 
Os estudos das propriedades ópticas conferidas aos materiais pelas NPs, que se iniciaram em 1950, deram inicio à plasmônica: área em que se estuda a geração de bandas de RPS ocasionadas pela presença de NPs metálicas [53].

A RPS relativa à estas NPs pode alterar a luminescência produzida pelos íons de TRs. Os três diferentes tipos de efeitos plasmônicos que podem interferir nas propriedades radiativas e não radiativas dos íons de TRs são [20]:

- Aumento do Campo Local - O aumento do campo local em torno dos íons de TRs devido à presença das NPs metálicas concentra a densidade de excitação local ao redor dos íons, aumentando a emissão luminescente.

- TE entre os íons de TRs e as NPs - Esta interação introduz um canal adicional de decaimento não-radiativo, que depende da distância entre o íon e a NP;

- Aumento da Taxa Radiativa - Interação entre o íon de TR e uma NP metálica que aumenta a taxa radiativa intrínseca do íon de TR. A taxa de decaimento radiativo é descrita pela Regra de Ouro de Fermi [20].

Portanto, se os íons de TRs estiverem a uma distância menor que $5 \mathrm{~nm}$ da superfície da NP, geralmente sua luminescência tende a diminuir (região I) [1]. Para distâncias compreendidas entre 5 e 20 nm, a luminescência da TR pode ser favorecida, tanto pelo aumento do campo local, como pelo aumento das taxas radiativas (região II); para distâncias superiores, o tempo de vida das radiações diminui (região III), como mostra a Figura 2.8 .

III

Nanopartícula

Íons de TR

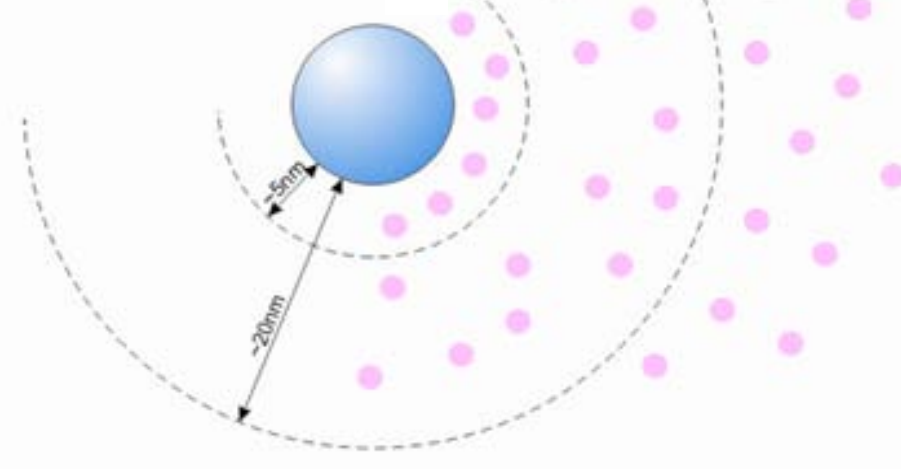

lons de TR

Figura 2.8 - Representação das distâncias entre NPs e íons de TRs. 
Entre as várias aplicações das NPs metálicas, destacam-se a construção de sensores químicos e biológicos de alto desempenho, em que as moléculas de interesse são detectadas por mudanças na região de absorção de luz das NPs; $\underline{0}$ tratamento de câncer, que se encontra em desenvolvimento pelo grupo da pesquisadora Naomi Halas nos EUA, através da sensibilização das NPs por radiação IV e a destruição das células cancerosas por emissão de calor; e $\underline{a}$ manipulação da luz em escala nanométrica, um tema que desafia os cientistas há muito tempo, pois a miniaturização dos componentes causa problemas de difração da luz, logo, com as NPs metálicas o problema se resolve já que são capazes de interagir com a luz abaixo do limite de difração, permitindo o desenvolvimento de dispositivos ópticos em escala nanométrica.

Gustav Mie foi o primeiro a racionalizar a interação da luz com uma dispersão de partículas de ouro em 1908 [1,20]. Em sua teoria, Mie assume que a distribuição das partículas e o meio hospedeiro são homogêneos; assim, ele descreve ambos pelas funções dielétricas ópticas do material hospedeiro. Resolvendo as equações de Maxwell, deduz-se a expressão da seção de choque de extinção das NPs metálicas, $\sigma_{\text {ext }}\left(\sigma_{\text {ext }}=\sigma_{a b s}+\sigma_{\text {esp }} \rightarrow\right.$ seção de choque de absorção + seção de choque de espalhamento), onde podemos verificar a interferência de oscilações elétricas e magnéticas [20].

A Teoria de Mie parte do princípio que as partículas não possuem nenhum tipo de interação entre si; suposição aplicável quando se trata de partículas em suspensões coloidais diluídas.

A teoria clássica de Mie para o espalhamento da luz e a teoria do elétron livre de Drude [53] explicam as características das bandas de absorção do plasmon. Na equação de Mie o coeficiente de absorção é dado por:

$$
\alpha(\omega)=\frac{9 q n^{3} \omega}{c} \frac{\epsilon_{m_{2}}(\omega)}{\left[\epsilon_{m_{1}}(\omega)+2 n^{2}\right]^{2}+\epsilon_{m_{2}}(\omega)^{2}}
$$

Na equação acima $n, q, \epsilon_{m}\left(=\epsilon_{m_{1}}+i \epsilon_{m_{2}}\right)$ [1], $\quad c \quad$ e $\quad \omega$ representam, respectivamente, o índice de refração do material hospedeiro, a fração do volume das partículas metálicas, a função dielétrica do material constituinte da partícula, a velocidade da luz no vácuo e a freqüência angular da radiação incidente. A teoria de 
Mie é aplicada somente nos casos de nanopartículas que não interagem, que estão bem separadas entre si, ou para baixas concentrações de nanopartículas em dispersão. De acordo com a teoria de Drude para o elétron livre, $\epsilon_{m}$ é expresso por:

$$
\epsilon_{m}(\omega)=1+i \frac{\omega_{P}^{2} \tau}{\omega(1-i \omega \tau)}
$$

$\mathrm{Na}$ equação acima $\tau$ representa 0 tempo de relaxação $\mathrm{e}$ $\omega_{p}=\left[\left(N_{e} e^{2}\right) /\left(\epsilon_{0} m\right)\right]^{1 / 2}$ é a freqüência de oscilação do plasma $\left(N_{e}, e\right.$, e $m$ representam o número a carga e a massa dos elétrons respectivamente). Doyle e Kreibig [54] propuseram que para uma partícula esférica muito menor do que o caminho livre médio dos elétrons no material, as colisões dos elétrons de condução com a superfície da partícula tornam-se importantes como um processo de relaxação adicional. Sendo assim o caminho livre médio torna-se restrito ao tamanho da partícula dada por 2R ( $\mathrm{R}$ representa o raio da partícula). Desta forma o tempo de relaxação $\tau$ pode ser substituído pelo tempo de colisão dado por: $\tau_{c}=2 R / v_{f}$. Nesta equação $v_{f}=1,39 \times 10^{8} \mathrm{~cm} / \mathrm{s}$ representa a velocidade de Fermi. Podemos, a partir das equações (1) e (2), obter a relação que segue, considerando $\omega \tau_{c}>>1$ :

$$
\alpha(\omega)=\frac{9 q n^{3}}{c\left(1+2 n^{2}\right)} \frac{\frac{\omega^{2} \omega_{r}^{2}}{\tau_{c}}}{\left(\omega^{2}-\omega_{r}^{2}\right)^{2}+\left(\frac{\omega_{r}^{2}}{\omega \tau_{c}}\right)^{2}}
$$

$\mathrm{Na}$ equação acima $\omega_{r}$ representa a frequência de ressonância do plasmon superficial e é dada por:

$$
\omega_{r}^{2}=\frac{\omega_{p}^{2}}{1+2 n^{2}}
$$

A equação (3) nos mostra a dependência do coeficiente de absorção do plasmon, $\alpha$, com o tamanho da partícula por meio do termo $\tau_{c}$ que depende de $\mathrm{R}$, raio da partícula. Cabe acrescentar que, para partículas com formas diferentes, a 
equação de $\tau_{\mathrm{c}}$ altera-se e com isto é possível termos a dependência do coeficiente de absorção do plasmon, $\alpha$, com a forma da partícula.

A geração dos PS dá origem a um campo elétrico oscilante na superfície da NP, denominado campo elétrico evanescente, apresentando um decaimento exponencial com a distância. Quando as NPs se aproximam ao ponto de formar aglomerados, os campos evanescentes sofrem interferências que geram ressonâncias em energias menores, o que explica o surgimento de novas bandas deslocadas em direção ao IV e também o seu alargamento. Sabe-se que quando as partículas metálicas apresentam-se desprovidas de uma camada de passivação (camada que evita o crescimento da NP) eficiente, que às estabilizaria eletrostaticamente ou estericamente, o fenômeno de agregação é observado.

Devemos salientar que há diferenças entre a coalescência e a aglomeração das NPs. No primeiro processo, duas ou mais partículas se unem formando uma nova partícula de tamanho maior. Nesse caso não são observadas bandas largas de RPS, apenas o deslocamento desta absorção em direção ao IV (Figura 2.9). Já o processo de aglomeração é observado quando duas ou mais partículas se aproximam o suficiente para que a interferência dos campos evanescentes ocorra, mas sem se fundirem. Observa-se então, o surgimento de uma nova banda de absorção (Figura 2.10). Esse tipo de comportamento é observado quando a camada de passivação é suficiente para evitar a fusão, mas ineficiente no impedimento da aproximação [55].

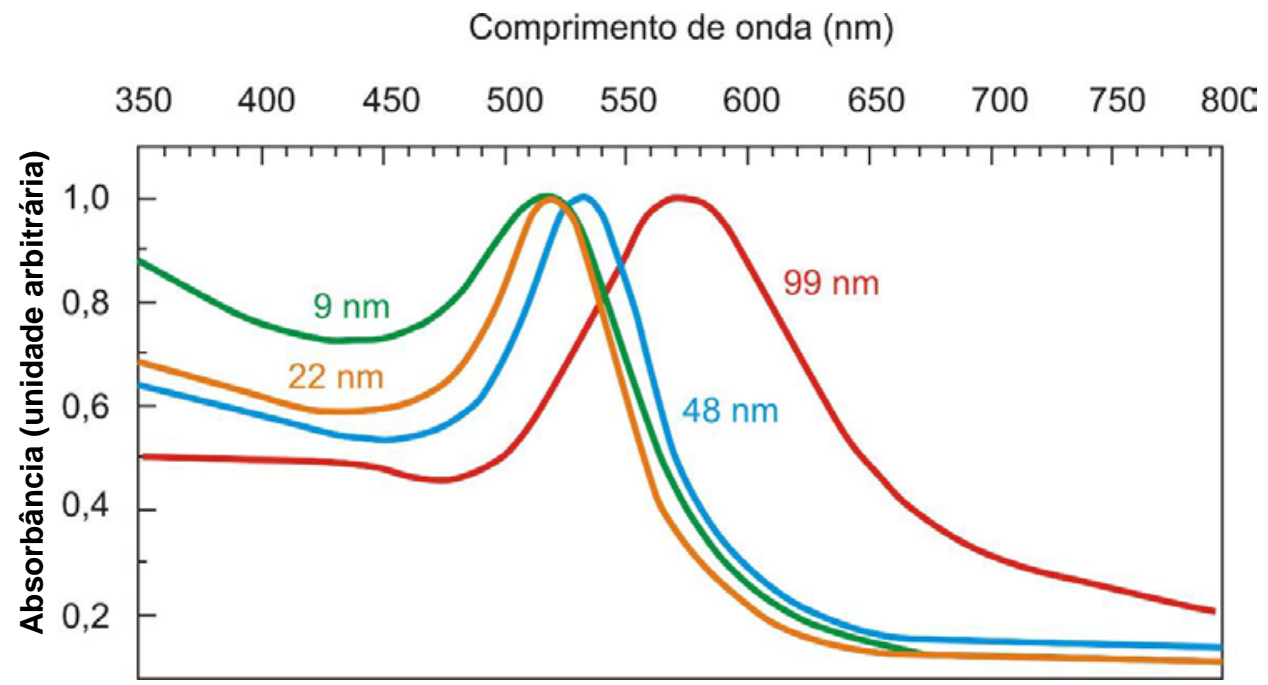

Figura 2.9 - Espectro de absorção de NPs de ouro com diferentes tamanhos [20]. 


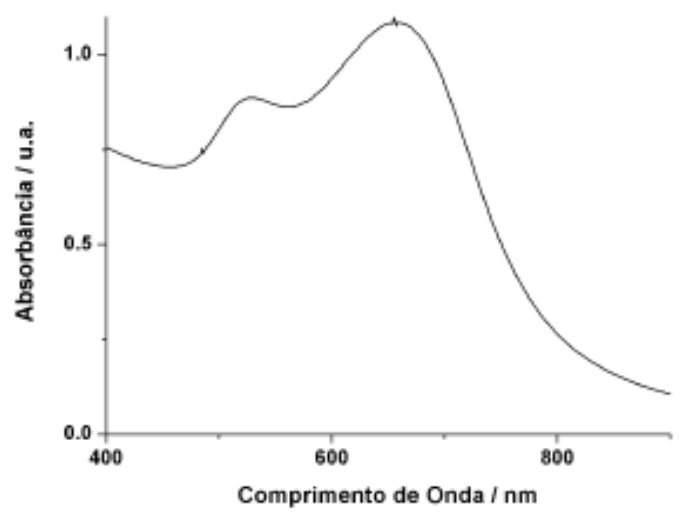

Figura 2.10 - Espectro de absorção de NPs de ouro em suspensão, mostrando a formação de banda de plasmon em 650nm, decorrente da aglomeração das NPs [55].

O mecanismo de formação e crescimento das NPs varia de acordo com o sistema hospedeiro e pode ser explicado pelo mecanismo de nucleação de La Mer [56]. Neste mecanismo, quando a concentração de átomos e íons que irão formar a NP ultrapassa certo limite, conhecido como concentração crítica de nucleação, ocorre a formação de pequenos aglomerados de átomos denominados núcleos ou sementes. Uma vez que ocorre a nucleação, a concentração de precursores disponíveis diminui, podendo ficar abaixo da concentração crítica de nucleação; a partir deste ponto ocorre somente o crescimento dos núcleos pré-formados pela incorporação das NPs. Em alguns casos, após essa etapa, quando a concentração de precursores torna-se maior que o valor crítico de crescimento, pode ocorrer também o processo Ostwald rippening que descreve a dissolução das partículas menores e o crescimento das maiores, ou mesmo o crescimento por incorporação de outros núcleos (aglomeração e coalescência). Nesta etapa de nucleação há o limite de fragmentação térmica, onde as NPs se "desprendem" umas das outras e se difundem pela matriz e dependendo da energia interna do sistema, podem se aglomerar novamente, formando novas estruturas [57].

O tamanho médio final das NPs depende, portanto, do precursor usado para obtê-las, do tempo e temperatura de tratamento térmico, da matriz hospedeira e do ambiente químico. O controle da distribuição de tamanhos depende da separação temporal das etapas de nucleação, da temperatura e da mobilidade dos íons metálicos no hospedeiro. Desta forma, os núcleos crescem sem que haja a formação simultânea de outros núcleos. Experimentalmente, a separação das etapas de nucleação e crescimento não é trivial e envolve a escolha correta da matriz e um procedimento de tratamento térmico adequado [57]. 
Uma distribuição não homogênea das NPs no hospedeiro e a formação de aglomerados podem influenciar a intensidade de luminescência dos íons de TRs em diferentes comprimentos de onda. Em geral, dizemos que as emissões mais próximas à banda de absorção da RPS são as mais afetadas. Outro fator importante é a concentração das NPs para um dado tamanho médio, pois em alguns casos, se a concentração for baixa, não se observa banda de absorção da RPS [57]. Isto foi visto em nossas amostras como será mostrado.

2.4.1 Ressonância dos Plamons Superficiais e a Nucleação das Nanopartículas de Prata

A Figura 2.11 apresenta a interferência do formato das NPs de prata no posicionamento das bandas de plasmon em colóides. NPs esféricas apresentam bandas de absorção entre 300 e $450 \mathrm{~nm}$; as pentagonais apresentam bandas entre 500 e $600 \mathrm{~nm}$ e as com formato de prisma triangular apresentam bandas entre $600 \mathrm{e}$ $750 \mathrm{~nm}$ [58]. Quando o tamanho da NP aumenta, ocorre o deslocamento da banda de plasmon para comprimentos de onda maiores como dito anteriormente. Por exemplo, NPs de prata esféricas com raio de $90 \mathrm{~nm}$ tem banda de plasmon em 700 nm. A banda de plasmon mostrada na Figura 2.11, compreendida entre 400 e 550 $\mathrm{nm}$ refere-se à NPs com diâmetros menores. A formação da NP (seu formato e tamanho) vai depender da energia de ativação do sistema (tempo e temperatura de tratamento térmico) e do ambiente hospedeiro na qual a NP está inserida (matriz).

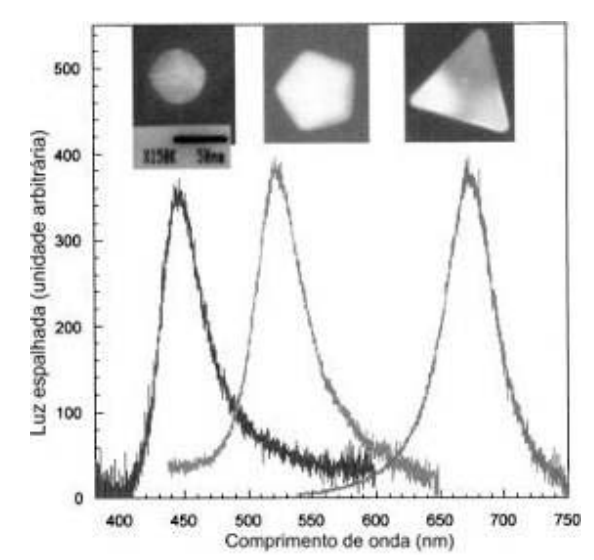

Figura 2.11 - Interferência da forma das nanopartículas de prata na posição das bandas de absorção dos PS em colóides com nanopartículas de prata [58]. 
A literatura reporta casos de nucleação de NPs de prata em vidros de sílica através de três procedimentos: tratamentos térmicos, irradiação através de laser na região do ultra-violeta e irradiação por raios X. Em amostras tratadas termicamente, a probabilidade de gerar NPs combinadas com outros elementos da matriz é maior em relação aos outros dois procedimentos. Ao irradiar com laser, a nucleação é local e a homogeneidade das NPs pode ficar comprometida. Na irradiação por raios $X$ pode-se promover defeitos e tornar o vidro instável quimicamente. A Figura 2.12 mostra a comparação entre bandas de plasmon de NPs de prata em amostras tratadas termicamente e irradiada por laser [59].

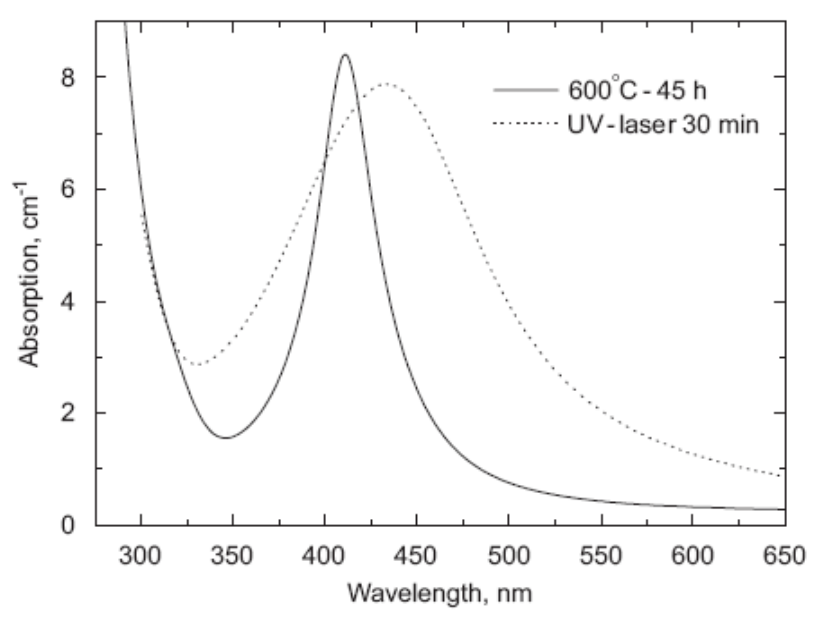

Figura 2.12 - Comparação de bandas de plasmon de NPs de prata em vidros de sílica [59].

O tamanho médio das NPs e a sua distribuição na matriz varia significativamente. $\mathrm{Na}$ amostra tratada termicamente, as NPs têm tamanho médio menor do que as obtidas por irradiação de laser UV. Isto pode ser visto pelo descolamento do pico da banda de absorção para comprimentos de onda menores. Além disto, a distribuição de tamanhos no caso da amostra irradiada por UV é mais variada, o que pode ser visto pela larga banda de absorção [59].

Outra característica importante a ser mencionada, é a alta mobilidade dos ions de prata e a facilidade de formar agregados quando o hospedeiro é uma matriz vitrea, podendo assim, coexistir vários tamanhos de NP e até a formação de agregados [60]. 


\subsubsection{Metodologias de Nucleação de Nanopartículas}

Dentre as várias técnicas empregadas atualmente na nucleação de NPs, podemos citar as técnicas de tratamento térmicos, irradiação por laser de femtosegundo, irradiação por laser/lâmpada UV, irradiação por feixe de elétrons e raios $X$, técnica sol-gel, campo elétrico, entre outras [49,51,61-66]. Embora materiais nanoestruturados apresentem perspectivas promissoras para aplicações tecnológicas e industriais resta ainda a necessidade de produzí-los com propriedades adequadas, isto é, com distribuição homogênea das NPs.

Neste trabalho foi empregada a técnica do tratamento térmico; o desenvolvimento deste processo é fundamental para o controle das dimensões e distribuição das NPs.

$\mathrm{Na}$ literatura são reportados processos de tratamento térmico formados por duas etapas para a redução da dispersão de tamanho das NPs: um pré-tratamento que propicie alta taxa de nucleação seguido de um tratamento a uma temperatura mais alta, onde a taxa de crescimento das NPs seja maior $[67,68]$. Uma baixa dispersão de tamanho é de extrema importância para que as não linearidades sejam suficientemente altas.

Assim sendo, é preciso determinar as condições necessárias para que ocorra, simultaneamente, a formação das NPs e a preservação da qualidade óptica evitando-se a cristalização de elementos da matriz hospedeira.

De maneira geral, as NPs tendem a adquirir formas esféricas, que correspondem à situações de menor energia. A obtenção preferêncial de partículas não-esféricas exige, portanto, interferência externa. Uma possiblidade de controle do tamanho das NPs seria a utilização de luz UV no processo de nucleação por tratamento termico, dando ao sistema uma nucleação preferencialmente no tamanho de NP que tenham PS ressonantes ao comprimento de onda da luz utilizada.

A metodologia adotada para a formação das NPs metálicas dos trabalhos realizados pelo grupo consiste no tratamento térmico das amostras em temperatura igual à utilizada para o alívio das tensões internas do vidro. Este processo é realizado por meio de sucessivos tratamentos até que seja atingido o tempo desejado. 
Na Figura 2.13 é ilustrado de maneira esquemática o processo de nucleação de NPs de prata a partir do precursor $\mathrm{AgNO}_{3}$. Cabe acrescentar que no processo de tratamento térmico, a nucleação depende da energia de ativação (temperatura utilizada), do tempo de tratamento e da matriz utilizada como hospedeira, pois esta última pode controlar o processo de crescimento das NPs, já que apresenta diferentes taxas de difusão para cada tipo de íon metálico. Como dito anteriormente, a prata possui grande mobilidade quando o hospedeiro é uma matriz vítrea podendo coexistir vários tamanhos de NP e até a formação de agregados.
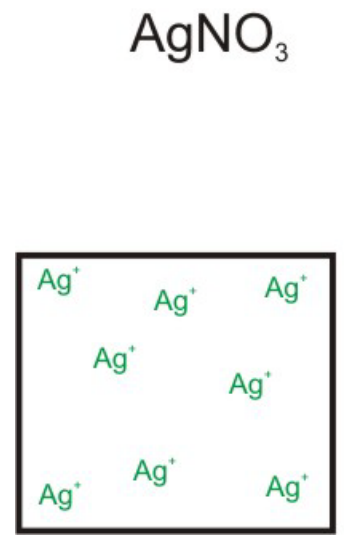

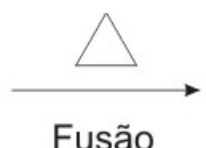

Fusão

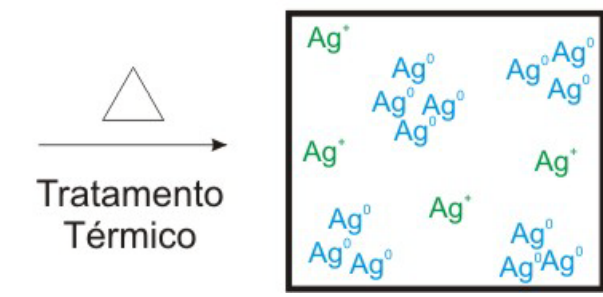

Figura 2.13 - Representação esquemática da nucleação das NPs de prata.

Neste trabalho, temos como propósito variar os tempos e as temperaturas de tratamento, a fim de verificar as influências geradas na forma, na distribuição do tamanho e na concentração das NPs. Maiores detalhes a respeito da metodologia adotada serão descritas no item 3.2.

Até o momento não encontramos na literatura trabalhos com a proposta igual ou similar a da pesquisa em tela.

\subsection{ANTECEDENTES DO GRUPO}

As recentes pesquisas em nanociência e nanotecnologia vêm apresentando resultados importantes e novas aplicações em diversos setores, como por exemplo, na medicina (em sistemas de diagnósticos e implantes), na construção civil (materiais mais reforçados e de maior duração), nas tecnologias da informação (com novas tecnologias de visualização, guias de ondas mais eficientes, novos biochips e 
chips quânticos), na alimentação e meio ambiente (resultando em menor gasto de matérias-primas e métodos de detecção de pragas), atraindo a atenção de muitos grupos científicos, empresas e pesquisadores [69].

A síntese de materiais formados por agregados atômicos com dimensões da ordem de nanômetros tem sido tema de muitos estudos no campo da ciência dos materiais e na engenharia. Como consequências destas dimensões reduzidas, esses materiais apresentam propriedades ópticas, termodinâmicas, mecânicas, magnéticas e elétricas que diferem das observadas nos materiais macroscópicos [70]. Estudos mostram que tais propriedades dependem do tamanho e da forma dos agregados $[71,72]$.

Esses novos materiais são potenciais candidatos para aplicação em dispositivos ópticos, devido às propriedades ópticas lineares e não-lineares observadas nos nanocristais semicondutores e metálicos [71-73]. Um dos desafios de produzi-los com as propriedades desejadas é a necessidade de evitar a aglomeração das nanopartículas e encontrar meios opticamente transparentes onde elas possam ser efetivamente incorporadas. Entre os materiais que satisfazem essa necessidade estão os vidros [74,75].

A fusão dos reagentes e o resfriamento do material fundido, seguido de processos de tratamento térmico, para promover a nucleação e o crescimento de nanocristais, é o método mais simples e mais utilizado na preparação de vidros contendo nanopartículas metálicas [76,77] ou semicondutoras [78,79].

Materiais vítreos com nanoestruturas metálicas têm sido pouco estudados, de forma que a literatura carece de estudos de NPs metálicas em vidros das famílias dos teluretos e germanatos, dopados com íons de TRs. As nanoestruturas metálicas causam o aumento da luminescência dos íons de TRs usados como dopantes e da não linearidade do índice de refração, características importantes para dispositivos fotônicos, o que também motiva a pesquisa em questão.

Estudos recentes feitos pelo Laboratório de Vidros e Datação da Faculdade de Tecnologia de São Paulo (LVD - FATEC-SP) em parceria com laboratórios de outras universidades (Escola Politécnica da USP, Universidade Federal de Pernambuco, Instituto de Pesquisas Energéticas e Nucleares - IPEN) e de laboratórios internacionais (Dlugosz University Czestochowa - Polônia) com materiais vítreos nanoestruturados têm sido pioneiros. Dois grupos de materiais vítreos são estudados atualmente pelo grupo: teluretos e germanatos que 
apresentam algumas propriedades ópticas semelhantes. A seguir, serão apresentados alguns resultados obtidos até o momento.

Em 2005 foi publicado o primeiro estudo da interferência da presença de NPs de prata na emissão de íons de $\mathrm{Pr}^{3+}$ em vidros de germanato. Foram observadas NPs de diâmetro médio de $2 \mathrm{~nm}$ e agregados menores que $100 \mathrm{~nm}$. Os íons de $\mathrm{Pr}^{3+}$ apresentam intensa emissão em torno de $480 \mathrm{~nm}$ e $610 \mathrm{~nm}$. Foi observada uma intensa banda de plasmon das NPs de prata em torno de $464 \mathrm{~nm}$, como mostra a Figura 2.14 [80].
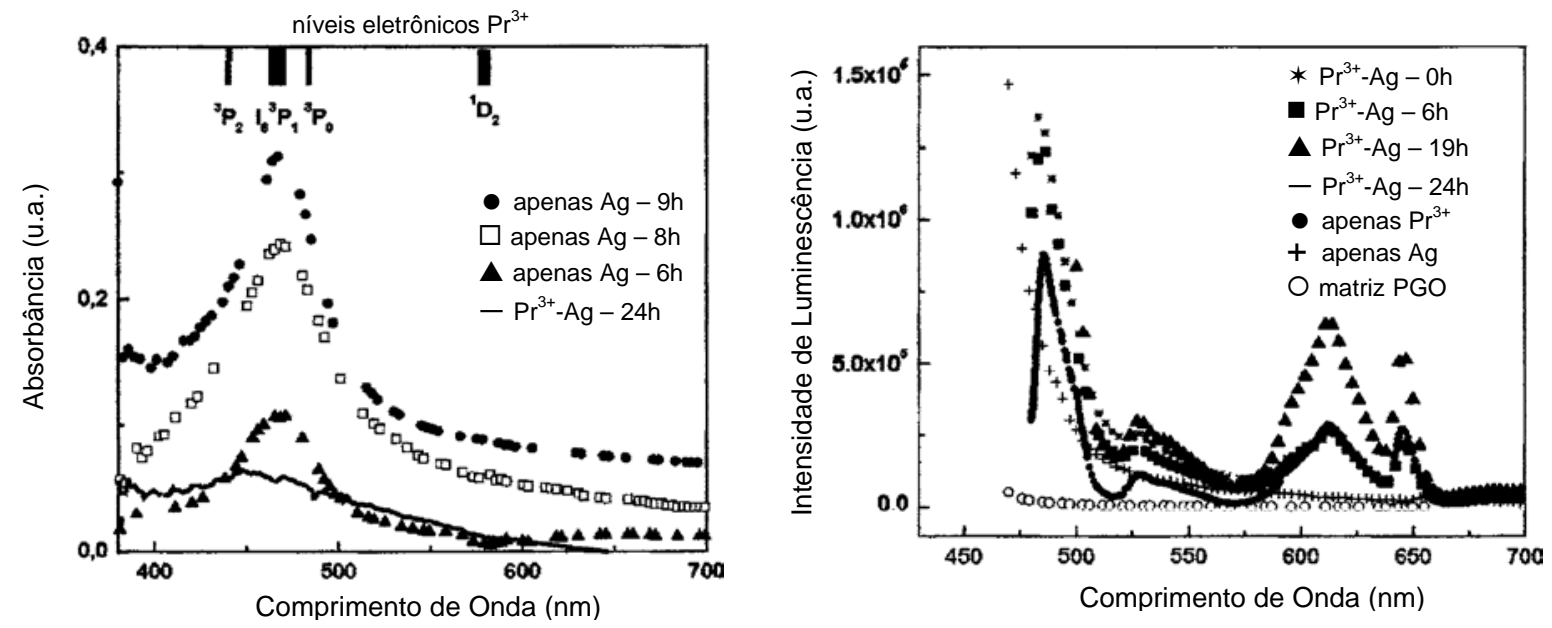

Figura 2.14 - Espectros de absorção (à esquerda) e emissão (à direita) de amostras de germanato dopadas com $\mathrm{Pr}^{3+}$ e NPs de prata [80].

A presença de NPs de prata de 2,2 nm em vidros de germanato dopados com íons de érbio foi reportada pela primeira vez pelo grupo. Nesse estudo, foi observado aumento da emissão luminescente dos íons de $\mathrm{Er}^{3+}$ proveniente de um processo de CA de energia. As amostras vítreas foram submetidas à diversas horas de tratamento térmico (metodologia adotada pelo grupo na obtenção dessas NPs) e observou-se um aumento superior a 100\% da emissão em 550 nm, proveniente dos íons $\mathrm{Er}^{3+}$. Nesse estudo também foi observada a presença da banda de plasmon da prata, em torno de 460 nm, fenômeno característico na presença das NPs [20,81], como é possível observar na Figura 2.15. 

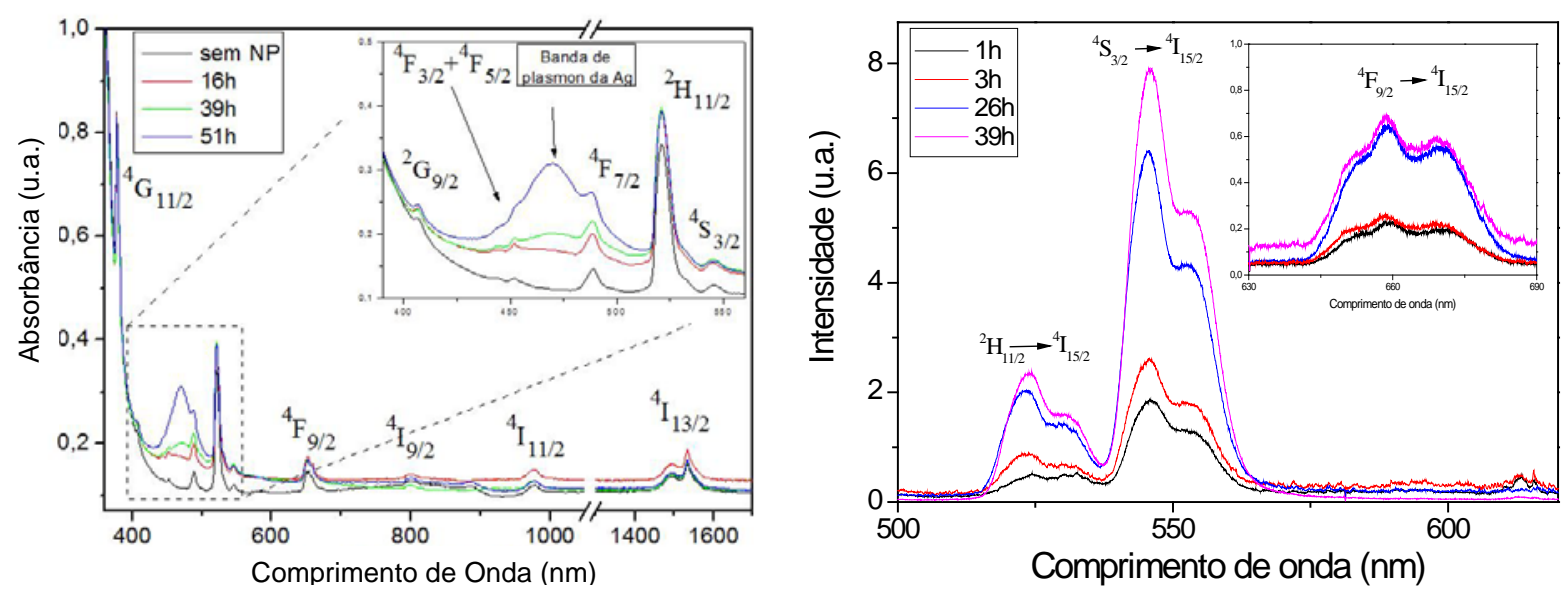

Figura 2.15 - Espectros de absorção (à esq.) e de emissão (à dir.) de amostra de germanatos dopadas com $\mathrm{Er}^{3+}$. As transições indicadas na figura são referentes aos íons de $\mathrm{Er}^{3+}[20,81]$.

Filmes finos de germanato contendo NPs de cobre com tamanho variando entre 1 e 15 nm, obtidos a partir da técnica de deposição por sputtering, também foram estudados pelo grupo [82]. Nestas amostras foi observada a presença das bandas de plasmon das NPs de $\mathrm{Cu}_{2} \mathrm{O}$ e $\mathrm{Cu}$ metálico em filmes finos, como mostra a Figura 2.16. Em ambas as amostras, a banda de plasmon se encontra em aproximadamente $460 \mathrm{~nm}$, indicando a presença de NPs de $\mathrm{Cu}_{2} \mathrm{O}$ [83]. O ombro situado em $580 \mathrm{~nm}$ é característico de NPs constituídas de cobre metálico [84].

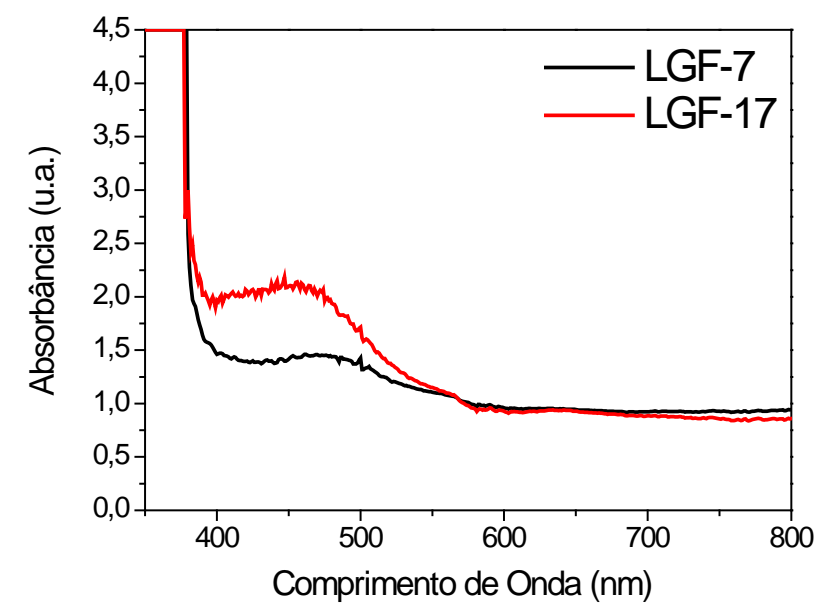

Figura 2.16 - Espectro de absorção de filmes finos de germanato contendo NPs de cobre e de $\mathrm{Cu}_{2} \mathrm{O}$. LGF-7 corresponde ao filme fino tratado por 7 horas e LGF-17, ao filme tratado por 17 horas [82].

Outro resultado reportado pela primeira vez é a influência das NPs de prata no processo de CA em vidros de germanato codopados com íons de $\mathrm{Yb}^{3+}$ e $\mathrm{Er}^{3+}$ [85]. Neste trabalho foi observado o aumento da luminescência na região do visível, provenientes dos íons $\mathrm{Er}^{3+}$ (Figura 2.17). Em trabalho anterior do mesmo autor, 
verificou-se que com o aumento da concentração dos íons $\mathrm{Yb}^{3+}$, a banda de emissão em $662 \mathrm{~nm}$, proveniente dos íons $\mathrm{Er}^{3+}$, foi intensificada em relação às emissões em 525 e 550 nm [86]. Entretanto, a formação de NPs maiores e de agregados mostraram que a luminescência em comprimentos de onda maiores também pode ser intensificada, pois a RPS destas tende a deslocar em direção ao IV. As outras emissões em 525 e 550 nm também foram intensificadas devido à presença de nanopartículas menores. A explicação para este efeito é a contribuição de dois fatores importantes que podem aumentar a luminescência dos íons de TRs, 0 aumento do campo local e a transferência de energia das NPs para os íons de TRs, devido à RPS.

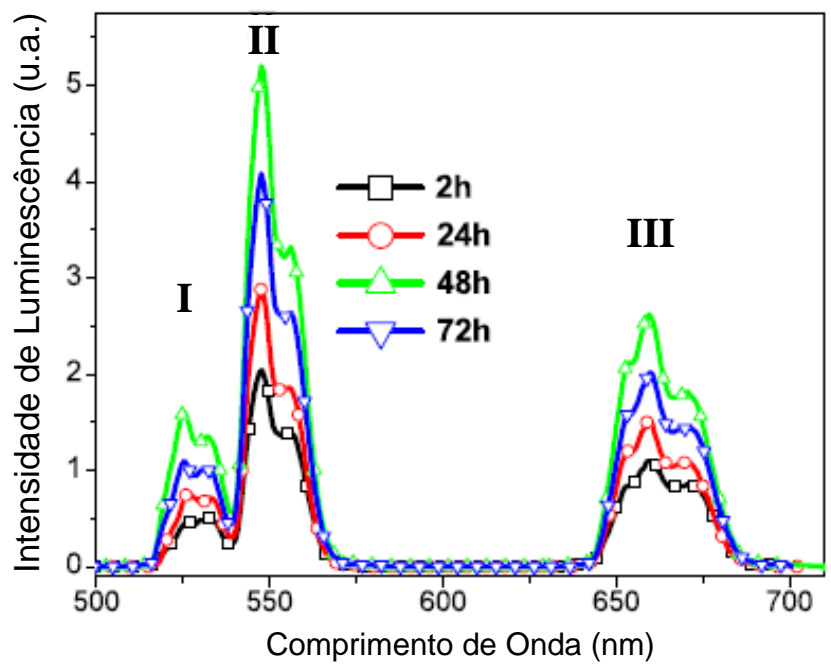

Figura 2.17 - Espectro de emissão das amostras de germanato codopadas com $\mathrm{Er}_{2} \mathrm{O}_{3}$ e $\mathrm{Yb}_{2} \mathrm{O}_{3}$ contendo NPs de prata. As transições identificadas por I, II e III são, respectivamente, ${ }^{2} \mathrm{H}_{11} \rightarrow{ }^{4} \mathrm{I}_{15 / 2}$ (525 $\mathrm{nm}),{ }^{4} \mathrm{~S}_{3 / 2} \rightarrow{ }^{4} \mathrm{I}_{15 / 2}(550 \mathrm{~nm})$ e ${ }^{4} \mathrm{~F}_{9 / 2} \rightarrow{ }^{4} \mathrm{I}_{15 / 2}(662 \mathrm{~nm})$, e correspondem aos íons de $\mathrm{Er}^{3+}[85]$.

Nanopartículas de ouro em vidros de germanato dopados $\mathrm{Eu}^{3+}$ também se mostraram bastante eficientes no aumento da luminescência dos íons de $\mathrm{Eu}^{3+}$ na região do visível. Neste trabalho as amostras foram submetidas à várias horas de tratamento, novamente, seguindo o método adotado pelo grupo. Uma banda de absorção associada a RPS das NPs de ouro, centrada em $\approx 500$ nm (Figura 2.18a), também foi observada. Foi obtido um aumento de $\approx 1000 \%$ na luminescência em $614 \mathrm{~nm}$, e um aumento considerável também nas outras emissões provenientes dos íons $\mathrm{Eu}^{3+}$ (Figura 2.18b) [87]. 
(a)
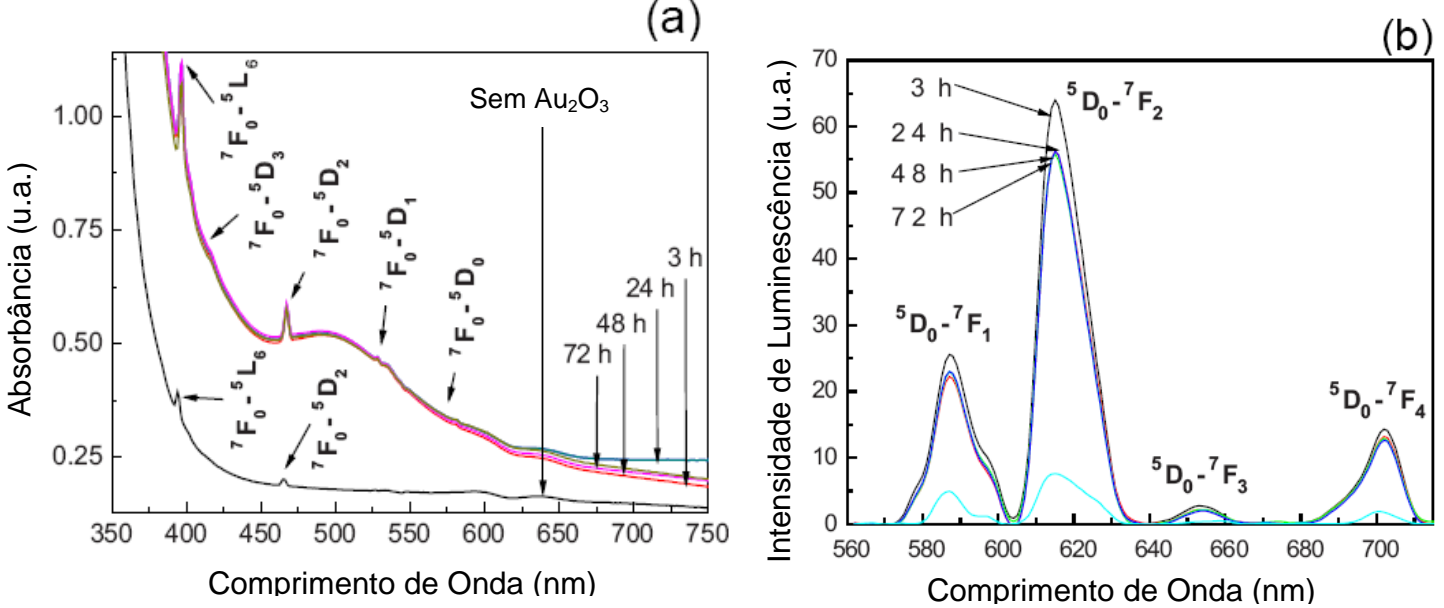

Figura 2.18 - Espectros de (a) absorção e de (b) emissão das amostra de germanato dopadas com $\mathrm{Eu}_{2} \mathrm{O}_{3}$ e $\mathrm{Au}_{2} \mathrm{O}_{3}$, tratadas termicamente de 1 a 72 horas. As transições identificadas nos espectros correspondem aos íons de $\mathrm{Eu}^{3+}$, e a larga banda de absorção centrada em $\approx 500 \mathrm{~nm}$ corresponde à RPS do ouro [87].

Estudos recentes, desenvolvidos em parceria com a Universidade Federal de Pernambuco (UFPE), estão sendo realizados para a gravação de trilhas através de um laser de femtosegundo em amostras de telureto e germanato. Foi possível verificar que esses vidros apresentam uma boa superfície de gravação e excelentes propriedades ópticas, que evitam o espalhamento da luz, como é possível observar na Figura 2.19, que apresenta o guiamento da luz em $980 \mathrm{~nm}$ em vidro de telureto preparado com $0.5 \%$ em peso de $\mathrm{Er}_{2} \mathrm{O}_{3}$. Acrescenta-se ainda que foi observado para vidros de germanato $\left(\mathrm{GeO}_{2}-\mathrm{PbO}-\mathrm{Ga}_{2} \mathrm{O}_{3}\right)$, dopados com íons de $\mathrm{Er}^{3+}$ e trilhas gravadas também pelo mesmo procedimento, amplificação da luz em 1500 nm, terceira janela de telecomunicação, comparável a vidros fosfatos comerciais.

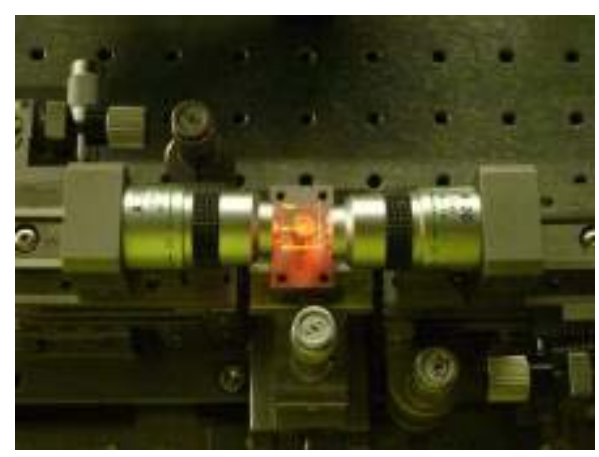

Figura 2.19 - Gravação em amostra de telureto.

A referida gravação da trilha é também designada por gravação por "escrita" e introduz mudanças na estrutura do material produzindo uma região de alto índice de refração no vidro, permitindo que o material se torne um potencial guia de onda [88]. 
A possibilidade de se produzir guias de onda a partir de vidros de óxidos de metais pesados tem atraído a atenção de pesquisadores, pois podem ser aplicados em amplificadores ópticos e dispositivos fotônicos, como por exemplo, divisores de potência, acopladores ópticos mono-modo, acopladores direcionais, acopladores direcionais 3D, fibras de Bragg, comutador óptico baseados em interferômetros Mach-Zehnder, lentes de Fresnel birrefringentes e cristais fotônicos e nanoestruturas [89].

Também estão sendo realizados estudos preliminares com a matriz telureto $\mathrm{TeO}_{2}-\mathrm{ZnO}$ para a deposição de filmes finos através da técnica sputtering visando a produção de guias de onda. A técnica consiste no bombardeamento de íons sobre um alvo (no caso, o vidro de telureto), e a conseqüente (remoção) expulsão de partículas do material que se quer depositar. Os íons são formados a partir de um gás inerte e seus movimentos são controlados por um campo magnético de radiofreqüência, o que os induz a irem até o alvo, que está num dos pólos (o catodo) e produzir as partículas. Por sua vez, o material expelido adere ao substrato, que está no outro pólo (o anodo), formando a película ou filme [90]. Na Figura 2.20, pode-se observar o sistema de deposição por sputtering do LVD da FATEC-SP.

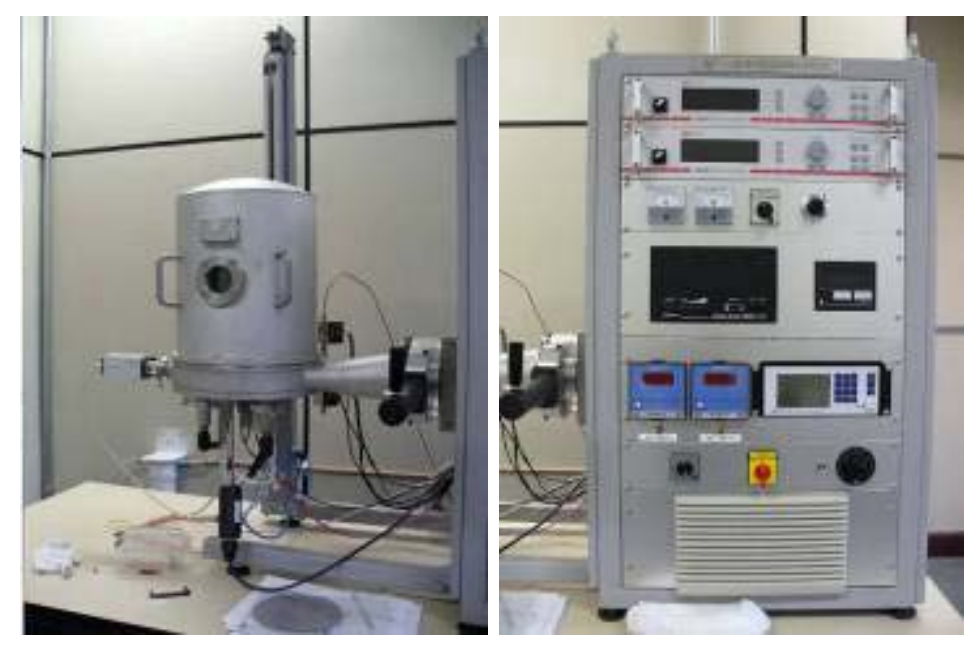

Figura 2.20 - Evaporadora PV 300 Prest Vácuo. À esquerda, a câmara de vácuo, onde se situa a amostra vítrea e o substrato. À direita, o painel de controle do sistema de vácuo e geração de rádio freqüência.

Foram produzidos dois alvos (matriz e matriz dopada com $2 \%$ em peso de $\mathrm{Au}_{2} \mathrm{O}_{3}$ ) a fim de se estudar os parâmetros de processo de deposição, as propriedades ópticas dos filmes, rugosidade, estequiometria e espessura. 
Para se obter um filme de espessura de 500๕̂, foi usado uma potência de $50 \mathrm{~W}$, durante aproximadamente 2 horas, a pressão de 3,5 mTorr e distância entre alvo e substrato de $15 \mathrm{~cm}$. Resultados iniciais mostraram que a taxa de deposição desse sistema vítreo é maior quando comparada com os vidros de germanato. $\mathrm{Na}$ Figura 2.21 verifica-se a geração de plasma de argônio durante o processo de deposição dos filmes finos. Testes realizados com a inserção de oxigênio no sistema também estão sendo realizados, para melhorar as propriedades ópticas do filme e investigar as alterações causadas na estequiometria. Estudos mais recentes foram feitos usando alvos vítreos e alvos de ouro ou prata e deposição por co-sputtering; neste caso, a nucleação das NPs foi mais eficiente do que no caso anterior.

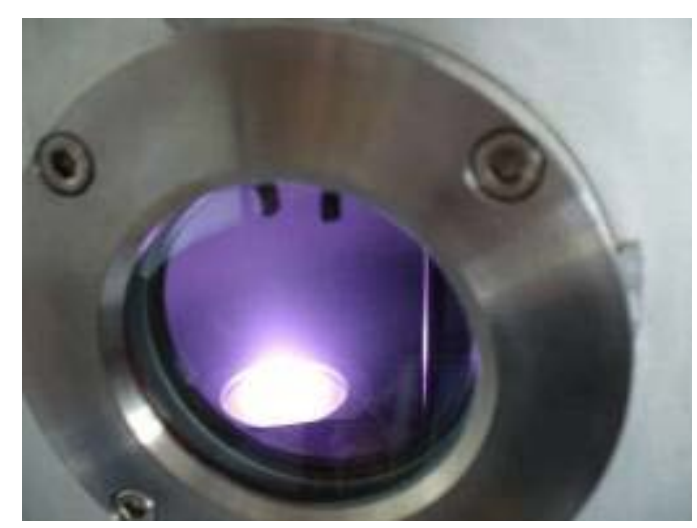

Figura 2.21 - Plasma de argônio gerado durante a deposição de filmes finos. 


\section{METODOLOGIA}

O vidro de germanato estudado pertence ao sistema binário nomeado GP $\left(\mathrm{GeO}_{2}-\mathrm{PbO}\right)$. Este vidro possui uma larga janela de transmissão $(400-4500 \mathrm{~nm})$ se comparado aos silicatos, boratos e fosfatos, boa estabilidade química e vítrea, alta resistência mecânica, alto índice de refração $(\approx 2,0)$ e baixa energia de fônon $(\approx 700$ $\mathrm{cm}^{-1}$ ) que indica baixas perdas por processos não-radiativos. A Figura 3.1 apresenta os espectros de absorção óptica e de transmissão no infravermelho do vidro estudado.
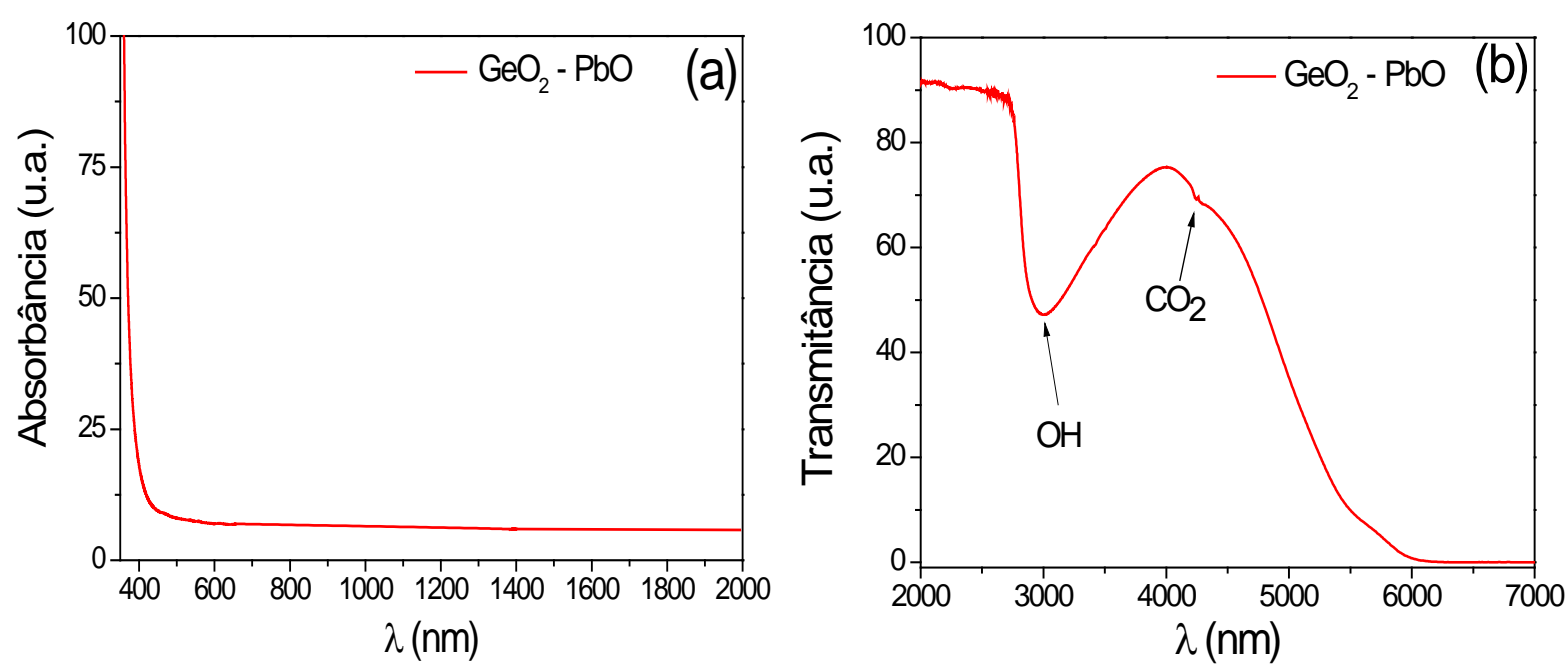

Figura 3.1 - Espectro de absorção na região do visível e infravermelho próximo (esquerda) e transmitância no infravermelho (direita) da matriz vítrea estudada.

\subsection{PREPARO DAS AMOSTRAS}

As amostras foram produzidas através do processo de fusão dos reagentes seguido da solidificação rápida. Para a confecção das amostras foram utilizados os óxidos $\mathrm{GeO}_{2}$ e $\mathrm{PbO}$. Como dopantes foram utilizados os óxidos de TRs $\mathrm{Tm}_{2} \mathrm{O}_{3} \mathrm{e}$ $\mathrm{Yb}_{2} \mathrm{O}_{3}$, e o reagente metálico $\mathrm{AgNO}_{3}$ (precursor que formará as NPs). As purezas dos reagentes da matriz e suas concentrações são apresentadas na Tabela 3.1. As amostras preparadas são apresentadas na Tabela 3.2. 
Tabela 3.1 - Concentração dos reagentes da matriz $\mathrm{GeO}_{2}-\mathrm{PbO}$.

\begin{tabular}{ccc}
\hline Reagentes & Concentração (\% em peso) & Pureza (\%) \\
\hline $\mathrm{GeO}_{2}$ & 41,0 & 99,999 \\
$\mathrm{PbO}$ & 59,0 & $\geq 99,0$ \\
\hline
\end{tabular}

Tabela 3.2 - Amostras preparadas em cadinho de $\mathrm{Al}_{2} \mathrm{O}_{3}-\mathrm{SiO}_{2}$.

\begin{tabular}{ccc}
\hline $\begin{array}{c}\text { Concentração de } \mathrm{Tm}_{2} \mathrm{O}_{3} \\
\text { (\% em peso) }\end{array}$ & $\begin{array}{c}\text { Concentração de } \mathrm{Yb}_{2} \mathrm{O}_{3} \\
\text { (\% em peso) } \\
\text { Pureza }-99,9 \%\end{array}$ & $\begin{array}{c}\text { Concentração de } \mathrm{AgNO}_{3} \\
\text { (\% em peso) } \\
\text { Pureza - 99,999\% }\end{array}$ \\
\hline 0,5 & 0,5 & - \\
0,5 & 1,0 & - \\
0,5 & 2,0 & 1,0 \\
0,5 & 2,0 & 3,0 \\
0,5 & 3,0 & 3,0 \\
\hline
\end{tabular}

Além das amostras preparadas com reagente metálico, foram produzidas duas amostras contendo apenas $\mathrm{Tm}_{2} \mathrm{O}_{3}$ e $\mathrm{Yb}_{2} \mathrm{O}_{3}$, apresentadas na Tabela 3.2 para comparação com as amostras contendo NPs e para realização de estudo da transferência de energia entre os íons $\mathrm{Yb}^{3+} \mathrm{e} \mathrm{Tm}^{3+}$.

Cabe acrescentar que as amostras apresentadas na Tabela 3.2 foram produzidas em cadinho de alumina-silicato $\left(\mathrm{Al}_{2} \mathrm{O}_{3}-\mathrm{SiO}_{2}\right)$. A partir dos resultados apresentados, verificou-se a necessidade de realizar novas amostras em cadinho de alumina pura, pois a incorporação do $\mathrm{SiO}_{2}$ proveniente do cadinho, impede que altas concentrações de $\mathrm{Yb}_{2} \mathrm{O}_{3}$ possam ser introduzidas a matriz vítrea, conforme foi constado em trabalhos recentes [91, 92].

$\mathrm{Na}$ Tabela 3.3 são apresentadas as amostras produzidas em cadinho de alumina pura, cuja pureza dos reagentes é a mesma apresentada anteriormente.

Tabela 3.3 - Amostras preparadas em cadinho de alumina pura.

\begin{tabular}{ccc}
\hline $\begin{array}{c}\text { Concentração de } \mathrm{Tm}_{2} \mathrm{O}_{3} \\
\text { (\% em peso) }\end{array}$ & $\begin{array}{c}\text { Concentração de } \mathrm{Yb}_{2} \mathrm{O}_{3} \\
\text { (\% em peso) }\end{array}$ & $\begin{array}{c}\text { Concentração de } \mathrm{AgNO}_{3} \\
\text { (\% em peso) }\end{array}$ \\
\hline 1,0 & - & 5,0 \\
0,5 & 2,0 & 3,0 \\
\hline
\end{tabular}

Para ajudar na identificação das amostras estudadas neste trabalho, adotamos um código formado por letras e números, onde $\mathrm{Tm}_{2} \mathrm{O}_{3}, \mathrm{Yb}_{2} \mathrm{O}_{3}$ e $\mathrm{AgNO}_{3}$ serão representados pelas letras $\mathrm{T}, \mathrm{Y}$ e $\mathrm{A}$, respectivamente. Lembrando, conforme 
mostrado nas tabelas anteriores, que a concentração de $\mathrm{Tm}_{2} \mathrm{O}_{3}$, nas amostras codopadas foi mantida constante em $0,5 \%$ em peso, e que nas amostras contendo apenas $\mathrm{Tm}_{2} \mathrm{O}_{3}$ e $\mathrm{AgNO}_{3}$, a concentração foi mantida em 1,0 \% em peso, adotamos números para representar as várias concentrações utilizadas para os outros dopantes $\left(\mathrm{Yb}_{2} \mathrm{O}_{3}\right.$ e $\left.\mathrm{AgNO}_{3}\right)$, que antecedem os respectivos dopantes. $\mathrm{Na}$ Tabela 3.4 estão representados os códigos de cada amostra.

Tabela 3.4 - Amostras estudadas neste trabalho e respectivos códigos de identificação

\begin{tabular}{cc}
\hline Composição da amostra & Código da amostra \\
\hline $\mathrm{GP}-0,5 \% \mathrm{Tm}_{2} \mathrm{O}_{3}-0,5 \% \mathrm{Yb}_{2} \mathrm{O}_{3}$ & $\mathrm{~T} 05 \mathrm{Y}$ \\
$\mathrm{GP}-0,5 \% \mathrm{Tm}_{2} \mathrm{O}_{3}-1,0 \% \mathrm{Yb}_{2} \mathrm{O}_{3}$ & $\mathrm{~T} 1 \mathrm{Y}$ \\
$\mathrm{GP}-0,5 \% \mathrm{Tm}_{2} \mathrm{O}_{3}-2,0 \% \mathrm{Yb}_{2} \mathrm{O}_{3}$ & $\mathrm{~T} 2 \mathrm{Y}$ \\
$\mathrm{GP}-0,5 \% \mathrm{Tm}_{2} \mathrm{O}_{3}-3,0 \% \mathrm{Yb}_{2} \mathrm{O}_{3}$ & $\mathrm{~T} \mathrm{Y}$ \\
$\mathrm{GP}-0,5 \% \mathrm{Tm}_{2} \mathrm{O}_{3}-2,0 \% \mathrm{Yb}_{2} \mathrm{O}_{3}-1,0 \% \mathrm{AgNO}_{3}$ & $\mathrm{~T} 2 \mathrm{Y} 1 \mathrm{~A}$ \\
$\mathrm{GP}-0,5 \% \mathrm{Tm}_{2} \mathrm{O}_{3}-2,0 \% \mathrm{Yb}_{2} \mathrm{O}_{3}-3,0 \% \mathrm{AgNO}_{3}$ & $\mathrm{~T} 2 \mathrm{Y} 3 \mathrm{~A}$ \\
$\mathrm{GP}-0,5 \% \mathrm{Tm}_{2} \mathrm{O}_{3}-3,0 \% \mathrm{Yb}_{2} \mathrm{O}_{3}-3,0 \% \mathrm{AgNO}_{3}$ & $\mathrm{~T} 3 \mathrm{YA}$ \\
$\mathrm{GP}-1,0 \% \mathrm{Tm}_{2} \mathrm{O}_{3}-5,0 \% \mathrm{AgNO}_{3}$ & $\mathrm{~T} 5 \mathrm{~A}$ \\
\hline
\end{tabular}

A Tabela 3.4 apresenta todas as amostras produzidas neste trabalho, bem como T2Y e T3Y que foram produzidas na Iniciação Cientifica; isto teve que ser feito com o objetivo de complementar os resultados obtidos para as amostras T05Y e T1Y, no que diz respeito aos estudos de transferência de energia anteriormente mencionados, que explicaram o número de íons que participam do processo de CA conforme será visto.

Para as amostras tratadas termicamente a fim de nuclear NPs de prata, são adicionados aos seus códigos o tempo e a temperatura de tratamento seguindo o exemplo a seguir: amostra GP com 0,5\% $\mathrm{Tm}_{2} \mathrm{O}_{3}, 2,0 \% \mathrm{Yb}_{2} \mathrm{O}_{3}$ e 3,0\% $\mathrm{AgNO}_{3}$ tratada por 6 h à $500{ }^{\circ} \mathrm{C} \rightarrow$ T2Y3A $(6 h-500)$.

A Figura 3.2 mostra um fluxograma dos procedimentos realizados na confecção das amostras. 


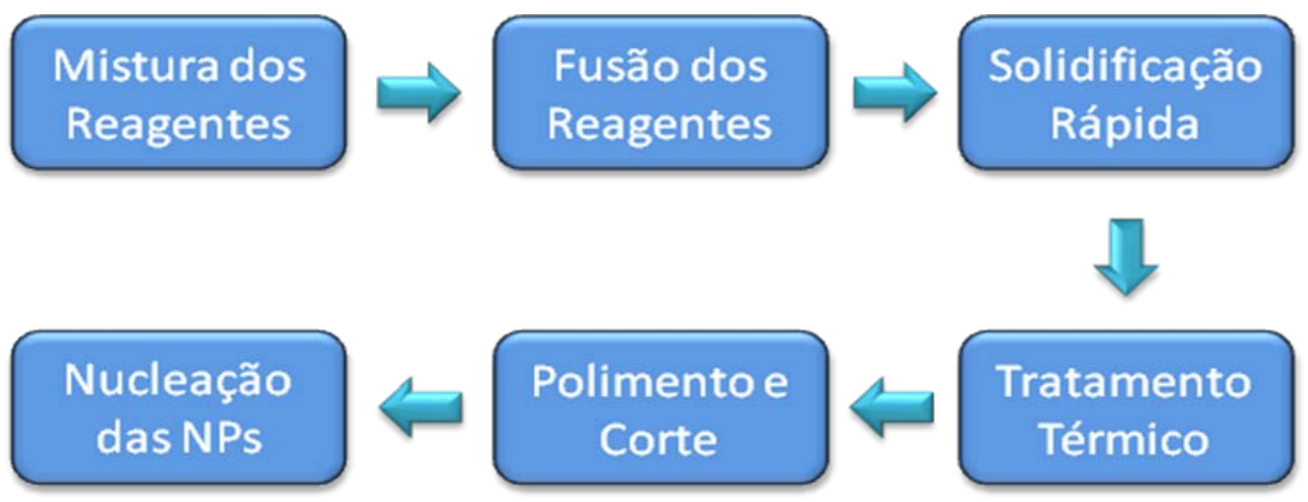

Figura 3.2 - Etapas utilizadas na confecção das amostras vítreas.

- Mistura dos Reagentes: Os reagentes são pesados em béqueres, previamente limpos com álcool etílico, em uma balança com precisão de $\pm 10^{-4}$ g. Cada reagente é pesado separadamente e com espátulas descartáveis. Posteriormente, todos são colocados no cadinho e misturados mecanicamente com uma espátula.

- Fusão dos Reagentes: O cadinho contendo a mistura é levado ao forno de atmosfera não controlada, pré-aquecido à temperatura de $1200{ }^{\circ} \mathrm{C}$, permanecendo por 1 hora. O tempo depende da composição da matriz e sua finalidade é permitir que a massa fundida se torne homogênea.

- Solidificação Rápida: Em seguida, o material fundido é rapidamente vertido em molde de latão pré-aquecido à temperatura de $420^{\circ} \mathrm{C}$, inferior a $\mathrm{T}_{\mathrm{g}}$ da matriz utilizada no estudo $\left(\mathrm{T}_{\mathrm{g}} \approx 450{ }^{\circ} \mathrm{C}\right)$. O molde utilizado é previamente lixado e polido para remover eventuais impurezas ou resíduos de outra amostra que tenham ficado retidos na superfície. É também pré-aquecido para evitar que a amostra sofra choque térmico e conseqüente perda do material.

- Tratamento Térmico: Depois de vertido, o material é levado a um forno com a mesma temperatura do molde $\left(420^{\circ} \mathrm{C}\right)$, por 1 hora. A finalidade do tratamento térmico consiste em evitar o surgimento de trincas minimizando o acúmulo de tensões internas ao material, pois ao ser resfriado rapidamente, apresenta sua estrutura desordenada. A amostra só é retirada do forno após ser atingida a temperatura ambiente.

- Polimento e Corte: Terminado o tratamento térmico, a amostra é lixada até que seja atingida a espessura de $2 \mathrm{~mm}$, mantendo-se sempre as faces paralelas. São utilizadas lixas de carbeto de silício de várias granulométricas, 
de forma que ao final do processo de lixamento a superfície se encontre praticamente lisa. O acabamento é realizado com a utilização de um material abrasivo (líquido ou pastoso) juntamente com um feltro. Esta amostra é então cortada em várias partes, para que sejam submetidas ao processo de nucleação das NPs.

- Nucleacãa das Nanopartículas: As amostras cortadas são submetidas ao tratamento térmico com temperaturas e tempos que podem variar com a matriz vítrea utilizada e com o objetivo do estudo. De cada amostra cortada, pelo menos um pedaço é guardado a fim de posteriormente podermos observar quais foram as influências desta etapa nas propriedades do material. A seguir, esta etapa será descrita com maiores detalhes.

\subsection{NUCLEAÇÃO DE NANOPARTÍCULAS}

Dentre os vários métodos de nucleação mencionados anteriormente, 0 empregado neste trabalho foi o tratamento térmico, que já vem sendo utilizado pelo grupo desde 2005. Usualmente utilizamos como temperatura de tratamento para nucleação a mesma temperatura utilizada no tratamento para alívio de tensões. Os tempos de tratamento são normalmente divididos em múltiplos e também se baseiam em trabalhos realizados pelo grupo anteriormente. As primeiras nucleações foram realizadas empiricamente. A Figura 3.3 mostra o método adotado pelo grupo. Todas as amostras são tratadas juntamente no forno e atingidos os tempos escolhidos, elas são retiradas guardadas. Por exemplo, se os tratamentos desejados são de 1, 12, 24 e 36 horas, a amostra depois de polida é divida em 4 pedaços, já que são 4 intervalos de tempos. Uma das amostras é mantida como referência e as outras três são submetidas a tratamentos em intervalos de 12 horas, sempre tirando do forno uma delas, depois de atingido o intervalo de tempo desejado. 


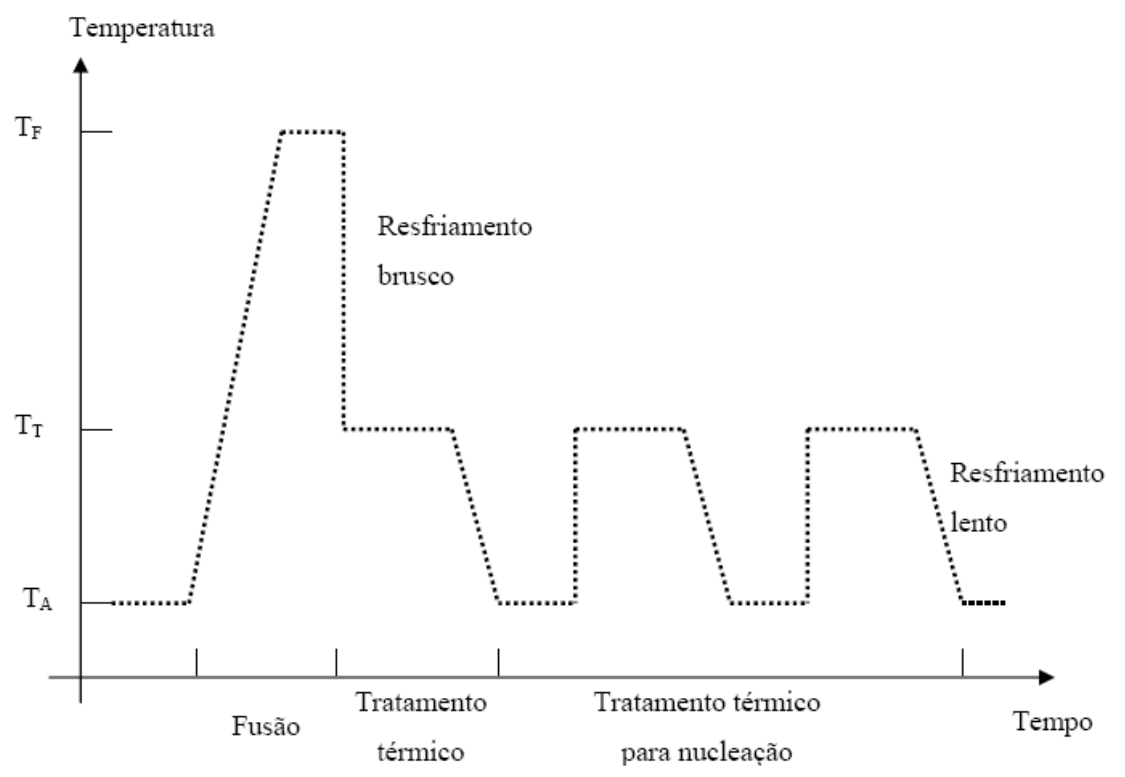

Figura 3.3 - Diagrama das etapas de produção do vidro e nucleação das NPs metálicas.

Na figura apresentada, as temperaturas representadas por $T_{F}, T_{T}$ e $T_{A}$ são as temperaturas de fusão $\left(1200{ }^{\circ} \mathrm{C}\right)$, tratamento térmico $\left(420{ }^{\circ} \mathrm{C}\right)$ e do ambiente, respectivamente.

Devido às varias composições de matriz estudadas pelo grupo, a temperatura de tratamento térmico varia de acordo com a transição vítrea; logo, o mesmo ocorre para a temperatura de nucleação das NPs. Entretanto não há garantia que esta temperatura seja a mais adequada para a nucleação, e consequentemente, produza os maiores aumentos para a luminescência. Uma análise da amostra pela técnica de Análise Térmica Diferencial (ATD) poderia informar qual a temperatura de nucleação das NPs metálicas. Porém, esta análise foi realizada em trabalho anterior, mostrando que para baixas concentrações do reagente metálico, o pico de cristalização não é observado [91]. Isto nos levou a utilizar temperaturas superiores a da transição vítrea para o processo de nucleação $\left(T_{g} \approx 450^{\circ} \mathrm{C}\right)$.

Considerando que tanto a variação de temperatura quanto a variação dos tempos de tratamento e respectivos intervalos podem interferir na nucleação das NPs, alteramos diversas variáveis conforme exposto a seguir.

Inicialmente, decidimos variar o tempo de tratamento, mas mantivemos a temperatura de nucleação usada em trabalhos anteriores, isto é, usamos a temperatura de tratamento térmico habitual. Os tempos de tratamento foram divididos em tratamentos contínuos (24 h) e em patamares, ou seja, 2 intervalos de tempo de $12 \mathrm{~h}$, conforme mostra a Figura 3.4. 


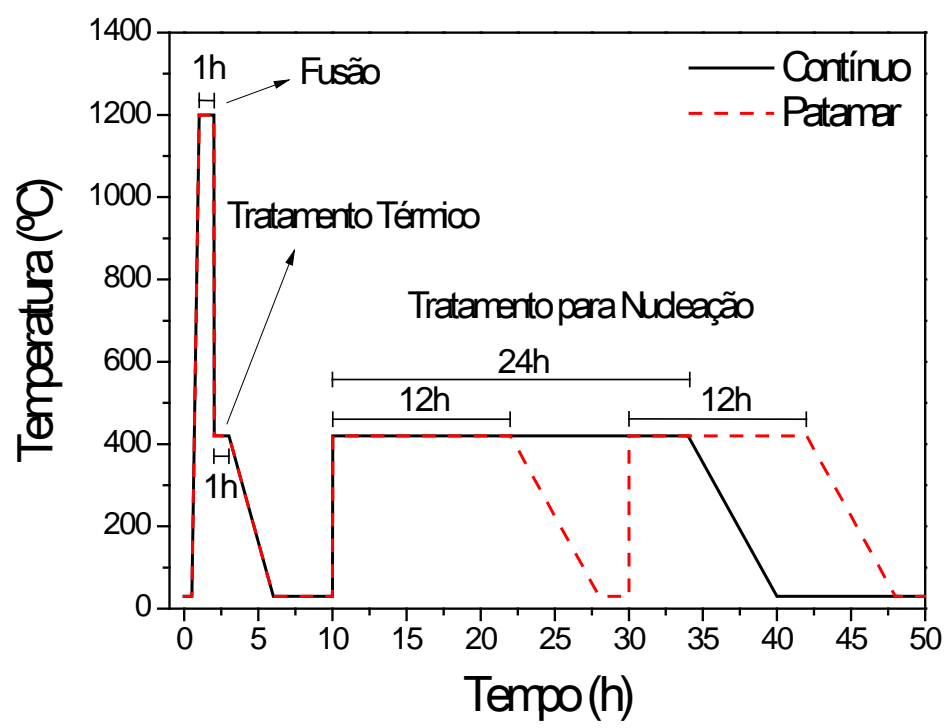

Figura 3.4 - Diagrama das etapas utilizadas para nuclear as NPs variando-se os tempos de tratamento.

Em segundo momento alteramos a temperatura de tratamento térmico, conforme mostra a Figura 3.5. Dessa forma, foram realizados tratamentos térmicos com intervalo de 6 horas em temperaturas de 480, 500, 520, 540 e $570{ }^{\circ} \mathrm{C}$. Cabe acrescentar que uma das amostras foi submetida a $600{ }^{\circ} \mathrm{C}$ e não suportou a temperatura, fato constatado pelo amolecimento do material. A matriz estudada neste trabalho apresentou estabilidade em todas as temperaturas utilizadas, isto é, não houve cristalização considerável para que houvesse mudanças nas propriedades ópticas na região do visível. Na Figura 3.5 é apresentado um diagrama do procedimento usado.

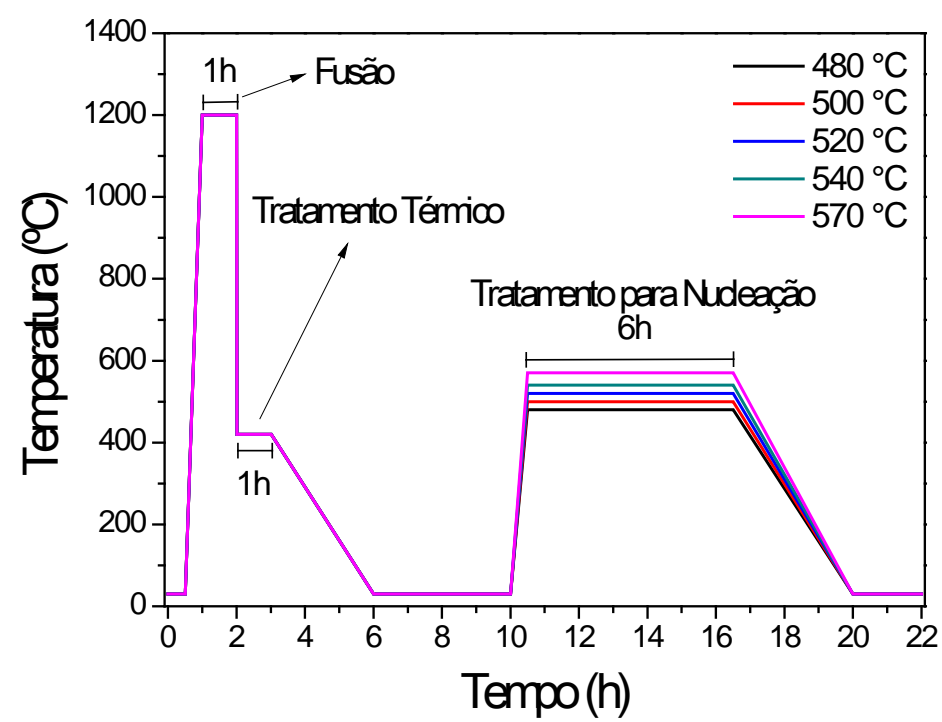

Figura 3.5 - Diagrama das etapas utilizadas para a nucleação das NPs em diferentes temperaturas. 


\subsection{TÉCNICAS DE CARACTERIZAÇÃO}

As técnicas de caracterização utilizadas tiveram como objetivo verificar a presença das nanopartículas metálicas nas amostras produzidas, e a interferência das mesmas nas emissões dos íons de TRs e nos espectros de absorção óptica. A partir da interpretação destes resultados, é possível determinar de que forma as variáveis do tratamento térmico influenciam a nucleação das NPs.

\subsubsection{Medida de Absorção Óptica}

As medidas de absorção óptica foram realizadas através de um espectrofotômetro (Cary 500), em temperatura ambiente, no Laboratório de Cristais Iônicos do Instituto de Física da USP. Esta medida permite a identificação da posição dos níveis de energia dos íons de TRs, e consequentemente, a verificação da incorporação das mesmas na forma iônica trivalente. Também é possível identificar a banda correspondente à RPS das NPs metálicas. A Figura 3.6 é a fotografia do equipamento usado nesta medida.

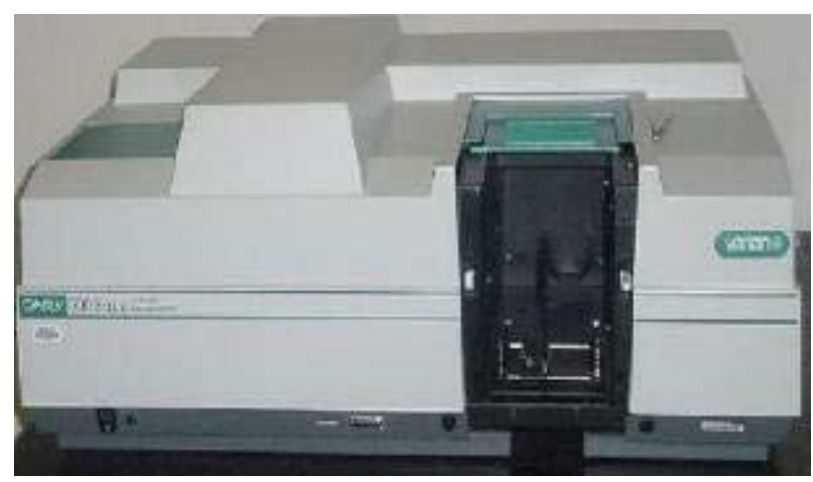

Figura 3.6 - Espectrofotômetro Cary 500 usado nas medidas de absorção óptica.

Para realizar as medidas de absorção óptica é necessário que as amostras tenham as faces paralelas e polidas para que sejam minimizadas as perdas relativas à espalhamento. 
A Figura 3.7 representa o arranjo experimental para este tipo de medida; pode-se observar que um feixe de luz passa por uma rede de difração no monocromador que o separa em vários comprimentos de onda; cada comprimento depende do ângulo formado entre a fonte de luz e a rede de difração. Este monocromador se move sincronizado com o computador. A luz com comprimento de onda determinado pelo monocromador passa por um divisor de feixe (semi-espelho); parte dela atravessa a amostra e é detectada pelo sensor, e a outra vai direto ao sensor de referência. Os sinais de ambos os sensores são comparados tendo como saída, um sinal proporcional à transmissão óptica, sendo registrado no computador [26].

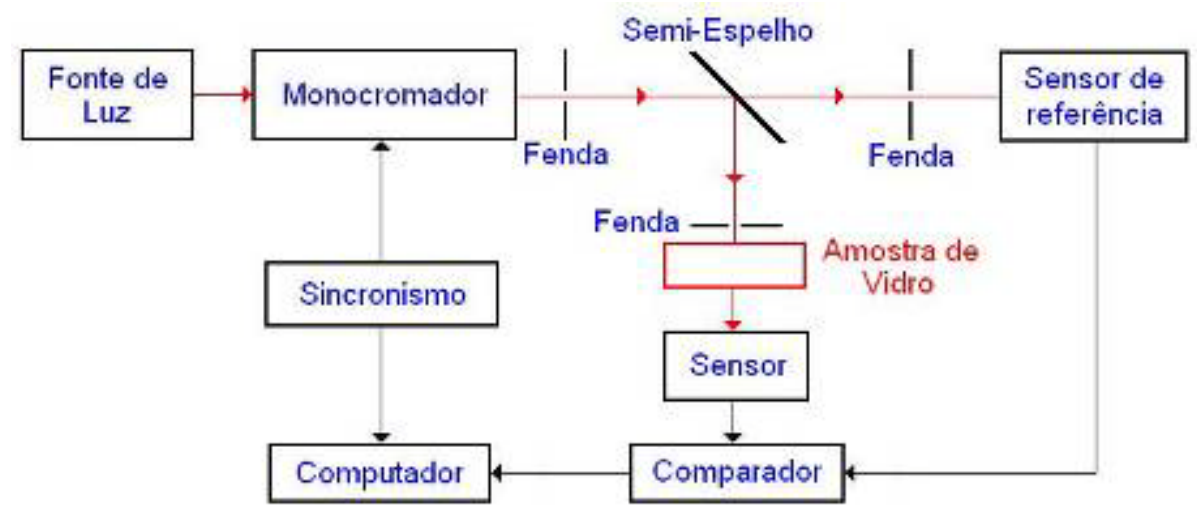

Figura 3.7 - Arranjo experimental para as medidas de absorção óptica [26].

\subsubsection{Medida de Luminescência}

As medidas de luminescência nas regiões do visível e do infravermelho foram realizadas usado o arranjo experimental mostrado na Figura 3.9. A fonte de excitação é um laser de diodo, operando em 980nm, para as amostras codopadas com $\mathrm{Tm}_{2} \mathrm{O}_{3}$ e $\mathrm{Yb}_{2} \mathrm{O}_{3}$, devido à banda de absorção dos íons de $\mathrm{Yb}^{3+}$ que compreende o intervalo 900-1000 nm. Para as amostras dopadas apenas com $\mathrm{Tm}_{2} \mathrm{O}_{3}$ foi utilizado um laser de Itérbio acoplado a uma fibra óptica, operando em $1050 \mathrm{~nm}$. As primeiras medidas foram feitas no arranjo experimental do LVD e as últimas no arranjo experimental do Departamento de Física da UFPE.

O feixe incidente do laser é colimado por uma lente, de modo que a amostra seja bombeada perpendicularmente à direção do detector (bombeio lateral). Caso 
contrário a medida poderia ser prejudicada ou ainda a fotomultiplicadora danificada. O laser de diodo é pulsado por um gerador de função que tem como propósito evitar efeitos térmicos na amostra e a interferência da luz ambiente $(60 \mathrm{~Hz})$ na medida (Figura 3.9). O arranjo experimental das medidas realizadas na UFPE é similar ao do LVD, com a diferença que no lugar do gerador de função, o próprio controlador do laser oscilava o sinal, e no lugar de uma fotomultiplicadora foi utilizada uma CCD com abrangência espectral na região do UV-Visível.

A luz emitida pela amostra é colimada por outras duas lentes e passa pela fenda do monocromador que separa os vários comprimentos de onda provenientes da emissão. Em seguida o feixe passa por uma segunda fenda, chegando à fotomultiplicadora que amplifica o sinal, e então os sinais elétricos alternados são convertidos pelo LOCK-IN em contínuos e enviados para o computador (Figura 3.8).

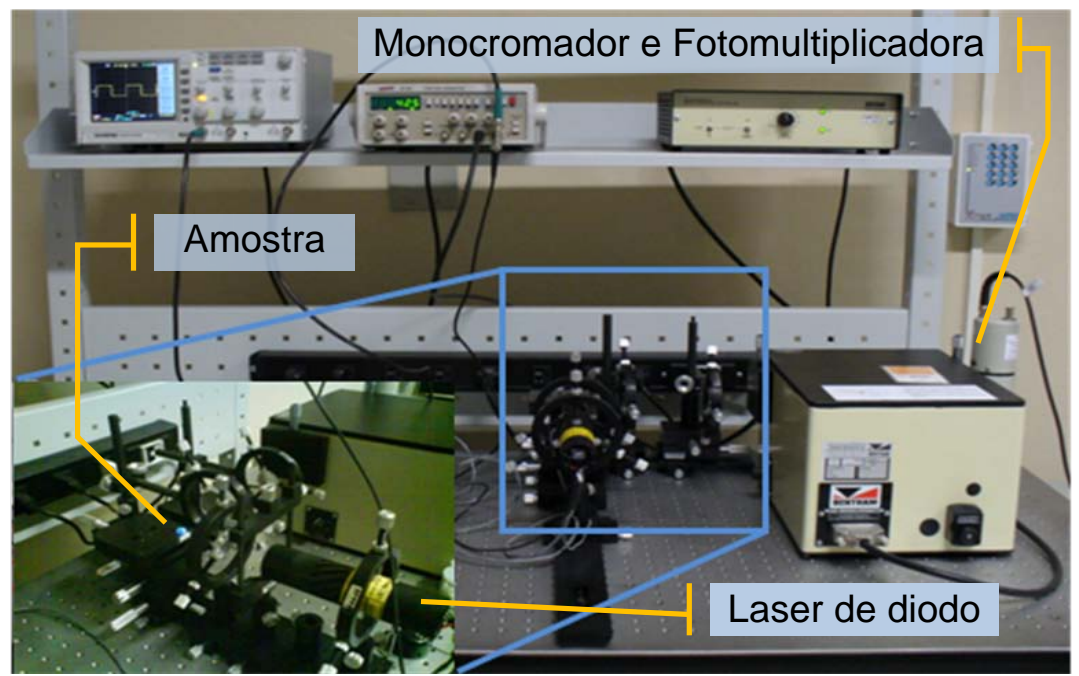

Figura 3.8 - Foto do arranjo experimental das medidas de emissão realizadas nas amostras codopadas com $\mathrm{Tm}_{2} \mathrm{O}_{3}$ e $\mathrm{Yb}_{2} \mathrm{O}_{3}$.

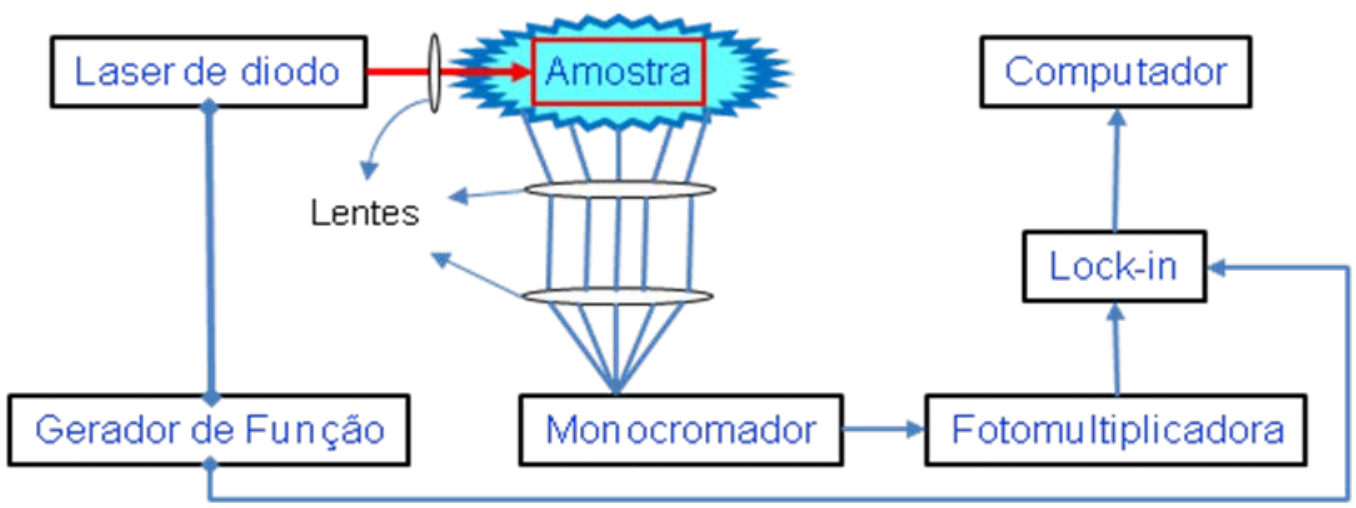

Figura 3.9 - Arranjo experimental das medidas de emissão realizadas nas amostras. 
Foram realizados testes de luminescência em função da potência do laser para identificarmos o número de fótons absorvidos nos processos de CA. Neste estudo são utilizados filtros ópticos neutros com diferentes transmitâncias, de forma que a intensidade do laser seja variada, e consequentemente, a intensidade de emissão. A dependência da intensidade de emissão em função da intensidade do laser é analisada e obtemos a informação do número de fótons que participam em cada emissão proveniente dos íons de TRs. Este estudo foi realizado em ambos os arranjos experimentais.

Para realizar as medidas de luminescência utilizando o arranjo experimental descrito na Figura 3.8, foi necessário o desenvolvimento de um software. A partir dos drivers do equipamento compatíveis ao LABVIEW, fornecidos pelo fabricante do LOCK-IN, o software foi desenvolvido no National Instruments LABVIEW 8.5; o ambiente gráfico e a programação visual são mostrados na Figura 3.10. Todo o entendimento das funções e variáveis do Lock-in foi necessário para que cada módulo apresentado nos drivers fosse interpretado e utilizado corretamente, pois cada módulo possui ligações entre si, já que alguns utilizam as mesmas variáveis.

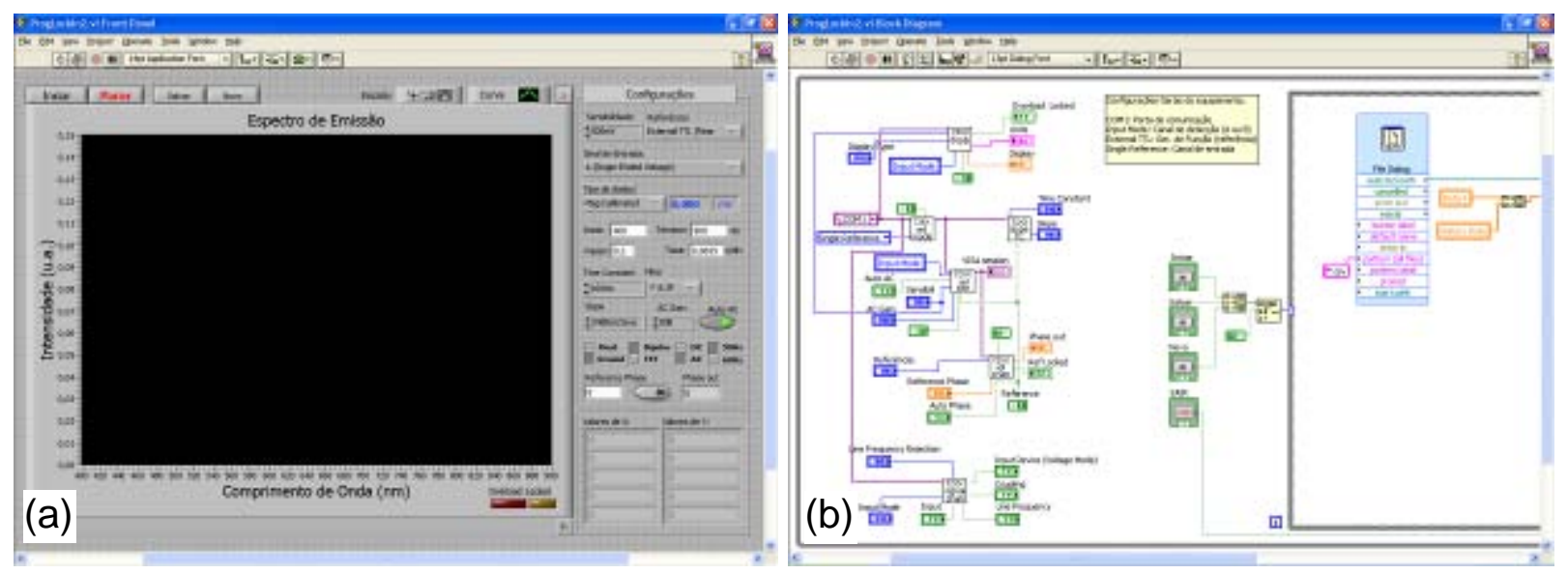

Figura 3.10 - Imagens do (a) ambiente gráfico e da (b) programação visual utilizadas no desenvolvimento do software empregado nas medidas de luminescência. 


\subsubsection{Microscopia Eletrônica de Transmissão e Espectroscopia de Energia Dispersiva (EDS)}

Para a obtenção das imagens e análise das NPs foi utilizado um Microscópio Eletrônico de Transmissão (MET) em colaboração com o Laboratório de Microscopia Eletrônica do Instituto de Física da USP (modelo Philips CM 200 operado a 200 kV).

O microscópio possui um catodo de grampo de tungstênio, que ao ser aquecido emite elétrons que são acelerados pelo anodo e colimados pelo cilindro de Wehnelt. O feixe eletrônico divergente é focalizado sobre a amostra pelas duas lentes condensadoras. Assim, com o condensador duplo, os elétrons deixando a ponta do catodo são focalizados na posição da amostra em uma mancha pequena que pode variar de 2 a $10 \mu \mathrm{m}$ dêrdetro. Com os feixes passando através da abertura da objetiva, é formada a primeira imagem ampliada da amostra. No plano desta imagem, a abertura designada seletora é focalizada. A lente intermediária e a projetora ampliam sucessivamente a primeira imagem mais duas vezes. A ampliação total é obtida pela multiplicação dos aumentos individuais da série de lentes. A imagem ampliada em três estágios é visível sobre o anteparo fluorescente final; quando o anteparo é levantado esta é registrada na placa fotográfica. Importante ressaltar que a colimação do feixe de elétrons só é eficaz quando o sistema está em alto vácuo. O que garante a identificação da composição da amostra é a difração por feixes de elétrons que o microscópio gera durante o ensaio e através da Equação (2.1) são identificados os elementos da difração eletrônica [20].

$$
d_{h k l}=\frac{2 \lambda L}{2 R}
$$

onde $d_{h k l}$ são as distâncias interplanares características de cada elemento, $2 R$ são obtidos através das distâncias de pontos e/ou anéis da difração e $2 \lambda L$ é a constante de câmara característica do feixe de elétrons do microscópio.

A preparação das amostras para microscopia é feita através de moagem e diluição em água. Apenas as partículas que ficam na superfície da solução são colocadas em uma microtela com carbono previamente depositado. As partículas metálicas espalham muito mais o feixe de elétrons do que o vidro. Por esse motivo as partículas podem ser identificadas por contraste claro-escuro nas micrografias. 
Quando o feixe de elétrons incide sobre um determinado material, os elétrons mais internos do átomo podem ser arrancados - dependendo da potencia do feixe deixando um espaço vazio no nível energético que se encontrava. Um elétron de uma camada externa, ao ocupar esta posição, libera a energia referente a esta transição, sendo ela de comprimento de onda do espectro de raios X. Um detector instalado na câmara de vácuo do MET mede a energia associada à esta fluorescência. Como a diferença entre os níveis de cada átomo possuem energias distintas, é possível, no ponto de incidência do feixe, determinar quais elementos químicos estão presentes naquele local e assim identificar que material está sendo observado. O diâmetro reduzido do feixe no MET permite a determinação da composição do material em amostras de tamanho muito reduzido, tornando possível uma análise quase pontual, logo, a determinação dos elementos presentes nas NPs. 


\section{RESULTADOS E DISCUSSÕES}

A seguir são apresentados separadamente os resultados obtidos através das várias técnicas descritas anteriormente, referentes às amostras produzidas neste trabalho que foram descritas nas Tabelas 2.2 e 2.3. Inicialmente as amostras foram produzidas em cadinho de alumina-silicato. Entretanto, devido à incorporação de uma alta concentração de $\mathrm{SiO}_{2}$, como dito anteriormente, passou-se a utilizar um cadinho de alumina pura.

Primeiramente, são apresentados os melhores resultados da Iniciação Científica para que se possa realizar posteriormente uma comparação com as amostras contendo NPs de prata. Será mostrado também o estudo realizado para determinar o número de íons $\mathrm{D}^{+}\left(\mathrm{Yb}^{3+}\right)$ que transfere energia para cada íon $\mathrm{A}^{+}$ $\left(\mathrm{Tm}^{3+}\right)$.

Posteriormente serão discutidos os resultados das amostras contendo $\mathrm{AgNO}_{3}$, de forma a interpretar os efeitos do tratamento térmico no processo de nucleação das NPs de prata.

\subsection{VIDROS CODOPADOS COM $\mathrm{Tm}_{2} \mathrm{O}_{3}$ E $\mathrm{Yb}_{2} \mathrm{O}_{3}$ PRODUZIDOS EM CADINHO DE ALUMINA-SILICATO}

$\mathrm{Na}$ Iniciação Científica foram estudadas as interações entre os íons $\mathrm{Tm}^{3+} \mathrm{e}$ $\mathrm{Yb}^{3+}, \mathrm{Tm}^{3+}$ e $\mathrm{Nd}^{3+}$, e $\mathrm{Tm}^{3+}, \mathrm{Yb}^{3+}$ e $\mathrm{Nd}^{3+}$ de forma que conseguimos determinar $\mathrm{o}$ número de fótons que participavam dos processos de emissão do $\mathrm{Tm}^{3+}$ no visível e no infravermelho próximo. Conseguimos verificar, dentre as matrizes estudadas (GP - $\mathrm{GeO}_{2}-\mathrm{PbO}$ e $\mathrm{GPG}-\mathrm{GeO}_{2}-\mathrm{PbO}-\mathrm{Ga}_{2} \mathrm{O}_{3}$ ), que a matriz mais indicada para as emissões no visível é a GP, pois apresentou maiores intensidades de luminescência para os íons de túlio. Dentre as amostras produzidas, as maiores luminescências foram obtidas para as amostras codopadas com $\mathrm{Tm}^{3+}$ e $\mathrm{Yb}^{3+}$ com concentrações de $0,5 \%$ e $2,0 \%$, e $0,5 \%$ e $3 \%$, respectivamente. Por este motivo estas concentrações 
foram usadas nas amostras preparadas com $\mathrm{AgNO}_{3}$, assim como foi escolhida a matriz GP.

Outras amostras com menores concentrações de $\mathrm{Yb}_{2} \mathrm{O}_{3}$, como mostrado na Tabela 3.2, foram produzidas com o intuito de verificar o numero de íons de $\mathrm{Yb}^{3+}$ que interagem com um íon de $\mathrm{Tm}^{3+}$, e também para efetuar comparação com as outras amostras produzidas neste trabalho. As amostras que serão analisadas neste trabalho são mostradas na Figura 4.1, com exceção da última que apresentou opacidade por não ter suportado a quantidade de dopante introduzida na matriz.

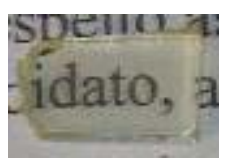

$0,5 \% \mathrm{Yb}_{2} \mathrm{O}_{3}$

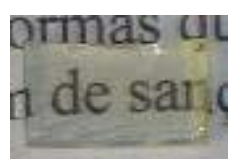

$1,0 \% \mathrm{Yb}_{2} \mathrm{O}_{3}$

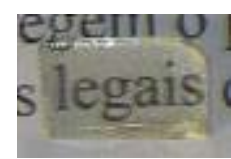

$2,0 \% \mathrm{Yb}_{2} \mathrm{O}_{3}$

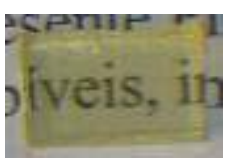

$3,0 \% \mathrm{Yb}_{2} \mathrm{O}_{3}$

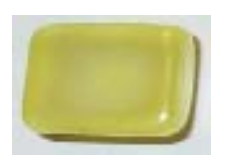

$4,0 \% \mathrm{Yb}_{2} \mathrm{O}_{3}$

Figura 4.1 - Amostras do sistema GP codopadas com 0,5\% $\mathrm{Tm}_{2} \mathrm{O}_{3}$ e diferentes concentrações de $\mathrm{Yb}_{2} \mathrm{O}_{3}$.

\subsubsection{Medidas de Absorção Óptica}

A Figura 4.2 mostra os espectros de absorção das amostras apresentadas na Figura 4.1, com exceção da amostra contendo $4 \%$ de $\mathrm{Yb}_{2} \mathrm{O}_{3}$, por motivo já mencionado anteriormente. A incorporação das TRs túlio e itérbio na forma iônica trivalente é confirmada devido à presença das bandas referentes às transições eletrônicas de cada íon, onde em destaque é mostrada a transição do $\mathrm{Yb}^{3+}$ que cresce com o aumento da concentração de $\mathrm{Yb}_{2} \mathrm{O}_{3}$. As demais bandas referem-se às transições que ocorrem nos íons $\mathrm{Tm}^{3+}$ a partir do nível fundamental $\left({ }^{3} \mathrm{H}_{6}\right)$. Podemos notar também que para a concentração de $3 \% \mathrm{Yb}_{2} \mathrm{O}_{3}$, a amostra apresentou tonalidade amarela e uma janela de transmissão um pouco menor, iniciando em $\approx 390 \mathrm{~nm}$, enquanto que as demais iniciam em $\approx 360 \mathrm{~nm}$. 


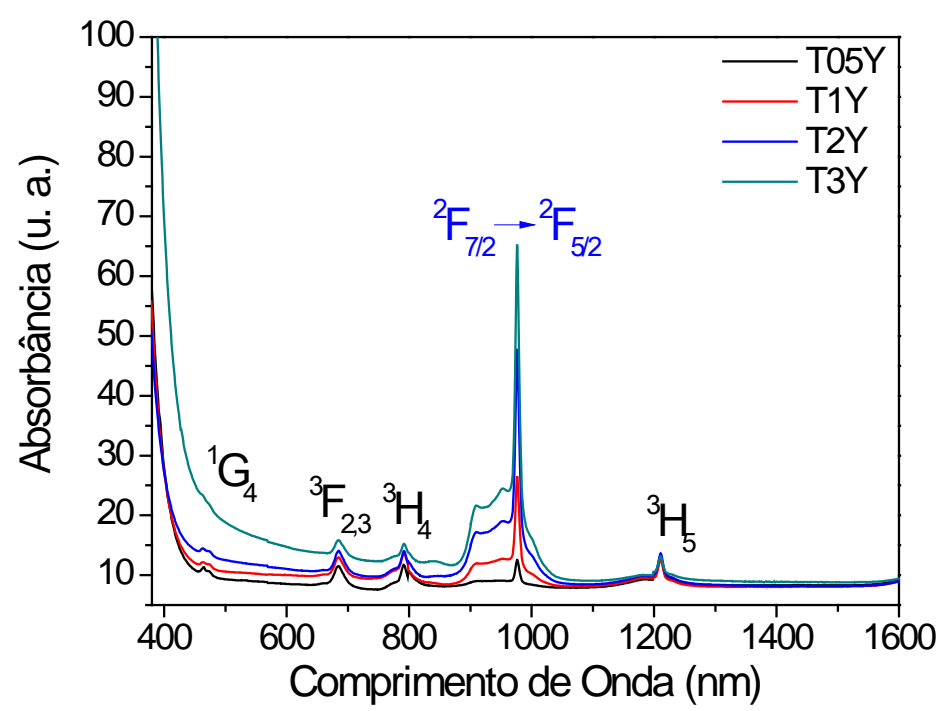

Figura 4.2 - Espectro de absorção das amostras do sistema GP codopadas com 0,5\% $\mathrm{Tm}_{2} \mathrm{O}_{3} \mathrm{e}$ diferentes concentrações de $\mathrm{Yb}_{2} \mathrm{O}_{3}$.

\subsubsection{Medidas de Luminescência}

Para a realização dos espectros de emissão foi utilizado um laser de diodo operando em 980 nm, em ressonância com a absorção dos íons $\mathrm{Yb}^{3+}$, como dito anteriormente no item 3.3.2, lembrando que o íon doador de energia deve estar presente em maior concentração do que o aceitador, como explicado no item 2.3.1. Na Figura 4.3 podemos observar os espectros de emissão das amostras codopadas com $\mathrm{Tm}_{2} \mathrm{O}_{3}$ e $\mathrm{Yb}_{2} \mathrm{O}_{3}$, onde a concentração do túlio foi fixada em 0,5\% e a do itérbio foi variada de 0,5 a $3,0 \%$.

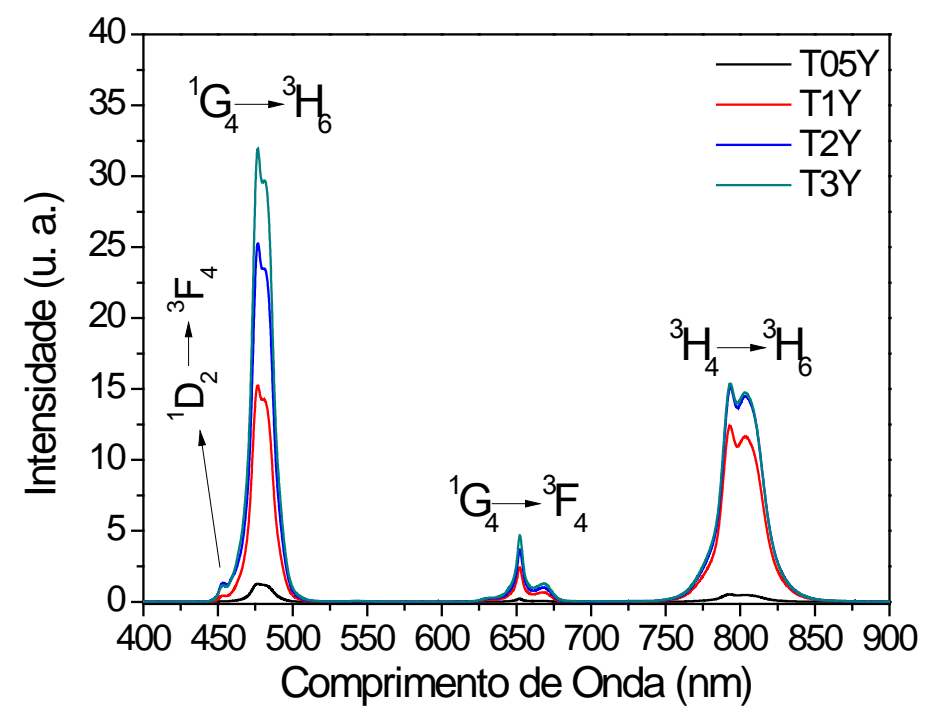

Figura 4.3 - Espectro de emissão das amostras do sistema GP codopadas com 0,5\% $\mathrm{Tm}_{2} \mathrm{O}_{3} \mathrm{e}$ diferentes concentrações de $\mathrm{Yb}_{2} \mathrm{O}_{3}$. 
Podemos observar no espectro acima que todas as emissões do $\mathrm{Tm}^{3+}$ crescem com o aumento da concentração do íon doador $\mathrm{Yb}^{3+}$. Isto mostra $\mathrm{a}$ interferência do $\mathrm{Yb}^{3+}$ no processo de transferência de energia $\mathrm{Yb}^{3+} \rightarrow \mathrm{Tm}^{3+}$.

A partir do estudo da intensidade luminescente em função da concentração dos íons de $\mathrm{Yb}^{3+}$, podemos determinar o número de íons de $\mathrm{Yb}^{3+}$ que interage com um íon de $\mathrm{Tm}^{3+}$ em cada transição. Para isto, basta obter a área de cada banda de emissão e relacioná-la à concentração de $\mathrm{Yb}_{2} \mathrm{O}_{3}$ empregada, como é mostrado na Figura 4.4. A quantidade de íons envolvidos em cada transição do $\mathrm{Tm}^{3+}$ é obtida através do coeficiente angular da reta ajustada aos valores calculados. Para a concentração de $3 \%$ de $\mathrm{Yb}_{2} \mathrm{O}_{3}$, notamos a tendência de saturação para a luminescência (Figura 4.4).

Para as transições ${ }^{1} \mathrm{G}_{4} \rightarrow{ }^{3} \mathrm{H}_{6}(480 \mathrm{~nm})$ e ${ }^{1} \mathrm{G}_{4} \rightarrow{ }^{3} \mathrm{~F}_{4}(650 \mathrm{~nm})$ podemos observar que há a interação de 3 íons de $\mathrm{Yb}^{3+}$ com cada íon de $\mathrm{Tm}^{3+}$, e para a transição ${ }^{3} \mathrm{H}_{4} \rightarrow{ }^{3} \mathrm{H}_{6}$ (800 nm) há a interação de 2 íons de $\mathrm{Yb}^{3+}$ com cada íon de $\mathrm{Tm}^{3+}$. Como foi visto no item 2.3, são necessários 3 fótons para que as emissões em 480 e 650 nm ocorram, e 2 fótons para a emissão em 800 nm. Portanto, podemos dizer que cada íon de itérbio contribui com 1 fóton para cada íon de túlio. Logo, concentrações maiores que 3\% podem gerar efeito de quenching para a concentração de $0,5 \%$ de túlio, para o caso das amostras estudadas neste projeto.

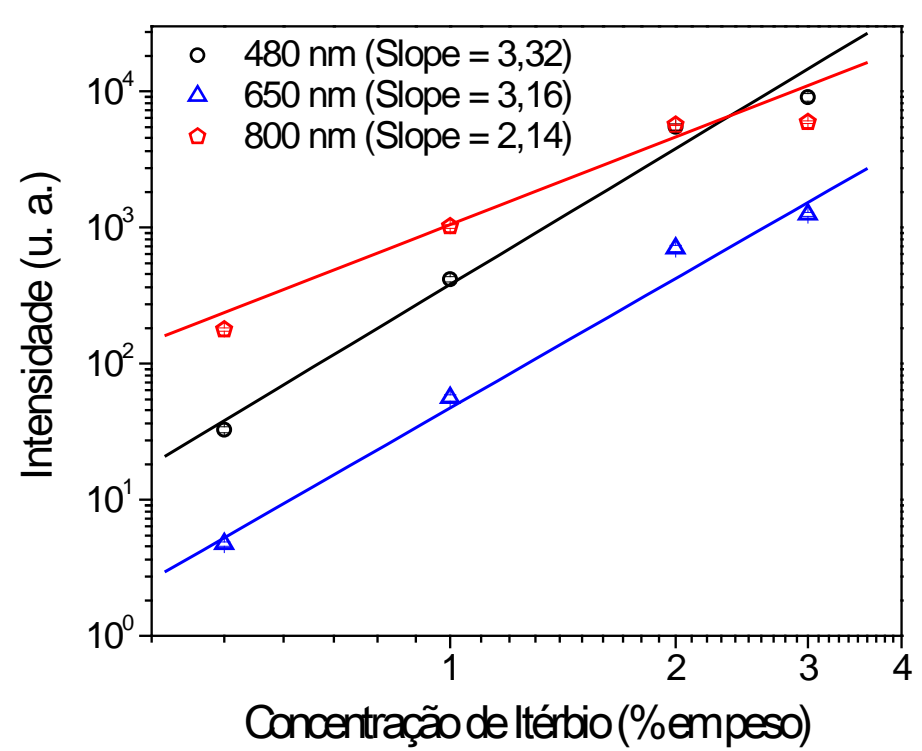

Figura 4.4 - Intensidades de luminescência dos íons de $\mathrm{Tm}^{3+}$ em função da concentração dos íons $\mathrm{Yb}^{3+}$. 


\subsection{VIDROS CODOPADOS COM $\mathrm{Tm}_{2} \mathrm{O}_{3} \mathrm{E} \mathrm{Yb}_{2} \mathrm{O}_{3}$ CONTENDO NPS DE PRATA PRODUZIDOS EM CADINHO DE ALUMINA-SILICATO}

A partir dos resultados das amostras que apresentaram maior luminescência (com concentrações de 2 e $3 \%$ de $\mathrm{Yb}_{2} \mathrm{O}_{3}$ ), preparamos amostras com diferentes concentrações de $\mathrm{AgNO}_{3}$, conforme será exposto a seguir.

Foram produzidas amostras contendo as concentrações de 0,5\% $\mathrm{Tm}_{2} \mathrm{O}_{3}$ e 2,0\% $\mathrm{Yb}_{2} \mathrm{O}_{3}$ e 1,0\% $\mathrm{AgNO}_{3}$ (T2Y1A). Estas foram tratadas termicamente para a obtenção das NPs metálicas, seguindo inicialmente o método utilizado pelo grupo. Baseados nos resultados obtidos por estas e em trabalhos anteriores, aumentamos a concentração do precursor das NPs para 3,0\%. Assim, foram produzidas também amostras com as concentrações de 0,5\% $\mathrm{Tm}_{2} \mathrm{O}_{3}$ e 2,0\% $\mathrm{Yb}_{2} \mathrm{O}_{3}$ e 3,0\% $\mathrm{AgNO}_{3}$ (T2Y3A), e 0,5\% $\mathrm{Tm}_{2} \mathrm{O}_{3}$ e 3,0\% $\mathrm{Yb}_{2} \mathrm{O}_{3}$ e 3,0\% $\mathrm{AgNO}_{3}$ (T3Y3A). A amostra T3Y3A não foi preparada com $1 \%$ de $\mathrm{AgNO}_{3}$, pois os resultados obtidos, conforme será mostrado, apresentaram ausência de NPs. Nas figuras a seguir podemos observar que não há mudança de tonalidade, e a banda de RPS também não é observada. Entretanto, a presença da NPs é evidenciada através da MET.

Podemos observar também que as amostra se apresentam "lascadas". Isto se deve ao fato que um pedaço da amostra é removido e moído para que as análises de MET sejam realizadas. Este procedimento é realizado após as caracterizações ópticas, evitando assim interferências nas medidas de emissão.

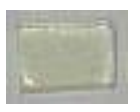

$1 \mathrm{~h}$

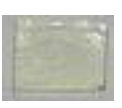

$24 \mathrm{~h}$

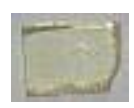

$30 \mathrm{~h}$

Figura 4.5 - Amostras do sistema GP - T2Y1A, tratadas por diferentes intervalos de tempo.

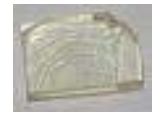

$1 \mathrm{~h}$

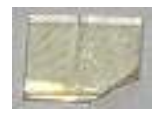

$24 \mathrm{~h}$

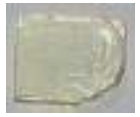

$30 \mathrm{~h}$

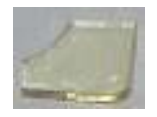

$60 \mathrm{~h}$

Figura 4.6 - Amostras do sistema GP - T2Y3A, tratadas por diferentes intervalos de tempo.

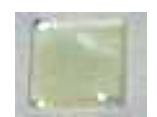

$1 \mathrm{~h}$

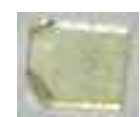

$24 \mathrm{~h}$

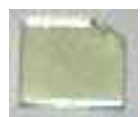

$30 \mathrm{~h}$

Figura 4.7 - Amostras do sistema GP - T3Y3A, tratadas por diferentes intervalos de tempo. 
Cabe ressaltar que o segundo conjunto foi tratado por 60 horas na tentativa de aumentarmos a concentração das NPs de prata, conforme será mostrado.

\subsubsection{Medidas de Absorção Óptica}

Os espectros de absorção a seguir (Figura 4.8, Figura 4.9 e Figura 4.10) mostram que as TRs foram incorporadas na forma iônica trivalente, como esperado. Porém, não foram observadas bandas de RPS referentes às NPs de prata. Isto ocorre quando a nucleação das NPs não é efetiva, ou a concentração de NPs é baixa, não possibilitando o aparecimento de uma banda de absorção significativa [57]. Cabe lembrar que esta banda se encontra normalmente no intervalo de $400 \mathrm{a}$ $500 \mathrm{~nm}[59]$.

Em trabalho anterior [91], o mesmo foi constatado. Apesar da ausência de uma banda de RPS no espectro de absorção a MET evidenciou a existência de NPS metálicas e o EDS confirmou que as NPs não eram provenientes dos elementos da matriz.

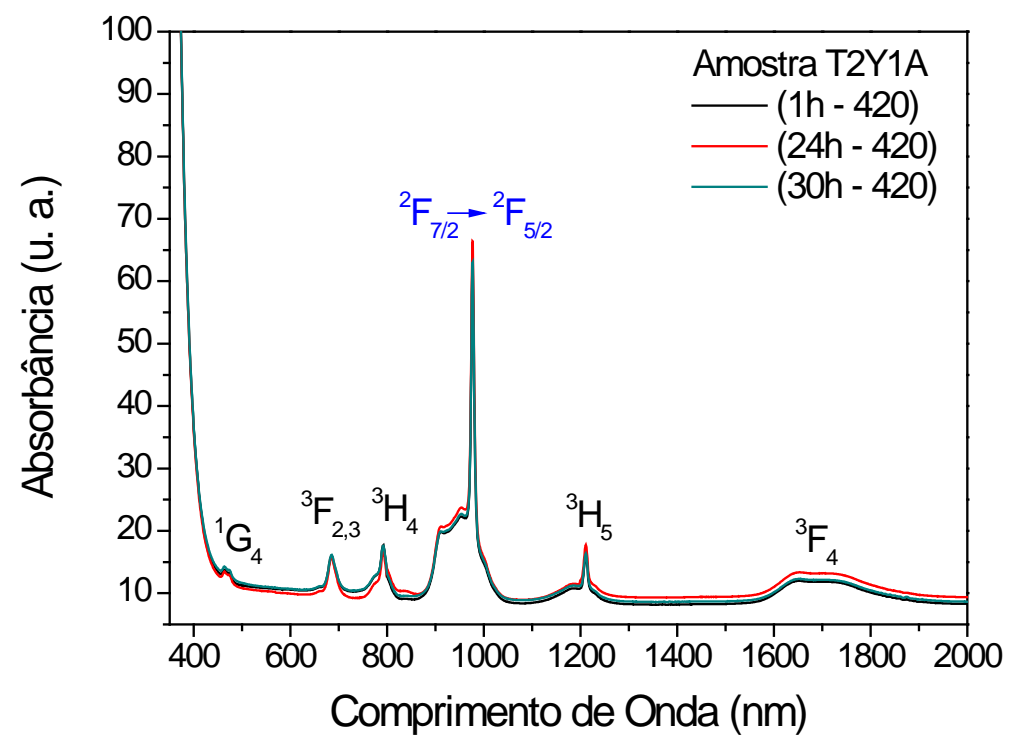

Figura 4.8 - Espectro de absorção das amostras T2Y1A, tratada por diferentes intervalos de tempo. 


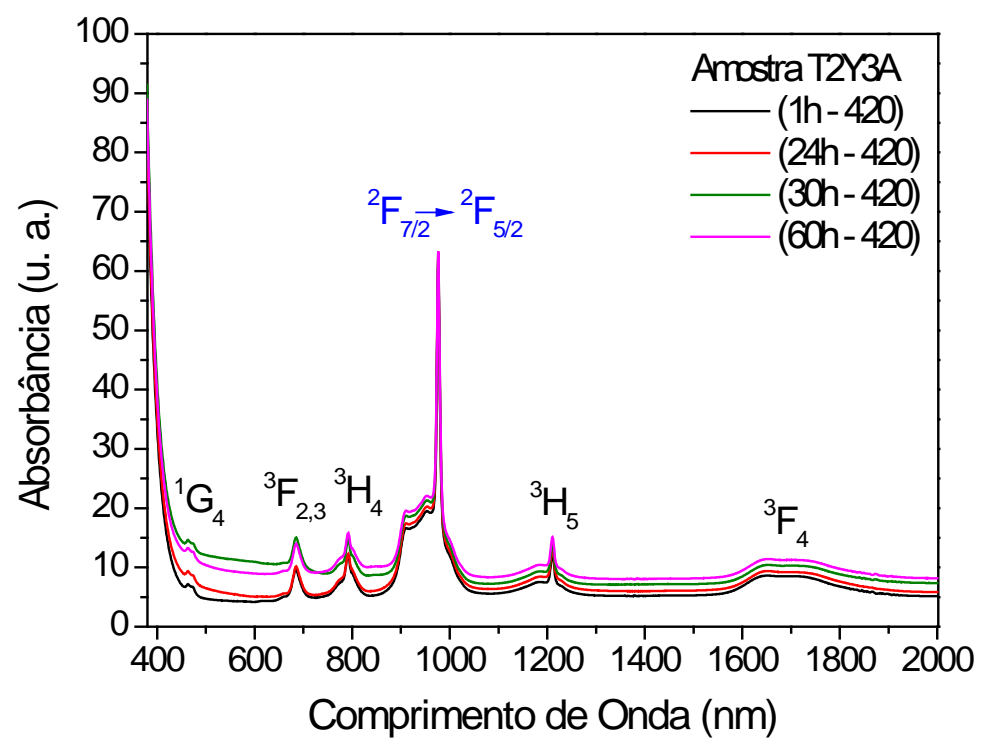

Figura 4.9 - Espectro de absorção das amostras T2Y3A, tratada por diferentes intervalos de tempo.

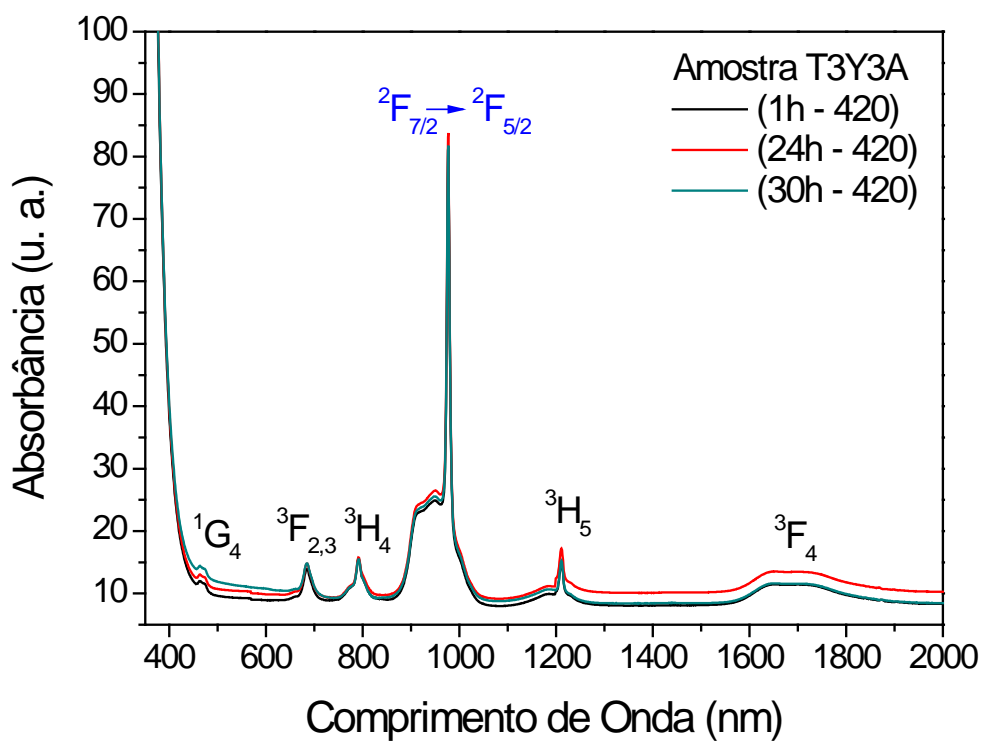

Figura 4.10 - Espectro de absorção das amostras T3Y3A, tratada por diferentes intervalos de tempo.

\subsubsection{Microscopia Eletrônica de Transmissão e EDS}

As imagens de MET obtidas para as amostras codopadas com $\mathrm{Tm}_{2} \mathrm{O}_{3}, \mathrm{Yb}_{2} \mathrm{O}_{3}$ e $\mathrm{AgNO}_{3}$ estão apresentadas na Figura 4.11 e Figura 4.16.

São apresentados também os histogramas e os espectros de EDS das respectivas imagens de $\mathrm{MET}$, mostrando a distribuição de tamanho e a composição destas NPs. Os histogramas são realizados a partir da contagem do diâmetro de 100 
NPs das micrografias. Quando a micrografia apresenta menos do que 100 NPs, medem-se os diâmetros horizontal e vertical até obtermos 100 números. Com isto são obtidos 2 diâmetros distintos, já que as NPs não são perfeitamente esféricas.

Nas amostras T2Y1A não foram observadas NPs de prata. Neste caso a nucleação não foi efetiva ou foi de baixa concentração. A Figura 4.11 mostra as micrografias da amostra T2Y3A tratada em diferentes intervalos de tempo. Na Figura 4.11a observamos a presença de NPs imersas na massa vítrea, de formato arredondado e de tamanho médio de $\approx 10 \mathrm{~nm}$ (Figura 4.12a). Para as amostras tratadas por 30 horas, o diâmetro médio aumenta para $\approx 20 \mathrm{~nm}$ (Figura 4.12b).

As amostras tratadas por 60 horas (Figura 4.11c) apresentaram NPs menores, de $\approx 3,5 \mathrm{~nm}$ (Figura 4.13), e agregados de $\approx 50 \mathrm{~nm}$. A presença de NPs menores é devido à possibilidade de quebra das NPs maiores e também da formação de novas, já que há a probabilidade da existência de íons de prata ainda dispersos no vidro. A formação de agregados se deve à tendência da prata apontada anteriormente (item 2.4.1).
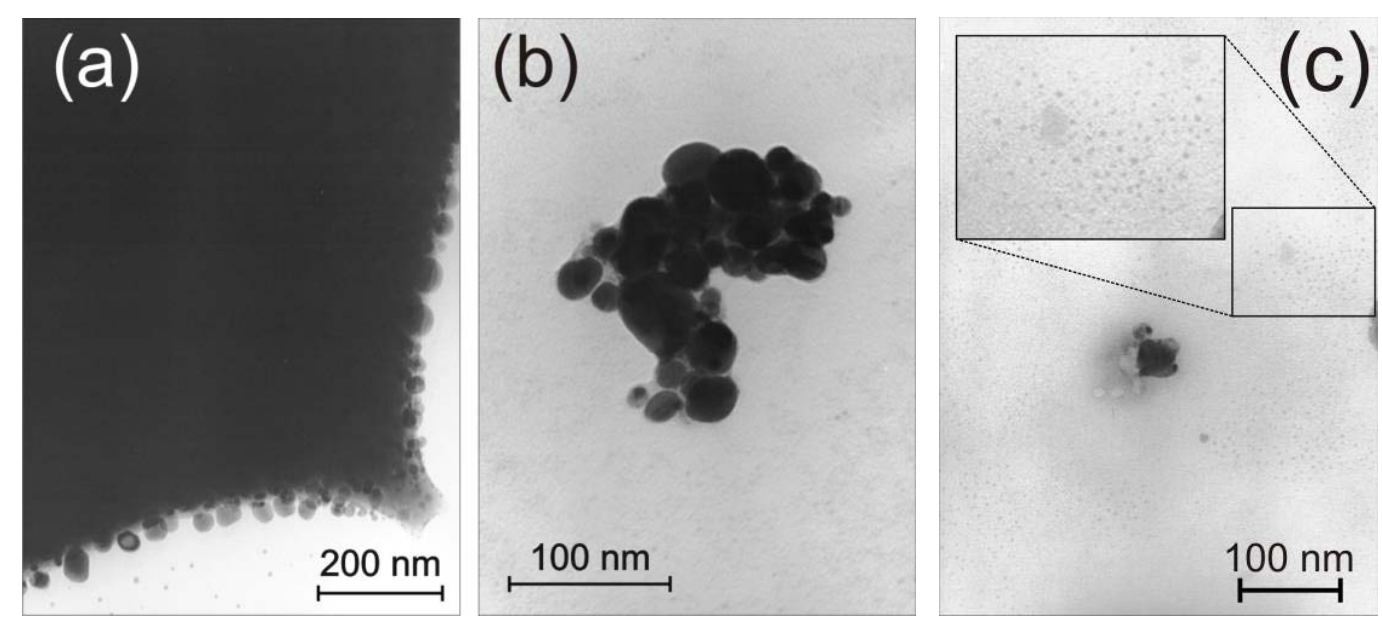

Figura 4.11 - Micrografias das amostras T2Y3A, tratadas por (a) 24, (b) 30 e (c) 60 horas.
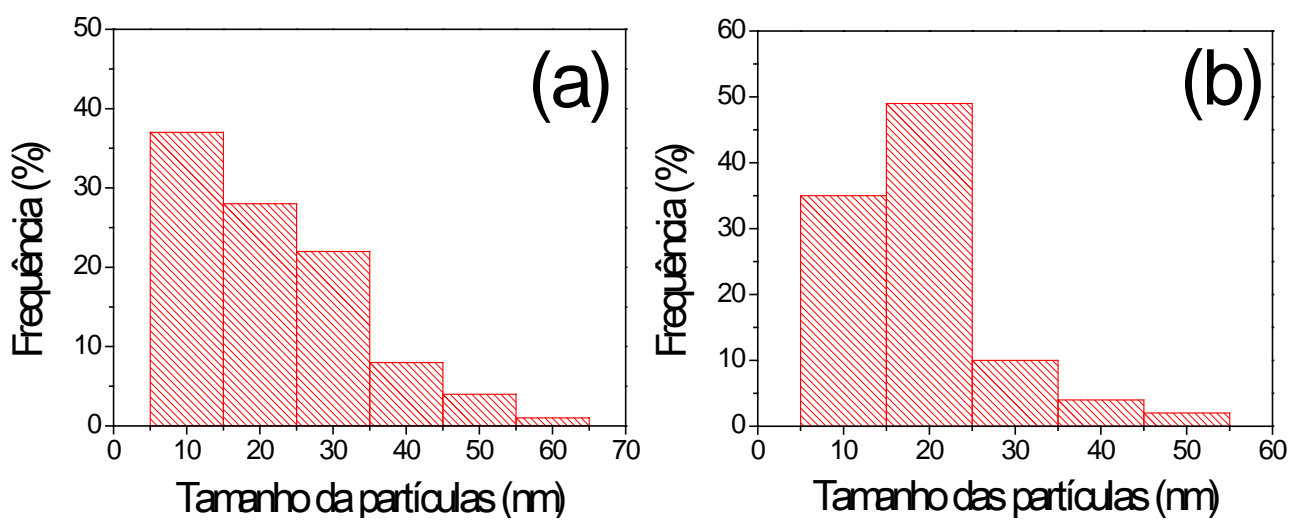

Figura 4.12 - Histogramas das amostras T2Y3A, tratadas por (a) 24 e (b) 30 horas. 


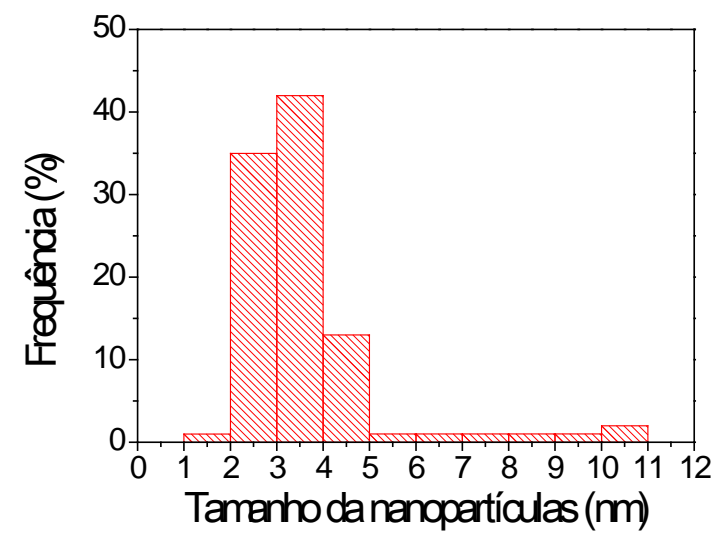

Figura 4.13 - Histogramas das amostras T2Y3A, tratada por 60 horas.

Na Figura 4.14 observamos que as NPs são de prata. Na Figura 4.14a percebemos que elas estão inseridas na massa vítrea pela presença das raias do germânio (Ge) e do chumbo (Pb), e na Figura 4.14b observamos apenas as raias da prata $(\mathrm{Ag})$.
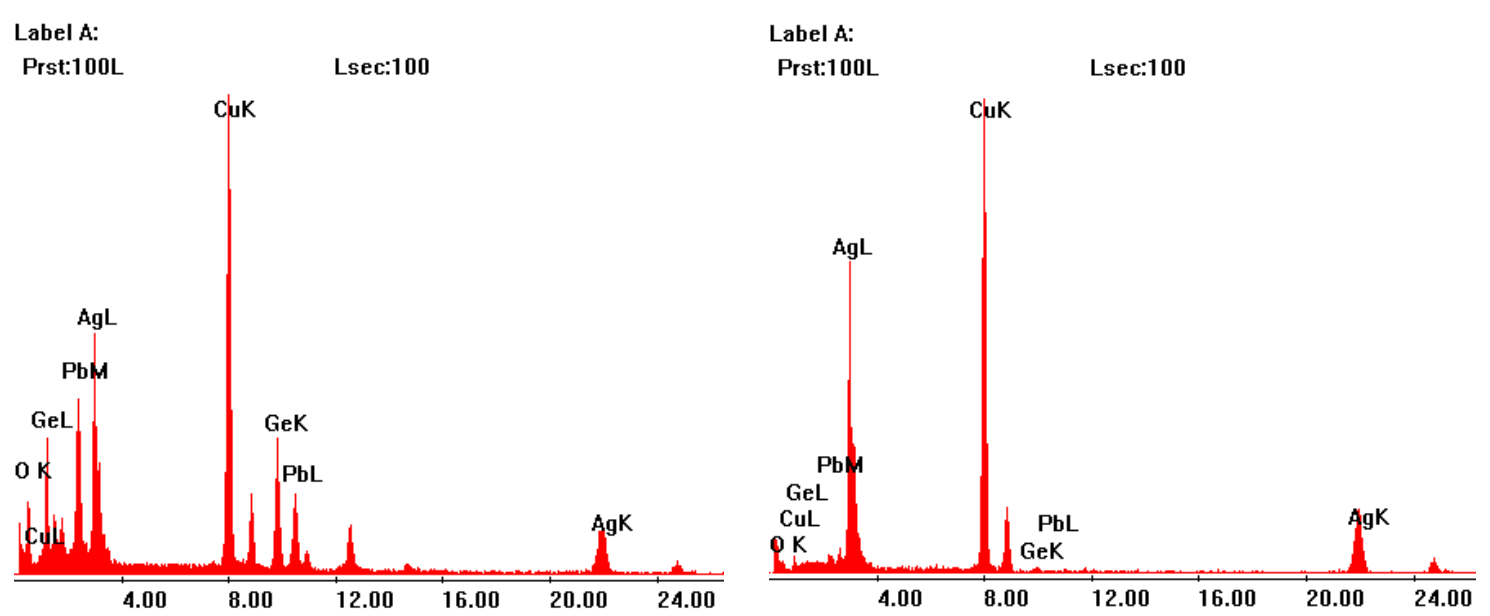

Figura 4.14 - Espectros de EDS das amostras T2Y3A, tratadas por 24 horas (à esquerda) e 30 horas (à direita).

As NPs das amostras tratadas por 60 horas apresentaram composição de chumbo misturada a prata, conforme mostrado na figura seguinte. 


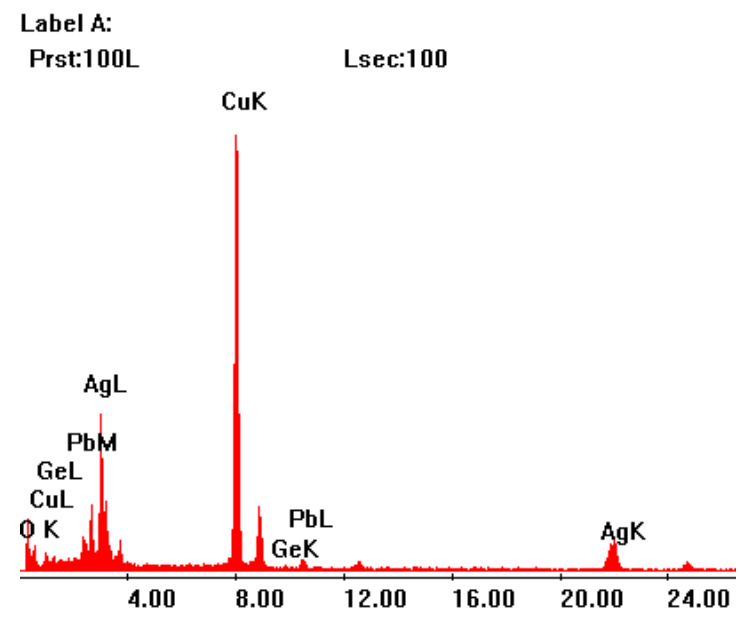

Figura 4.15 - Espectros de EDS das amostras T2Y3A, tratadas por 60 horas.

A seguir são apresentados os resultados das amostras codopadas T3Y3A. Nestas amostras percebemos que a concentração de NPs metálicas é ainda menor, como podemos ver na Figura 4.16. Por este motivo, a construção do histograma se torna inadequada, pois há a necessidade de normalização para 100\%, o que torna a média dos tamanhos de baixa representatividade. No entanto, podemos notar pelas micrografias que para a amostra tratada por 24 horas, há NPs de $\approx 10 \mathrm{~nm}$ a $30 \mathrm{~nm}$. Para a tratada por 30 horas, há NPs de $\approx 30 \mathrm{~nm}$ a $80 \mathrm{~nm}$. Cabe acrescentar que esta última ainda apresenta formação de aglomerados, onde as NPs aparentam estar coalescendo.

Os espectros de EDS confirmam que as NPs são de prata, e são apresentados na Figura 4.17.
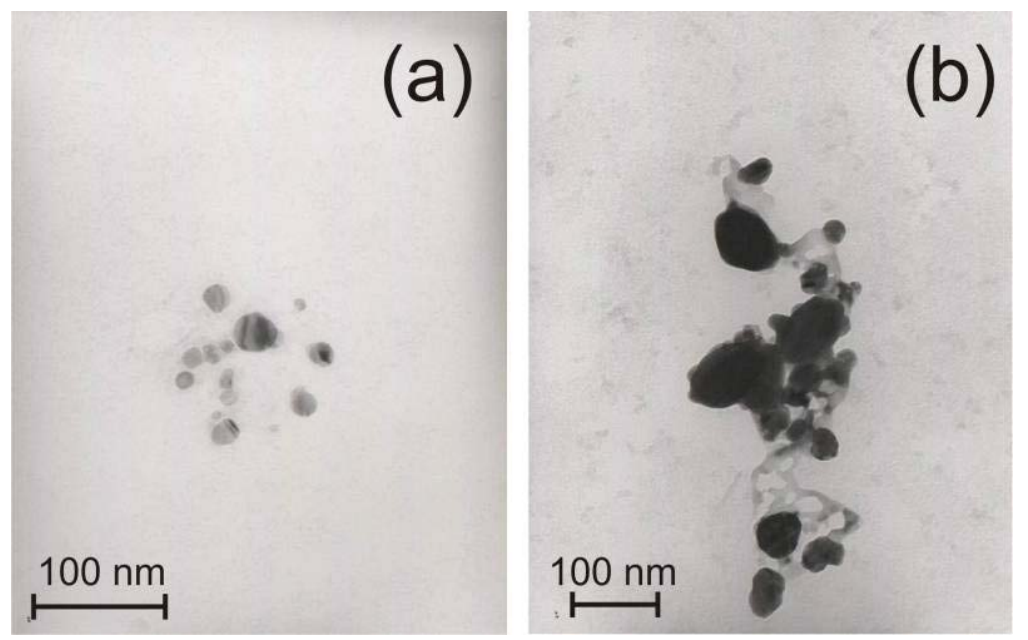

Figura 4.16 - Micrografias das amostras T3Y3A, tratadas por (a) 24 horas e (b) 30 horas. 

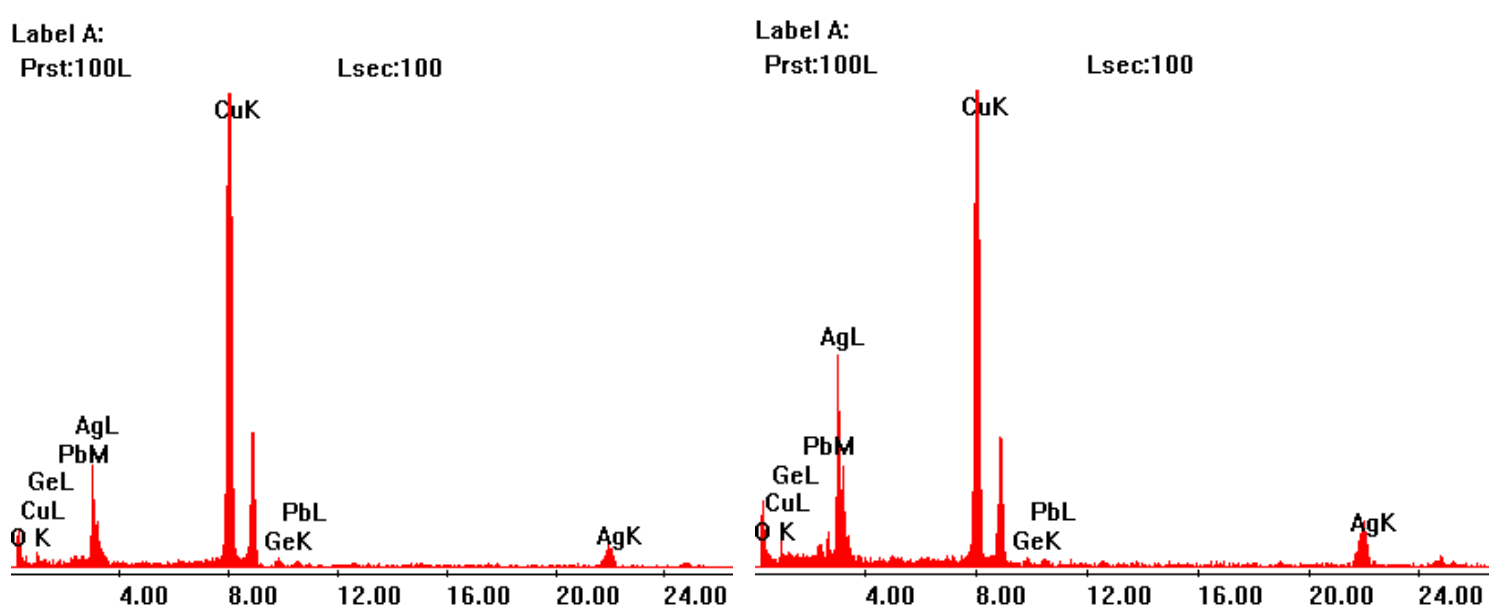

Figura 4.17 - Espectros de EDS das amostras T3Y3A, tratadas por 24 horas (a esq.) e 30 horas (à dir.).

Considerando que o sistema GP suportou apenas $3 \%$ de $\mathrm{Yb}_{2} \mathrm{O}_{3}$ quando codopado com $0,5 \%$ de $\mathrm{Tm}_{2} \mathrm{O}_{3}$, como mostrado anteriormente, e que para 0 tratamento de 30 horas, há NPs maiores e aglomerados, descartamos a possibilidade da utilização desta composição. Lembrando ainda que a mobilidade dos íons de prata depende da matriz, logo, quanto mais saturada esta última estiver, menor será a mobilidade da prata. Isto nos leva a crer que a dispersão da prata ficou prejudicada.

A presença de NPs grandes para o tratamento de 30 horas nos levou a não dar prosseguimento a tratamentos de 60 horas, conforme feito para o segundo conjunto.

\subsubsection{Medidas de Luminescência}

Para obtenção dos espectros de emissão destas amostras, foi utilizado o mesmo arranjo experimental e os mesmos parâmetros das medidas feitas para as amostras codopadas com $\mathrm{Tm}_{2} \mathrm{O}_{3}$ e $\mathrm{Yb}_{2} \mathrm{O}_{3}$.

Podemos observar que em todos os espectros (Figura 4.18, Figura 4.19 e Figura 4.20), o crescimento da luminescência é consideravelmente baixo. Isto se deve as baixas concentrações de NPs presentes nas amostras, tornando os processos do aumento do campo local e da TE entre os íons de TRs e as NPS, pouco eficientes. 
Nas amostras codopadas T2Y1A, o crescimento da luminescência na região do visível ocorre até o tratamento de 24 horas, e para a amostra tratada por 30 horas a intensidade se mantém. Nas amostras codopadas T2Y3A, não se observa crescimento da luminescência para os tratamentos de 24 e 30 horas. Entretanto, em ambas as composições, a intensidade da luminescência em $\approx 800 \mathrm{~nm}$ se torna menor à medida que cresce o tempo de tratamento até 30 horas (Figura 4.18 e Figura 4.19).

A complexidade da nucleação da prata faz com que tenhamos NPs de vários tamanhos e até agregados. Cabe lembrar que à medida que o tamanho das NPs aumenta a banda de absorção dos PS desloca-se para comprimentos de onda maiores. Isto faz com que todo o espectro seja influenciado por meio da competição entre os efeitos: aumento do campo local e transferência de energia entre as NPs e os íons de TRs. Para distâncias entre NPs e íons de TRs menores que $5 \mathrm{~nm}$, pode ocorrer diminuição da luminescência e para distâncias maiores (compreendida entre 5 e $20 \mathrm{~nm}$ ), pode ocorrer aumento da luminescência, conforme visto no item 2.4.

Uma das hipóteses para explicar o aumento da luminescência em $480 \mathrm{~nm}$ é a presença de NPs menores situadas entre 5 e 20 nm dos íons de TRs; e a diminuição em $800 \mathrm{~nm}$ é justificada pela presença de NPs maiores (ou agregados) situadas em distâncias inferiores à $5 \mathrm{~nm}$.

Outra hipótese seria a competição dos processos envolvidos na luminescência em 480 nm. Por se tratar de uma emissão ressonante com os PS das NPs de prata, o aumento da luminescência se dá pelo aumento do campo local e pela TE das NPs para os íons $\mathrm{Tm}^{3+}$. Contudo, se a distância entre os íons $\mathrm{Tm}^{3+}$ e as NPs for menor do que $5 \mathrm{~nm}$, a TE passa a ser dos íons $\mathrm{Tm}^{3+}$ para as NPs. Assim, à medida que cresce a concentração de NPs, aumentam também os efeitos abordados anteriormente e a intensidade de emissão em 480 nm se mantém inalterada, como visto para os tratamentos de 24 e 30 horas. Porém, tendo mais íons de $\mathrm{Tm}^{3+}$ emitindo em $480 \mathrm{~nm}$, menor será a quantidade de íons que emitem em 800 nm, logo, menor será a intensidade da emissão. 


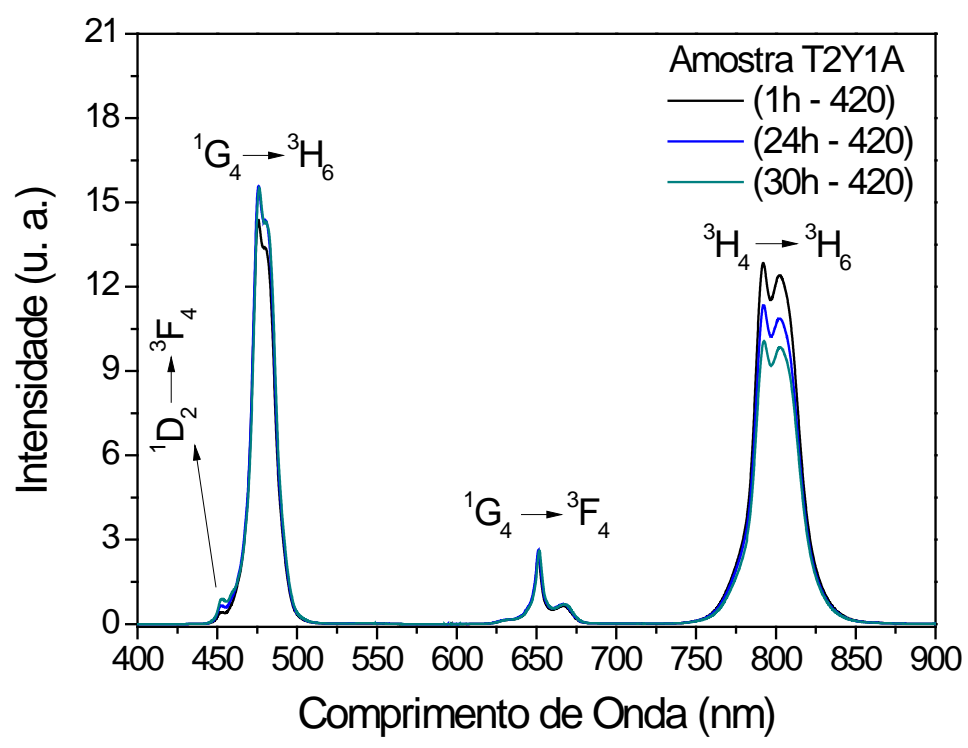

Figura 4.18 - Espectro de emissão das amostras T2Y1A, tratadas por diferentes intervalos de tempo.

Cabe acrescentar que a amostra tradada por 60 horas, mostrada na Figura 4.19, apresentou aumento da luminescência em 480 e 800 nm, devido à presença de NPs menores e a formação de agregados, como mostra a Figura 4.11c.

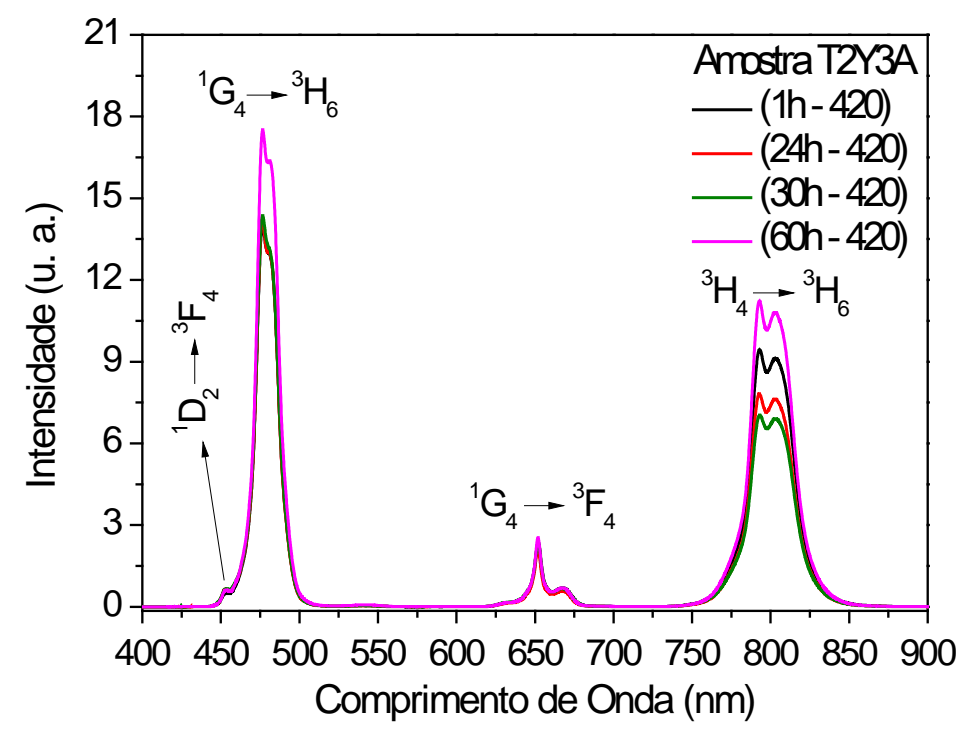

Figura 4.19 - Espectro de emissão das amostras T2Y3A, tratadas por diferentes intervalos de tempo.

Para amostras T3Y3A (Figura 4.19), a redução da intensidade em 800 nm não é observada devido à formação de NPs maiores e agregados. Como visto no item 2.4, para NPs maiores e agregados, há um deslocamento da banda de RPS das NPs, de forma que esse deslocamento, dependendo do tamanho da NPs pode a interferir na região do IV e aumentar a luminescência desta região também. No caso 
da existência de dois ou mais tamanhos médios de NPs, teremos mais de uma banda de RPS, fazendo com que todas as emissões no espectro visível e parte do IV possam ser intensificadas.

Cabe ressaltar que o aumento da concentração de $\mathrm{Yb}_{2} \mathrm{O}_{3}$ pode ter atenuado a mobilidade dos íons de prata. Com isto a concentração das NPs é reduzida, o que dificulta a observação das NPs nas medidas de MET. Assim, outra hipótese referente à manutenção da intensidade da emissão em 800 nm é a diminuição do número de NPs situadas em distâncias inferiores a $5 \mathrm{~nm}$ dos íons de TRs.

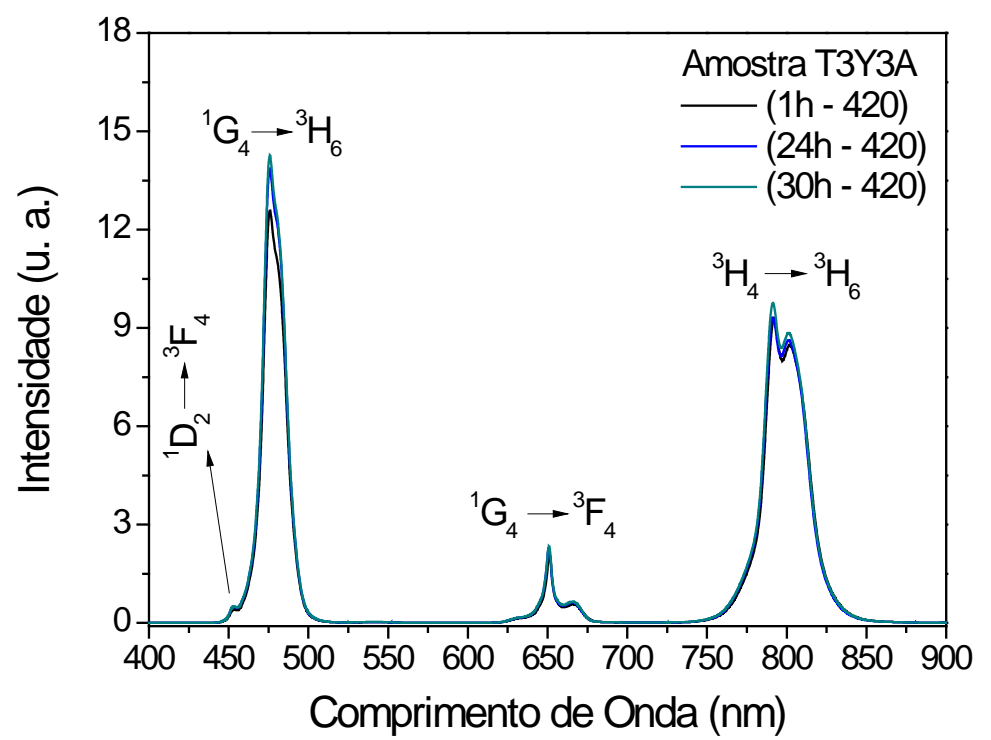

Figura 4.20 - Espectro de emissão das amostras T3Y3A, tratada por diferentes intervalos de tempo.

$\mathrm{Na}$ Figura 4.21 são apresentados os espectros referentes as amostra contendo NPs que tem a maior intensidade luminescente; as amostras sem NPs são mostradas para comparação. 


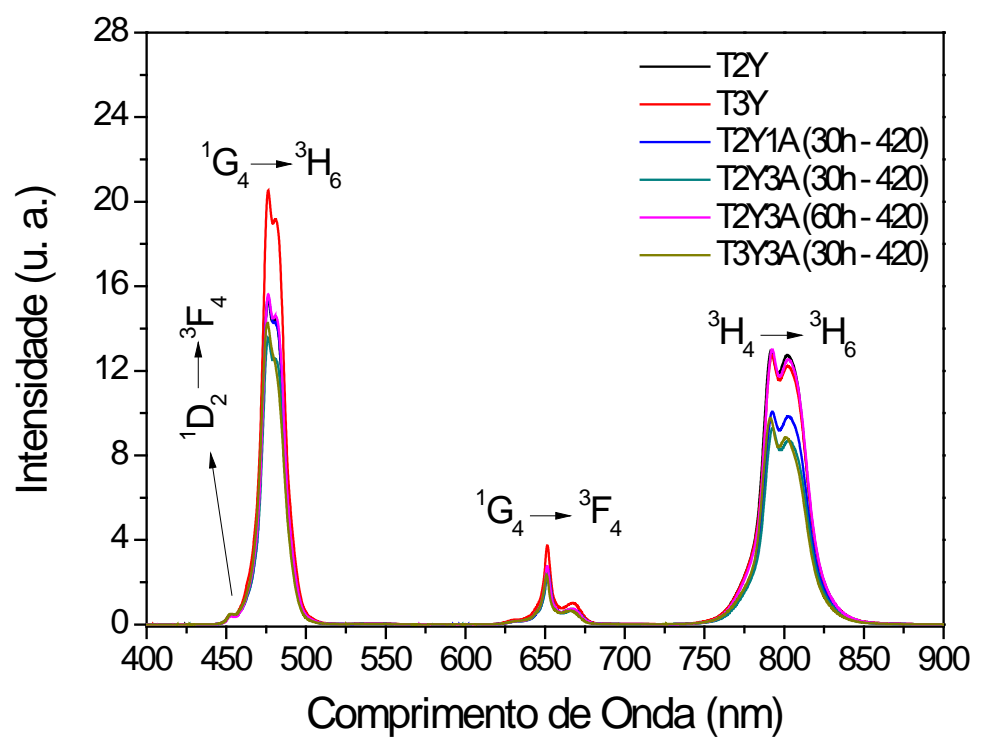

Figura 4.21 - Espectro de emissão das amostras com as maiores intensidades luminescentes.

Podemos verificar que a amostra T3Y, sem NPs, possui maior intensidade de emissões em $480 \mathrm{~nm}$. Isto se deve ao fato de que a emissão em $480 \mathrm{~nm}$ é ressonante aos PS das NPs de prata, logo, parte da emissão é absorvida pelas NPS. No caso da emissão em $800 \mathrm{~nm}$, as maiores intensidades luminescentes ocorrem para as amostras sem NPs e para a amostra com NPs tratada por 60 horas. Como explicado anteriormente, a formação de agregados é responsável pelo aumento da emissão em 800 nm. No caso da emissão em 650 nm, esta praticamente não muda devido à baixa probabilidade da transição correspondente, pois é oriunda do mesmo nível $\left({ }^{1} \mathrm{G}_{4}\right)$ da emissão em $480 \mathrm{~nm}$. A emissão em $455 \mathrm{~nm}$ não sofreu mudança com a nucleação das NPs de prata devido à diferença energética entre a banda de RPS e a transição ${ }^{3} \mathrm{H}_{6} \rightarrow{ }^{1} \mathrm{D}_{2}(\approx 365 \mathrm{~nm})$. Dentre as amostras com NPs, a maior emissão em $480 \mathrm{~nm}$ se deu para a amostra T2Y3A (60h - 420).

Em todas as amostras foram realizados medidas de intensidade de luminescência em função da potência do laser, a fim de verificar mudanças nos processos de transferência de energia entre $\mathrm{Yb}^{3+}$ e $\mathrm{Tm}^{3+}$. Como exemplo, mostramos os resultados da amostra T2Y3A na Figura 4.22, onde não foram observadas mudanças nos processos de transferência de energia, pois o número de fótons envolvidos em cada emissão não sofreu mudança considerável. De acordo com os processos de CA dos íons $\mathrm{Tm}^{3+}$, descritos no item 2.3.2, as emissão em 480 e 650 nm são observadas a partir da absorção de 3 fótons, a emissão em 455 nm acontece a partir da absorção de 4 fótons e a emissão em $800 \mathrm{~nm}$, a partir de 2 fótons. 


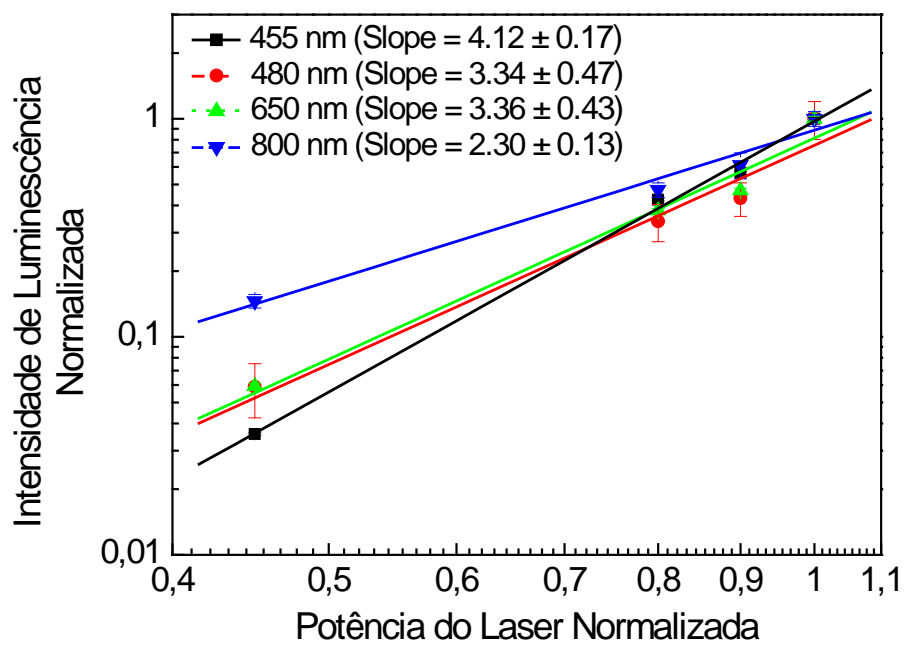

Figura 4.22 - Intensidade de luminescência em função da potência do laser para a amostra T2Y3A $(60 \mathrm{~h}-420)$.

\subsection{VIDROS DOPADOS COM $\mathrm{Tm}_{2} \mathrm{O}_{3}$ CONTENDO NPS DE PRATA PRODUZIDOS EM CADINHO DE ALUMINA PURA}

Com base nos resultados obtidos e na pequena concentração suportada pelo sistema GP quando produzido em cadinho de alumina-silicato, foram produzidas amostras contendo 1,0\% $\mathrm{Tm}_{2} \mathrm{O}_{3}$ e 5,0\% $\mathrm{AgNO}_{3}$ (T5A), com o intuito de verificar as mudanças produzidas tanto na luminescência dos íons $\mathrm{Tm}^{3+}$ como na nucleação das NPs de prata.

No processo de fabricação dessas amostras, durante o período de fusão, foi realizada a agitação da massa vítrea fundida por meio de uma vareta de quartzo para aumentar a homogeneidade do material. Nas amostras apresentadas anteriormente pudemos observar estrias, que caracterizam separação de fase prejudicando a qualidade óptica do vidro.

Foram realizados os seguintes tratamentos térmicos: tratamentos contínuos e em intervalos de tempo de 12 horas, como descrito no item 3.2. A Figura 4.23 apresenta as amostras e os respectivos tratamentos realizados. Neste estudo verificamos a interferência do tratamento térmico no processo de nucleação a partir da variação do tempo de tratamento e dos intervalos de tempo, e consequentemente, as mudanças nas propriedades ópticas do $\mathrm{Tm}^{3+}$. 


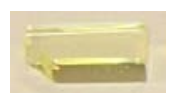

$1 \mathrm{~h}$

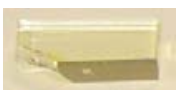

$12 \mathrm{~h}$
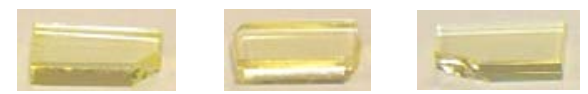

$48 \mathrm{~h}$

$24 \mathrm{~h}$

$24 \mathrm{~h}$

patamar

contínuo
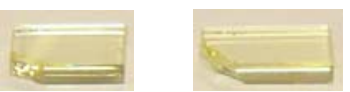

$72 \mathrm{~h}$

$48 \mathrm{~h}$ contínuo

patamar

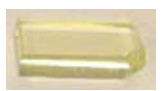

$72 \mathrm{~h}$

contínuo

Figura 4.23 - Amostras do sistema GP - T5A, tratadas por diferentes intervalos de tempo: tratamentos contínuos e não-contínuos.

\subsubsection{Medidas de Absorção Óptica}

A seguir são apresentados os espectros de absorção (Figura 4.24) das amostras produzidas em cadinho de alumina pura, tratadas por diferentes intervalos de tempo, conforme explicado anteriormente. Nestas amostras não foi observada banda de RPS das NPs de prata, embora tenhamos usado alta concentração de $\mathrm{AgNO}_{3}$. Contudo, veremos adiante que a presença das NPs pôde ser confirmada através da MET.

$\mathrm{Na}$ legenda dos espectros as designações $\left(22^{\star} 12 \mathrm{~h}\right),\left(4{ }^{\star} 12 \mathrm{~h}\right)$ e $\left(66^{\star} 12 \mathrm{~h}\right)$ significam 2, 4 e 6 intervalos de 12 horas, respectivamente. Nas demais amostras, o tratamento térmico foi realizado sem descontinuidade, e assim, cada amostra foi tratada em intervalos de 24,48 e 72 horas.

A incorporação dos íons $\mathrm{Tm}^{3+}$ é confirmada através das bandas de absorção apresentadas no espectro da Figura 4.24, com seus respectivos níveis energéticos.

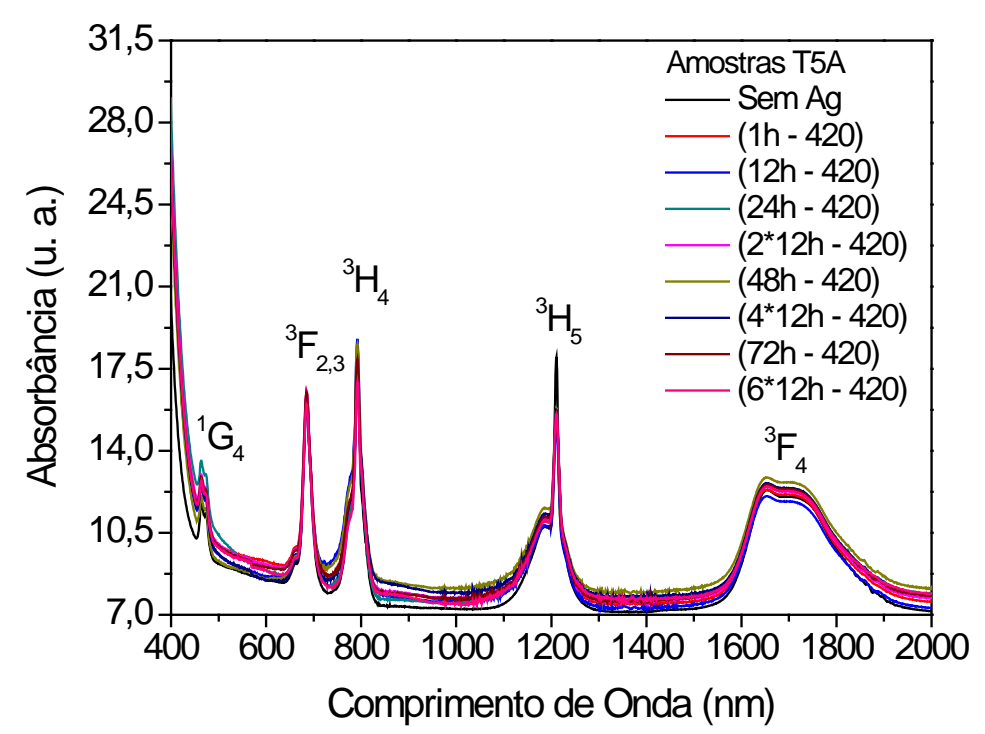

Figura 4.24 - Espectro de absorção das amostras T5A, tratadas por diferentes intervalos de tempo: tratamentos contínuos e não-contínuos. 


\subsubsection{Microscopia Eletrônica de Transmissão e EDS}

Na Figura 4.25 são apresentadas as imagens de MET das amostras T5A tratadas por 12 e 24 horas de forma contínua e não-contínua. Podemos observar que na amostra tratada por 12 horas, as NPs se apresentam inseridas na massa vítrea e com tamanho médio de $\approx 2,5 \mathrm{~nm}$ (Figura 4.26a).

Nas amostras tratadas por 24 horas em 2 intervalos de 12 horas, notamos que as partículas se apresentam dispersas e possuem tamanho médio de $\approx 10 \mathrm{~nm}$ (Figura 4.26b); nas amostras tratadas por 24 horas contínuas o tamanho médio é de $\approx 20 \mathrm{~nm}$ e verificamos também a tendência de formação de aglomerados (Figura 4.26c). Cabe acrescentar que em ambas ocorre a formação de NPs maiores, de $\approx 70$ $\mathrm{nm}$. Entretanto, as tratadas continuamente podem produzir efeitos diferentes nas intensidades de emissão devido à tendência de formação de aglomerados. Veremos mais adiante, que para tratamentos contínuos, os aglomerados irão formar NPs maiores e também agregados.
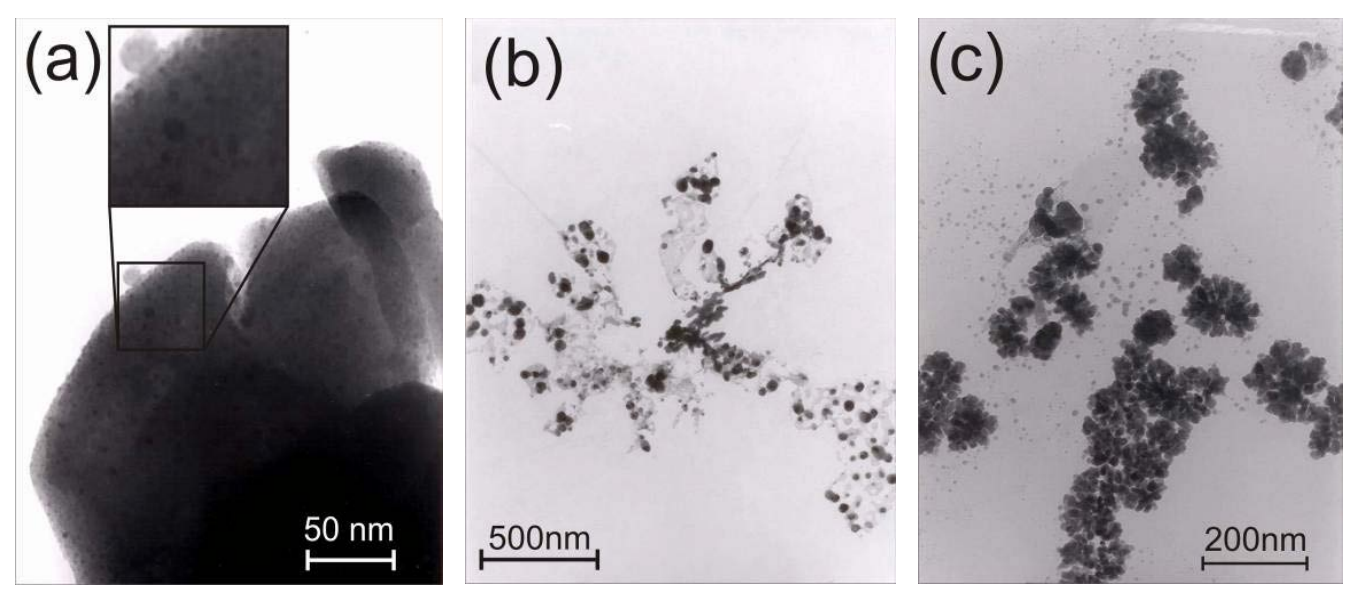

Figura 4.25 - Micrografias das amostras T5A, tratadas por (a) 12 horas, (b) 24 horas não-contínuas e por (c) 24 horas contínuas.
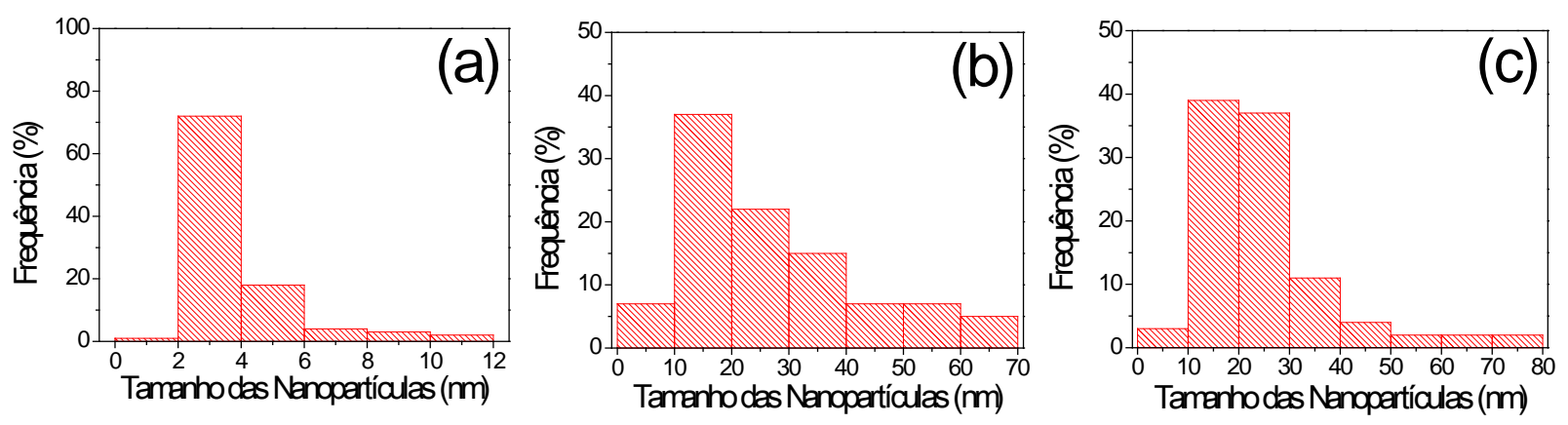

Figura 4.26 - Histogramas das amostras T5A, tratadas por (a) 12 horas, (b) 24 horas não-contínuas e por (c) 24 horas contínuas. 
Os espectros de EDS a seguir confirmam a composição das NPs de prata. $\mathrm{Na}$ Figura 4.27a podemos observar a presença das raias referentes aos elementos da composição do vidro, pois as NPs se encontram inseridas na massa vítrea.

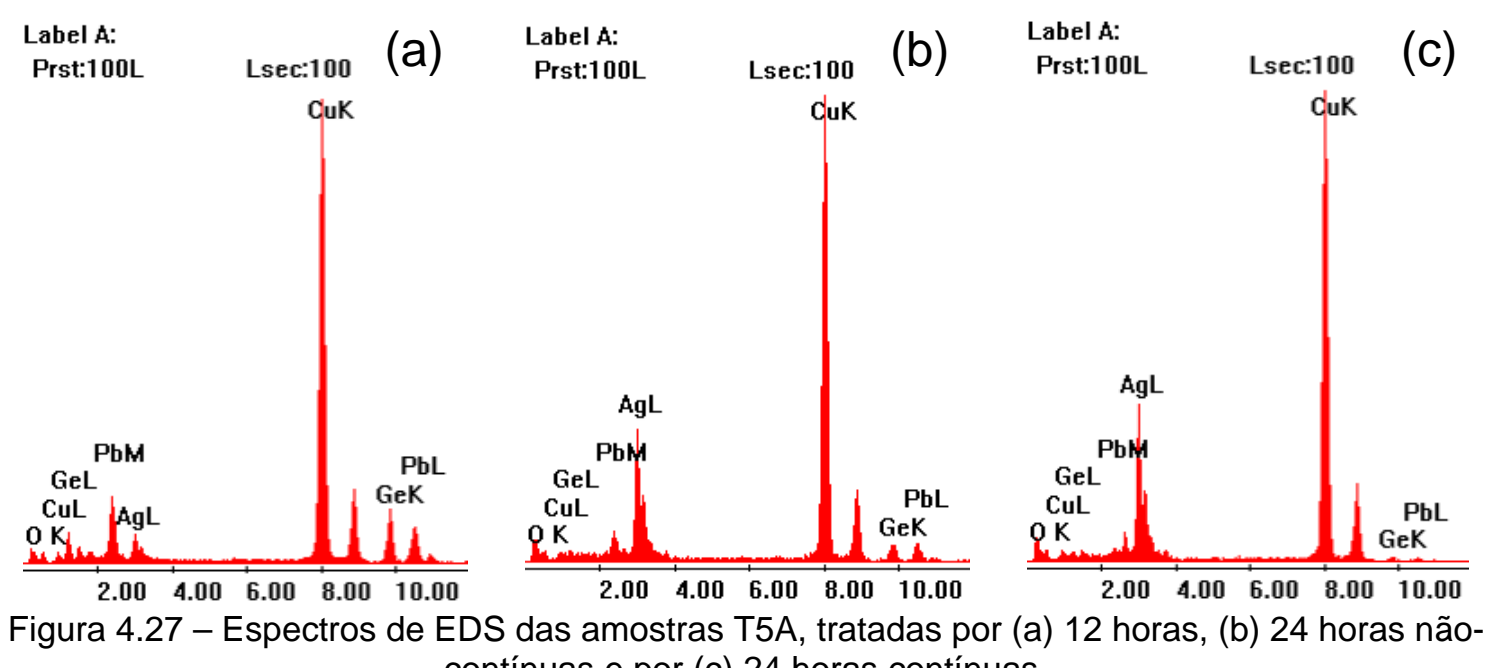
contínuas e por (c) 24 horas contínuas.

Podemos notar também raias dos elementos da matriz nas amostras tratadas por 24 horas, entretanto, em menor concentração. Estas se devem a massa cinzenta mais clara presente nas micrografias, que corresponde à massa vítrea.

Nas micrografias a seguir (Figura 4.28 e Figura 4.29) são apresentadas as imagens de MET das amostras tratadas por 48 e 72 horas. Podemos observar que ocorre o crescimento das NPs maiores e a fragmentação de NPs menores nas amostras tratadas descontinuamente, à medida que aumentamos o tempo de tratamento térmico. Isto se deve aos processos térmicos envolvidos [57]. Nas amostras tratadas continuamente observa-se o crescimento das NPs a partir da formação de aglomerados de NPs menores, seguido da coalescência destas, formando assim agregados. 


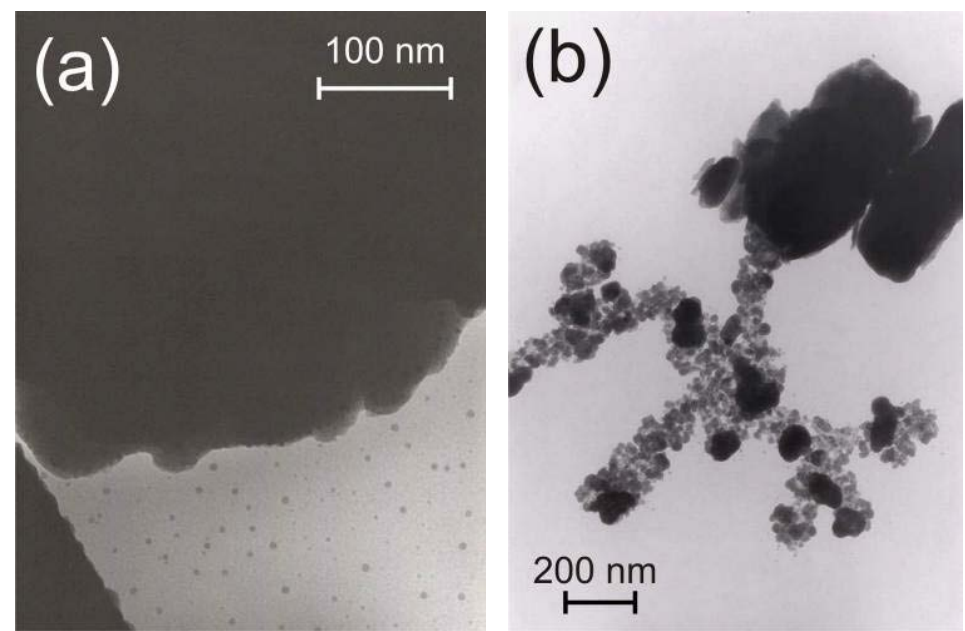

Figura 4.28 - Micrografias das amostras T5A, tratadas por (a) 48 horas não-contínuas e (b) 48 horas contínuas.
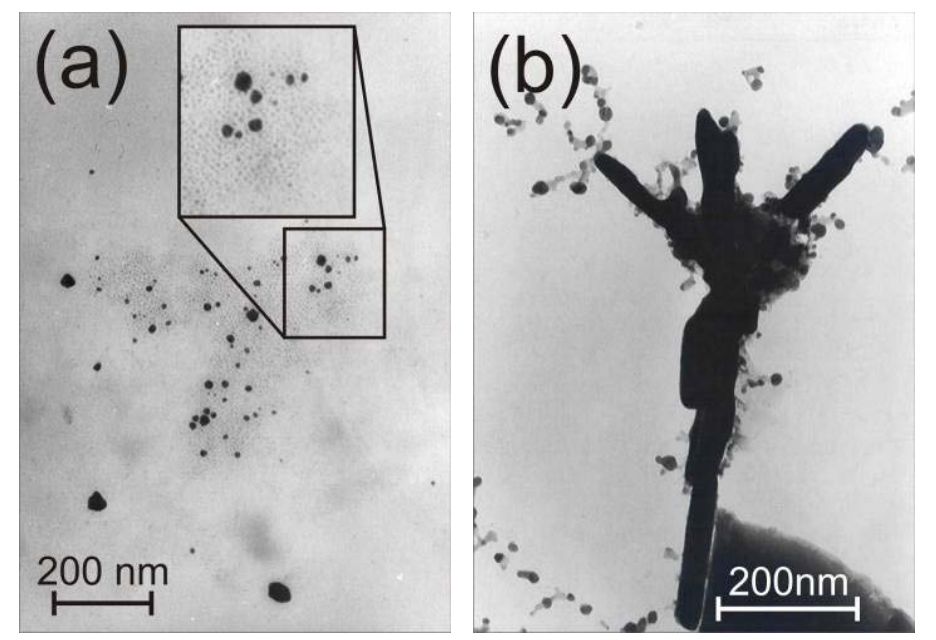

Figura 4.29 - Micrografias das amostras T5A, tratadas por (a) 72 horas não-contínuas e (b) 72 horas contínuas.

As amostras tratadas descontinuamente por 48 horas apresentaram tamanhos médios de $\approx 2,5$ e $\approx 4,5 \mathrm{~nm}$ (Figura 4 .30a) e as tratadas continuamente apresentaram tamanho médio de $\approx 24 \mathrm{~nm}$, agregados de $\approx 100 \mathrm{~nm}$ e NPs maiores que $200 \mathrm{~nm}$ (Figura 4.30b). Na Figura 4.31 é apresentado o histograma apenas da amostra tratada por 72 horas de forma não-contínua, pois a amostra tratada continuamente apresentou baixa concentração de NPs menores de $\approx 25 \mathrm{~nm}$. NP sem formato definido com uma das dimensões maiores do que $500 \mathrm{~nm}$ também foram observadas. 

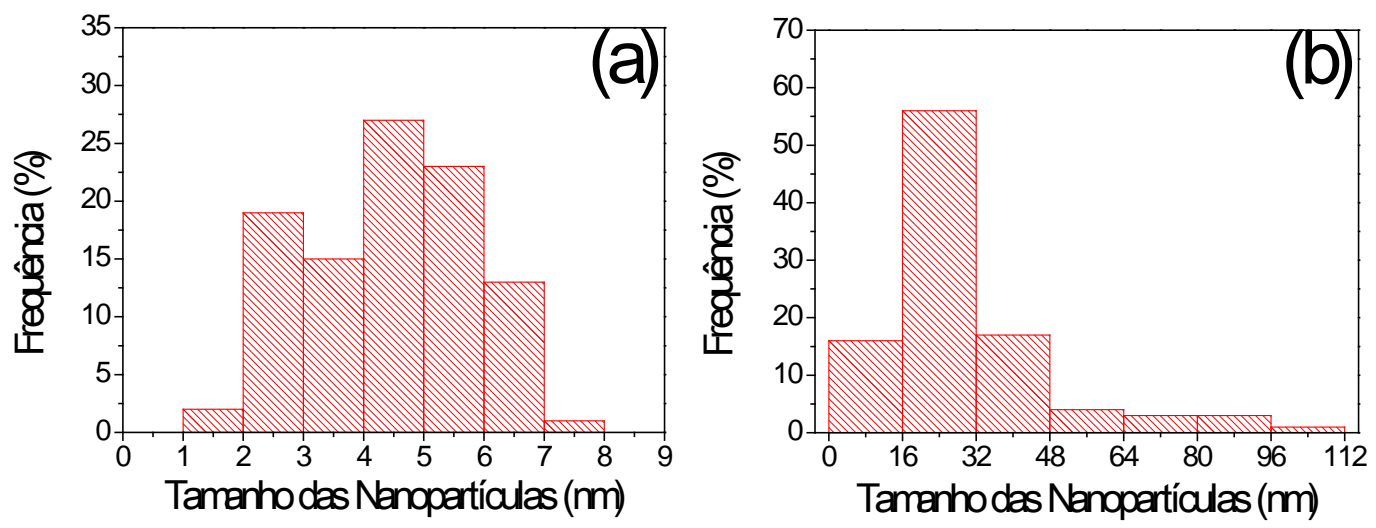

Figura 4.30 - Histogramas das amostras T5A, tratadas por (a) 48 horas não-contínuas e (b) 48 horas contínuas.

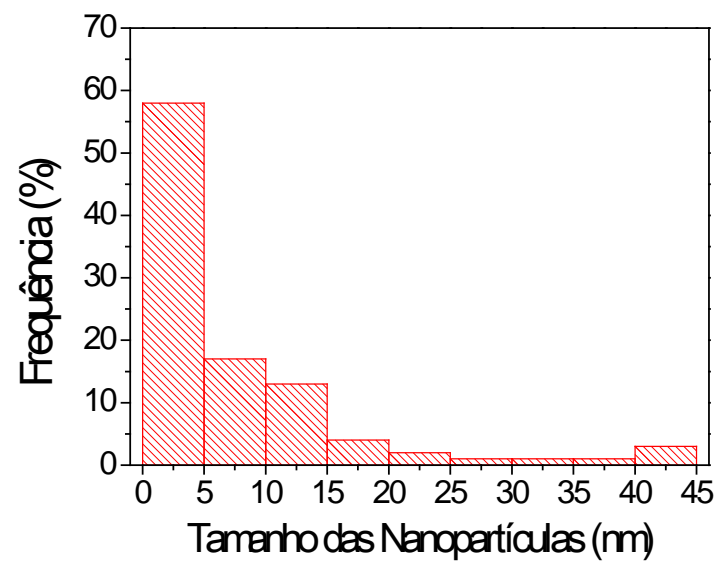

Figura 4.31 - Histogramas das amostras T5A, tratadas por 72 horas não-contínuas.

Os espectros de EDS das amostras tratadas por 48 e 72 horas confirmaram a presença de NPs prata, como é mostrado nas figuras a seguir.

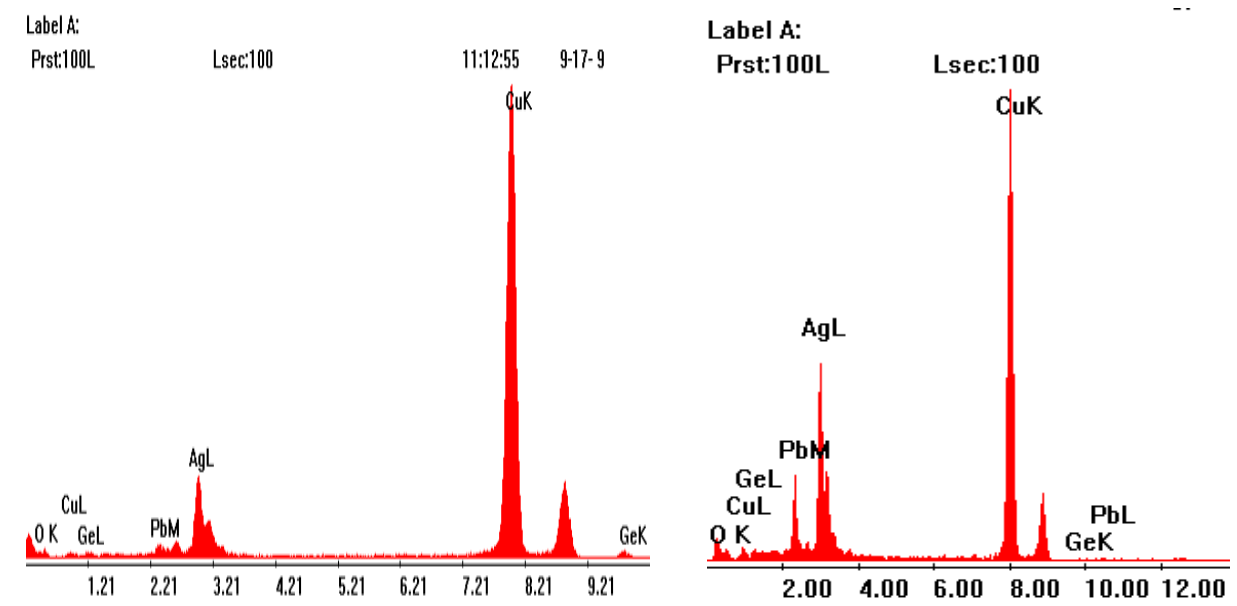

Figura 4.32 - Espectros de EDS das amostras T5A, tratadas por (à esq.) 48 horas não-contínuas e (à dir.) 48 horas contínuas. 

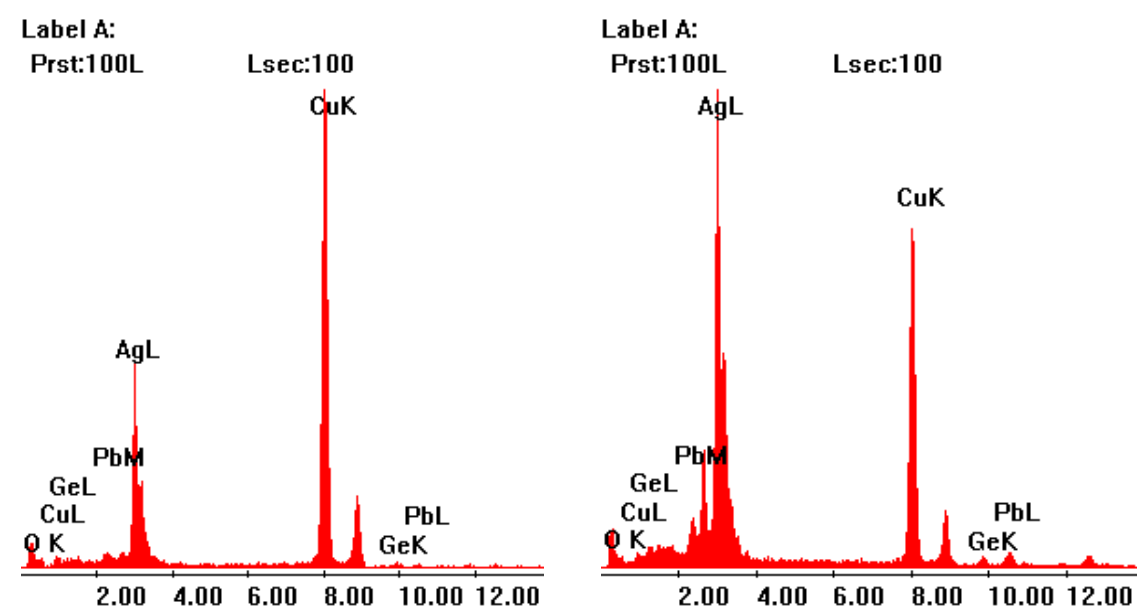

Figura 4.33 - Espectros de EDS das amostras T5A, tratadas por (à esq.) 72 horas não-contínuas e (à dir.) 72 horas contínuas.

\subsubsection{Medidas de Luminescência}

Os espectros de emissão apresentados na Figura 4.34 foram obtidos no laboratório da UFPE. Podemos observar aumento da luminescência na amostra tratada por 24 horas em 2 intervalos de tempo de 12 horas. Para os outros tratamentos, as amostras apresentaram luminescência relativamente menor. Dentre as amostras tratadas continuamente, apenas a de 24 horas apresentou luminescência próxima a sua correspondente em tratamento descontínuo. As demais apresentaram intensidade de luminescência próxima ou inferior a da amostra tratada por 12 horas.

Podemos notar que ao compararmos as amostras citadas com a de mesma composição sem o reagente metálico, a interferência das NPs de prata na luminescência dos íons de $\mathrm{Tm}^{3+}$ se mostrou mais eficiente. Verificamos também um notável crescimento da luminescência em 650 nm, o que não foi observado nas amostras codopadas apresentadas no item 4.2, preparadas em cadinho de aluminasilicato (Figura 4.21). Porém, a eficiência no processo de CA nas amostras contendo $\mathrm{Yb}_{2} \mathrm{O}_{3}$ é muito maior devido à interação entre os íons $\mathrm{Tm}^{3+}$ e $\mathrm{Yb}^{3+}$.

Cabe acrescentar que nestas medidas não foi apresentada a luminescência em $800 \mathrm{~nm}$ por limitação do detector utilizado. No caso foi usada uma CCD com espectro de abrangência na região do UV-Visível. 


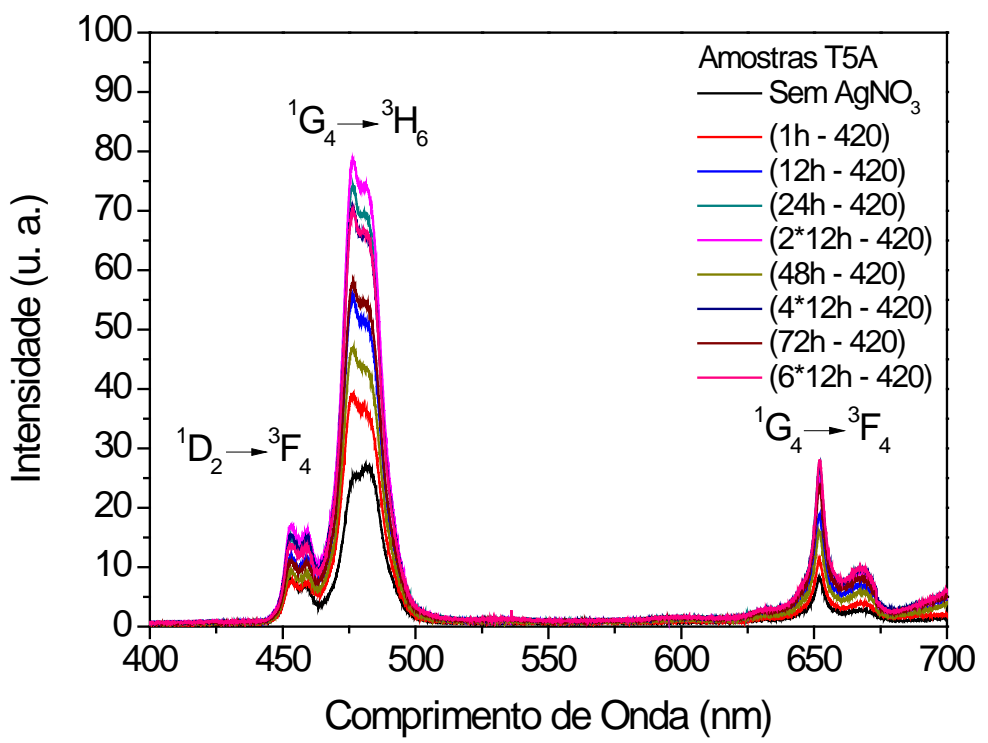

Figura 4.34 - Espectro de emissão na região do visível das amostras T5A, tratadas por diferentes intervalos de tempo: tratamentos contínuos e não-contínuos.

Baseado nos resultados de emissão obtidos, podemos explicar o aumento da luminescência a partir do aumento do campo local, como visto anteriormente. Este ocorre devido à sensibilização das NPs pela emissão em 480 nm, que é ressonante com a banda dos PS da prata, com tamanho médio entre 2 à $30 \mathrm{~nm}$, como visto nas micrografias e histogramas apresentados anteriormente para a amostras T5A.

Da mesma forma, foram realizadas medidas de intensidade de luminescência em função da potência para todas as amostras. Não foram observadas diferenças nos processos de transferência de energia entre $\mathrm{Yb}^{3+}$ e $\mathrm{Tm}^{3+}$, com relação aos resultados anteriores. Na Figura 4.35 são apresentados os resultados obtidos para a amostra T5A $(24 \mathrm{~h}-420)$.

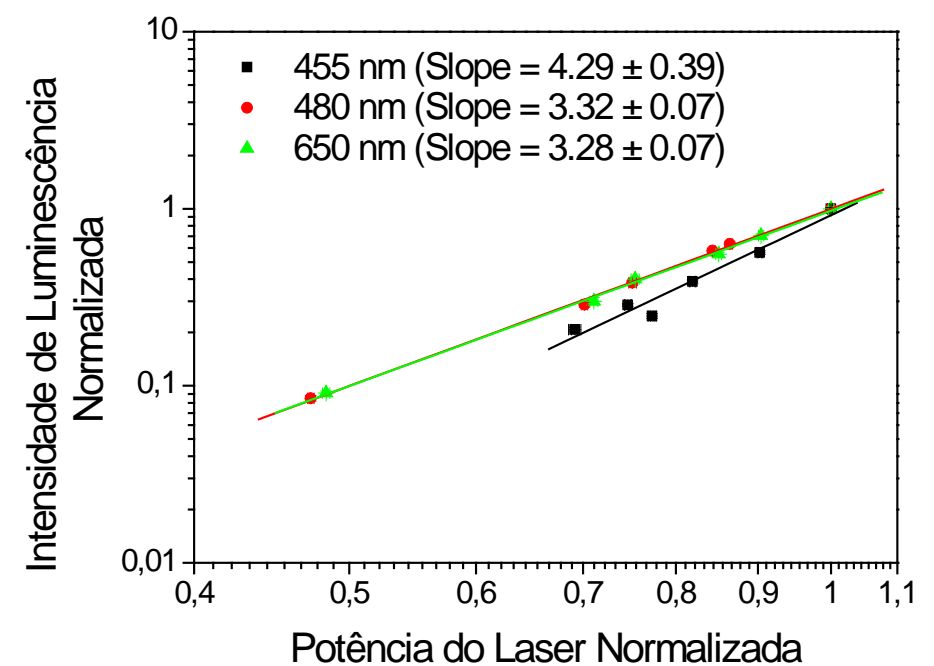

Figura 4.35 - Intensidade de luminescência em função da potência do laser para a amostra T5A $(24 \mathrm{~h}-420)$. 


\subsection{VIDROS CODOPADOS COM $\mathrm{Tm}_{2} \mathrm{O}_{3}$ e $\mathrm{Yb}_{2} \mathrm{O}_{3}$ CONTENDO NPS DE PRATA PRODUZIDOS EM CADINHO DE ALUMINA PURA}

A partir dos resultados obtidos nas amostras produzidas em cadinho de alumina pura, pudemos verificar que a incorporação das NPs se mostrou mais efetiva. Levando em consideração a alta eficiência dos íons $\mathrm{Yb}^{3+}$ nos processos de CA dos íons $\mathrm{Tm}^{3+}$, foram produzidas amostras do sistema GP codopadas com 0,5\% $\mathrm{Tm}_{2} \mathrm{O}_{3}, 2,0 \% \mathrm{Yb}_{2} \mathrm{O}_{3}$ e 3,0\% $\mathrm{AgNO}_{3}$ (T2Y3A) no referido cadinho. Contudo, nestas amostras foi variada a temperatura de tratamento térmico devido à baixa concentração de NPs apresentadas pelas amostras tratadas a $420^{\circ} \mathrm{C}$, e ao fato da luminescência da amostra T3Y ser maior do que as amostras contendo NPs. As referidas amostras são mostradas na Figura 4.36. Podemos observar que elas apresentaram diferentes tonalidades, mesmo que tratadas por 6 horas, se comparadas aos resultados anteriores.

No processo de fabricação dessas amostras, durante o período de fusão, foi utilizado o mesmo sistema mencionado anteriormente para aumentar a homogeneidade da massa vítrea fundida. Assim, pudemos garantir tanto a qualidade óptica quanto uma maior dissolução dos dopantes ao longo de todo o vidro, inclusive do reagente metálico precursor das NPs.

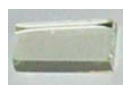

$1 \mathrm{~h}$ $420^{\circ} \mathrm{C}$

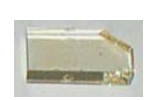

$6 \mathrm{~h}$ $480^{\circ} \mathrm{C}$

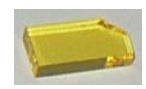

$6 \mathrm{~h}$ $500{ }^{\circ} \mathrm{C}$

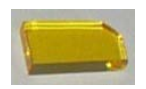

$6 \mathrm{~h}$ $520^{\circ} \mathrm{C}$

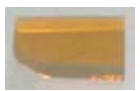

$6 \mathrm{~h}$ $540^{\circ} \mathrm{C}$

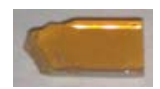

$2 * 6 \mathrm{~h}$ $540^{\circ} \mathrm{C}$

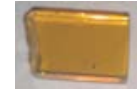

$12 \mathrm{~h}$

$540{ }^{\circ} \mathrm{C}$

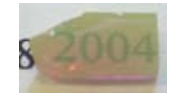

$6 \mathrm{~h}$ $570^{\circ} \mathrm{C}$

Figura 4.36 - Amostras T2Y3A produzidas em cadinho de alumina pura e tratadas em diferentes temperaturas para nucleação das NPs.

$\mathrm{Na}$ Figura 4.36 podemos notar que com o aumento da temperatura, as amostras apresentaram tonalidades diferentes, variando do amarelo ao laranja. No caso da ultima amostra, a tonalidade ficou esverdeada. Isto pode ser considerado como uma evidência da nucleação das NPs de prata, pois a RPS interage com a luz na região visível do espectro, proporcionando às amostras cores que podem ser explicadas pela presença da banda de RPS das NPs de prata, um efeito similar a da taça de Lycurgus [3], como pode ser visto também na Figura 4.37. 

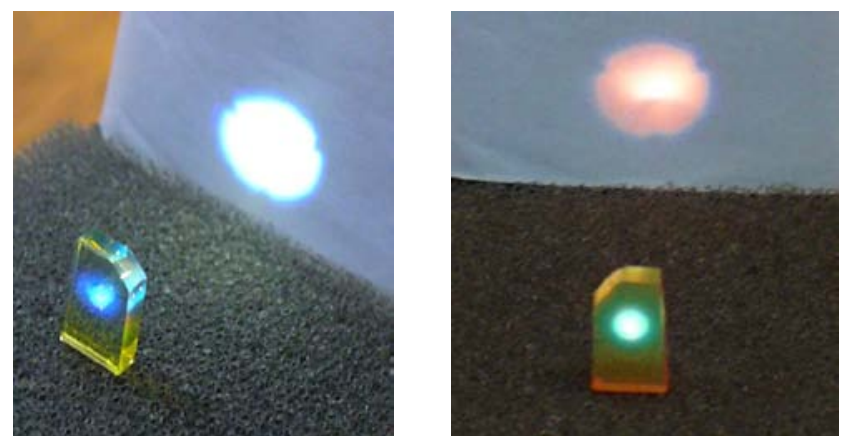

Figura 4.37 - Efeito da banda de RPS das NPs de prata na amostra tratada por 6 horas à $500{ }^{\circ} \mathrm{C}$ (à esq.) e à $540^{\circ} \mathrm{C}$ (à dir.).

\subsubsection{Medidas de Absorção Óptica}

No espectro de absorção apresentado na Figura 4.38 podemos observar o surgimento da banda de RPS das NPs de prata que cresce e alarga-se à medida que aumentamos a temperatura de tratamento térmico. O aumento da intensidade de absorção ocorre quando a concentração das NPs aumenta, e o alargamento da banda é devido à dispersão de tamanhos das NPs. Nota-se ainda a presença de duas bandas de RPS para as amostras tratadas às temperaturas de 540 e $570{ }^{\circ} \mathrm{C}$. O surgimento de duas bandas pode ser explicado pela presença de NPs de tamanhos médios distintos, como veremos adiante. O deslocamento da banda é devido à mudança do tamanho médio das NPs [20]. Estas bandas não são observadas para tratamentos inferiores a $500{ }^{\circ} \mathrm{C}$, dada a baixa concentração de NPs. Amostras tratadas a $540^{\circ} \mathrm{C}$ em intervalos de $12 \mathrm{~h}$ apresentaram espectro similar à tratada por $6 \mathrm{~h}$.

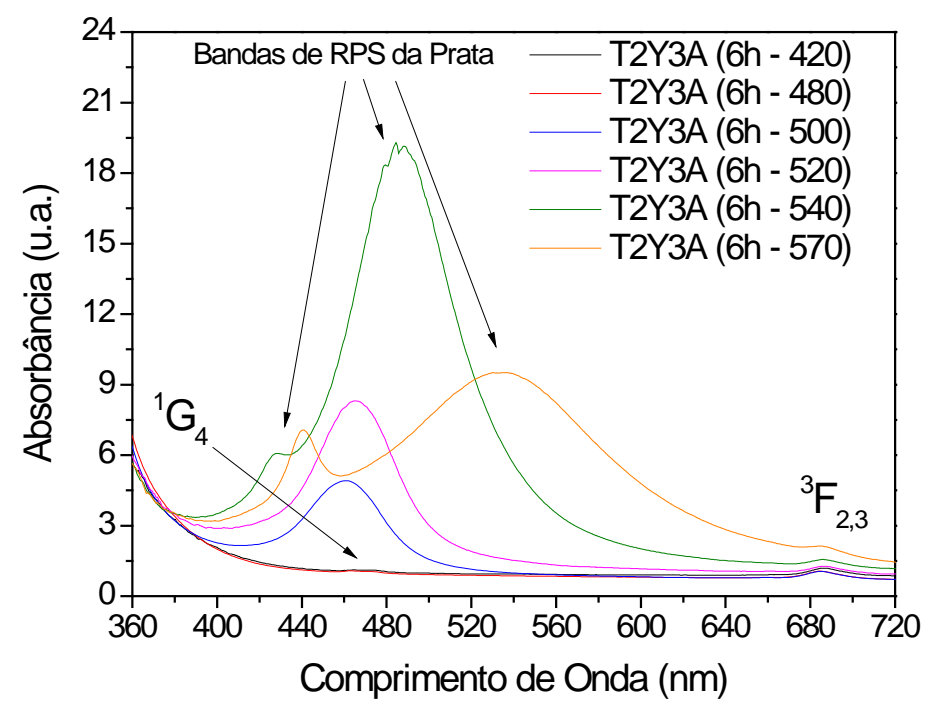

Figura 4.38 - Espectro de absorção das amostras T2Y3A, tratadas em diferentes temperaturas. 


\subsubsection{Microscopia Eletrônica de Transmissão e EDS}

As imagens de MET apresentadas a seguir correspondem às amostras T2Y3A tratadas por 6 horas a diferentes temperaturas. Com o intuito de verificar o efeito de tratamentos térmicos contínuos e tratamentos em intervalos de tempo, foram realizados dois tratamentos a $540{ }^{\circ} \mathrm{C}$ : um tratamento em 12 horas contínuas, e outro de 12 horas em 2 intervalos de 6 horas. Desta forma, conseguimos realizar uma comparação com o estudo realizado para as amostras T5A.

A amostra T2Y3A (6h - 480), apesar de não ter apresentado banda de RPS, apresentou a formação de NPs de tamanhos médios de $\approx 4$ e 12 nm (Figura 4.39). A ausência da banda se deve a baixa concentração de NPs.
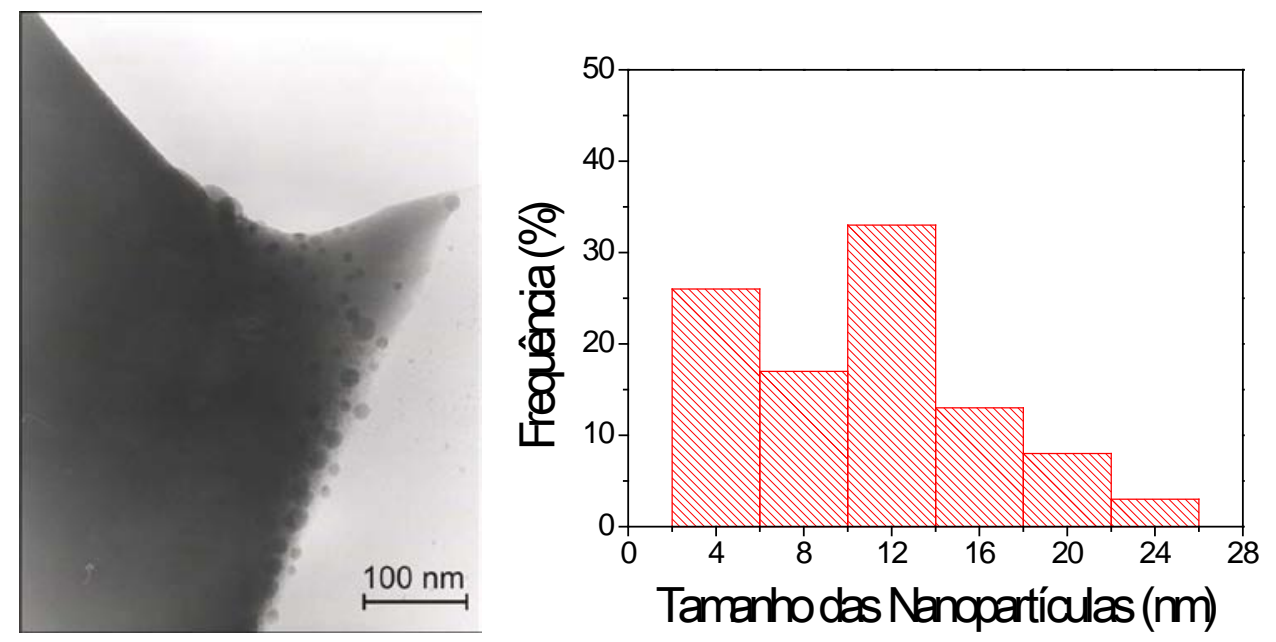

Figura 4.39 - Micrografia e histograma da amostra T2Y3A (6h - 480).

O espectro de EDS apresentado na Figura 4.40 confirmou a composição das NPs como sendo de prata. Observam-se também as raias referentes aos elementos da matriz. Isso ocorre, pois as NPs se encontram inseridas na massa vítrea. 

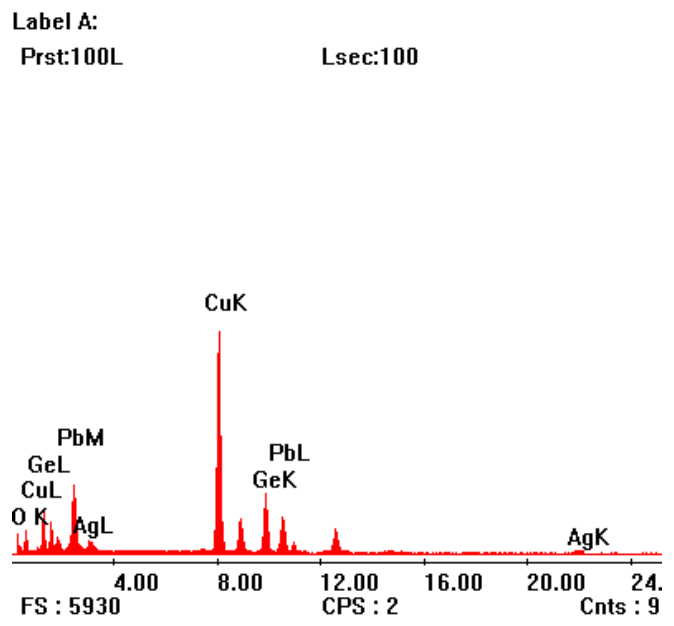

Figura 4.40 - Espectro de EDS da amostra T2Y3A (6h - 480).

No caso das amostras T2Y3A (6h - 500) e T2Y3A (6h - 520), foi observada a formação de uma banda de absorção em $\approx 465 \mathrm{~nm}$ (Figura 4.38), que pode ser descrita pela obtenção de NPs menores, em torno de 5 à 20 nm, como mostra a Figura 4.41. Entretanto, observa-se também a formação de NPs maiores, em torno de 50 à 100 nm, as quais não se encontram em alta concentração, pois não foi vista banda de RPS. A diferença existente entre as duas amostras está na concentração de NPs presentes, onde a amostra tratada à temperatura de $520{ }^{\circ} \mathrm{C}$ possui maior concentração de NPs do que a amostra tratada à $500{ }^{\circ} \mathrm{C}$, como podemos ver na Figura 4.38, onde as intensidades da banda de RPS são diferentes.
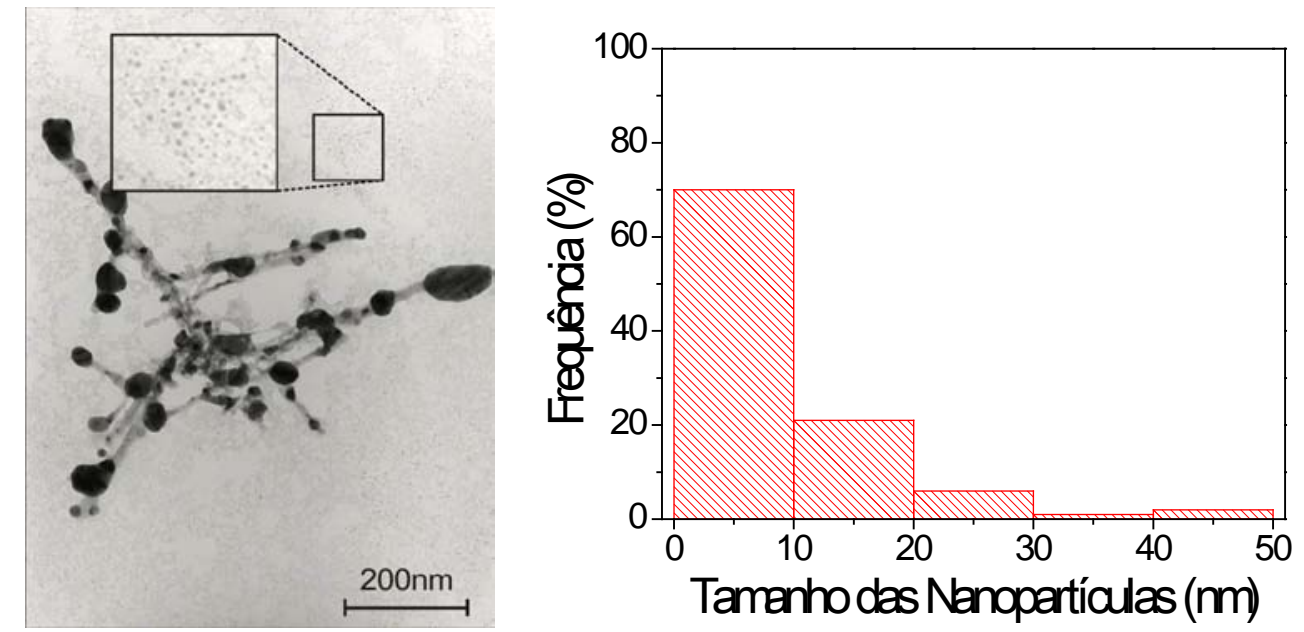

Figura 4.41 - Micrografia e histograma da amostra T2Y3A (6h - 500).

Como esperado, o espectro de EDS confirmou a presença de NPs de prata e é mostrado na Figura 4.42. 


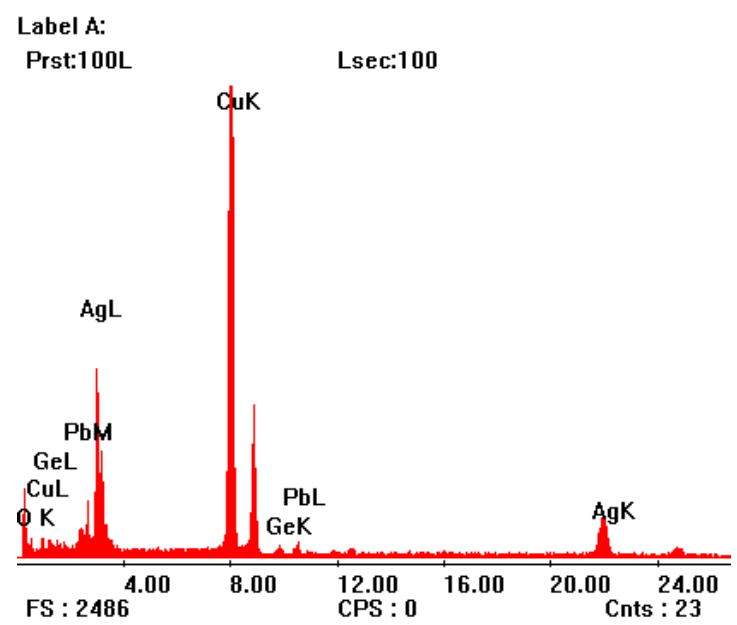

Figura 4.42 - Espectro de EDS da amostra T2Y3A (6h - 500).

$\mathrm{Na}$ imagem de MET apresentada na Figura 4.43 observamos a presença de dois tamanhos de NPs de prata distintos, confirmando a explicação para o surgimento de duas bandas de RPS, como podemos ver na Figura 4.38, onde a amostra T2Y3A (6h - 540) apresenta uma banda em $\approx 425 \mathrm{~nm}$ e outra em $\approx 485 \mathrm{~nm}$. O tamanho médio das NPs menores, neste caso, foi de $\approx 2,5 \mathrm{~nm}$ e das maiores de $\approx 12,5 \mathrm{~nm}$.
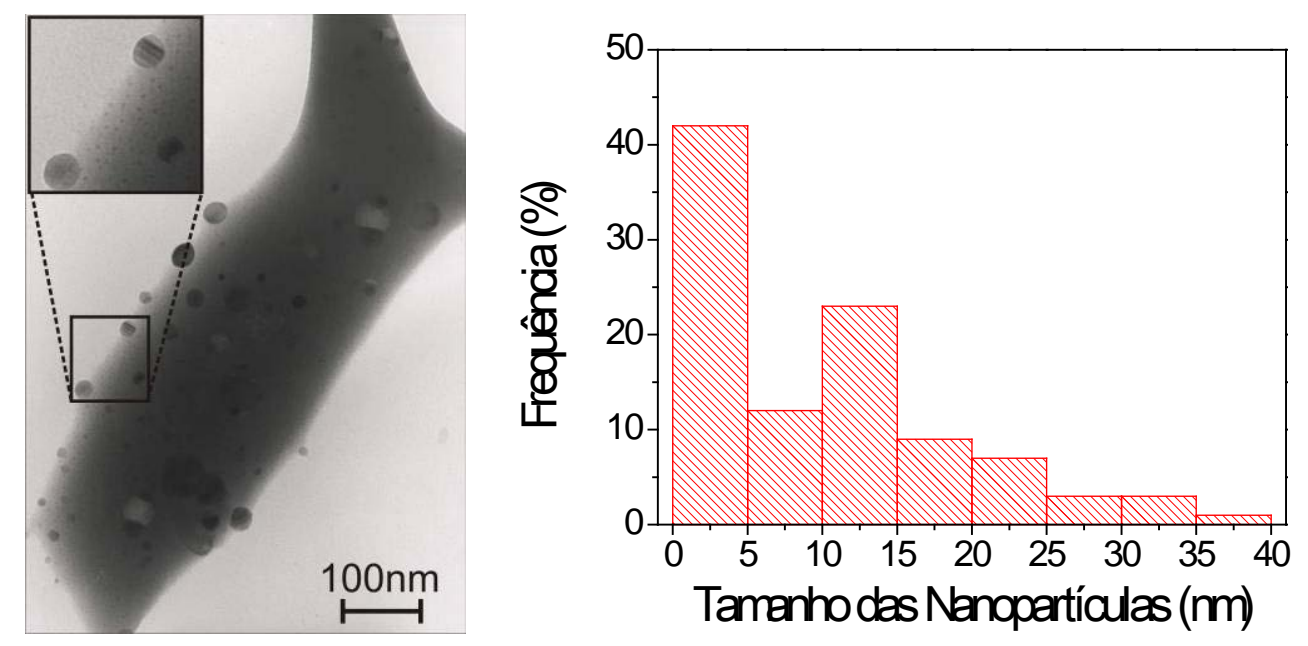

Figura 4.43 - Micrografia e histograma da amostra T2Y3A (6h - 540).

O espectro de EDS apresentado na Figura 4.44 confirma a composição das NPs como sendo de prata. Contudo, apresenta também as raias dos elementos da matriz, já que as NPs se encontram inseridas na massa vítrea. 


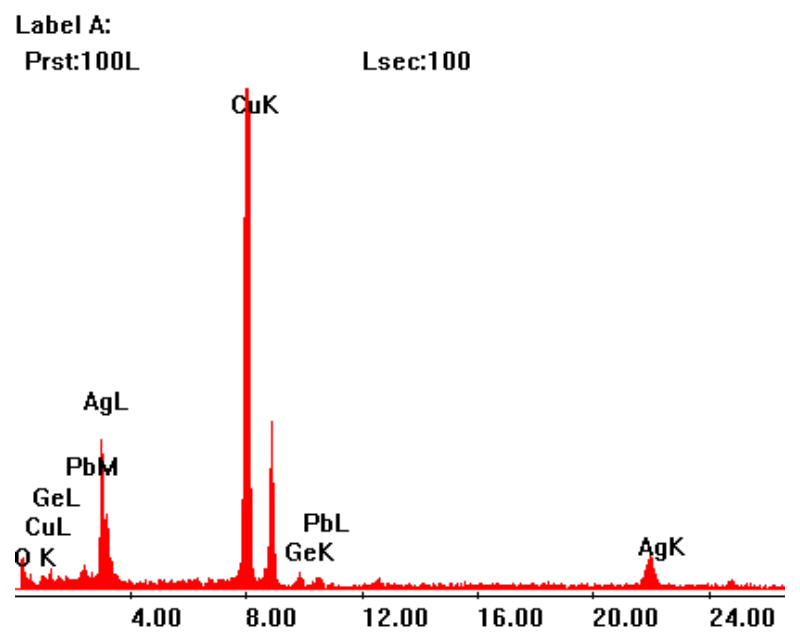

Figura 4.44 - Espectro de EDS da amostra T2Y3A (6h - 540).

Na MET da amostra T2Y3A (6h - 570), apresentada na Figura 4.45, também observamos a presença de dois tamanhos de NPs de prata distintos, confirmando, da mesma forma, o surgimento de duas bandas de RPS. O tamanho médio das NPs menores foi de $\approx 4,5 \mathrm{~nm}$ e das maiores de $\approx 40$ à $60 \mathrm{~nm}$. Apesar da evidencia de apenas 2 NPs maiores nesta micrografia, sabemos que a concentração de ambos os tamanhos é alta devido a intensidade de absorção apresentada anteriormente (Figura 4.38).
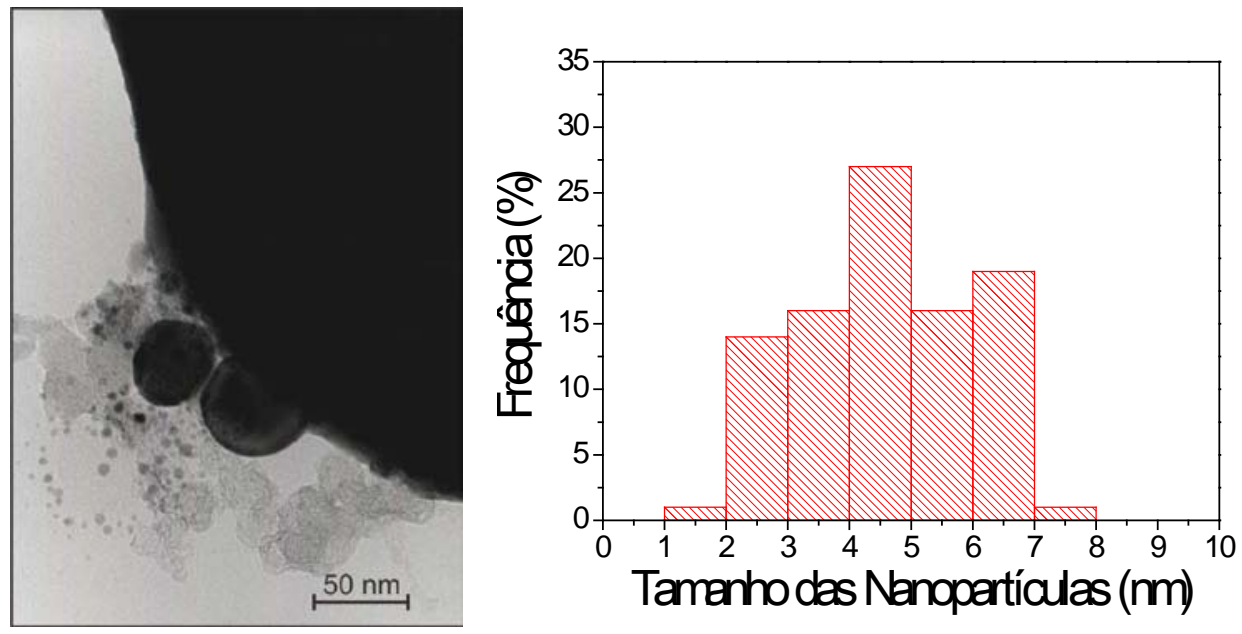

Figura 4.45 - Micrografia e histograma da amostra T2Y3A (6h - 570).

O espectro de EDS da amostra T2Y3A $(6 \mathrm{~h}$ - 570) confirmou a presença de NPs de prata, como pode ser visto na Figura 4.46. 


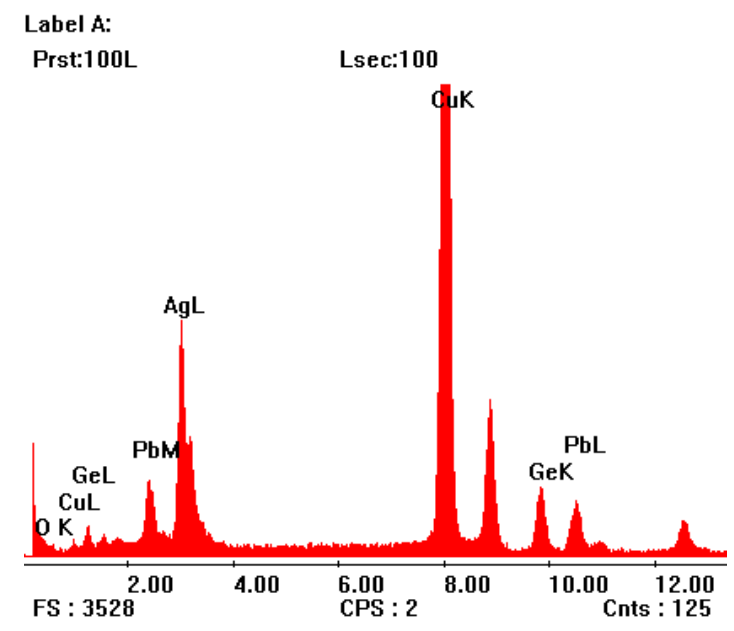

Figura 4.46 - Espectro de EDS da amostra T2Y3A (6h - 570).

Desta forma conseguimos verificar que a temperatura é um dos fatores que mais interfere no processo de nucleação das NPs metálicas. Como cada material possui uma temperatura diferente de cristalização, para cada tipo de elemento metálico teremos uma temperatura de nucleação de NPs ideal. Este procedimento nos permite empiricamente encontrar a temperatura de nucleação ideal.

Cabe acrescentar que testes desta natureza foram feitos em vidros de telureto, e mostraram que este sistema vítreo não suporta tratamentos superiores a temperatura de tratamento térmico para alivio das tensões.

No caso das amostras tratadas à $540{ }^{\circ} \mathrm{C}$ por 12 horas, observamos os mesmos resultados das amostras tratadas por 6 horas. Entretanto, a amostra que foi tratada por 12 horas continuamente apresentou também a formação de NPs de chumbo-germânio, o que caracteriza a cristalização parcial de um dos elementos da matriz vítrea. $\mathrm{Na}$ amostra tratada à $570{ }^{\circ} \mathrm{C}$ este efeito também foi verificado, onde se obteve NPs de chumbo. A Figura 4.47 apresenta as imagens de MET destas amostras. Foram obtidas NPs de chumbo-germânio de $\approx 15 \mathrm{~nm}$ para a amostra T2Y3A $(12 \mathrm{~h}-540)$ e NPs de chumbo de $\approx 35 \mathrm{~nm}$ para a amostra T2Y3A $(6 \mathrm{~h}-570)$.

Os espectros de EDS apresentados na Figura 4.48 confirmam a presença de NPs de chumbo-germânio e chumbo nas amostras T2Y3A (12h - 540) e T2Y3A (6h $-570)$. 

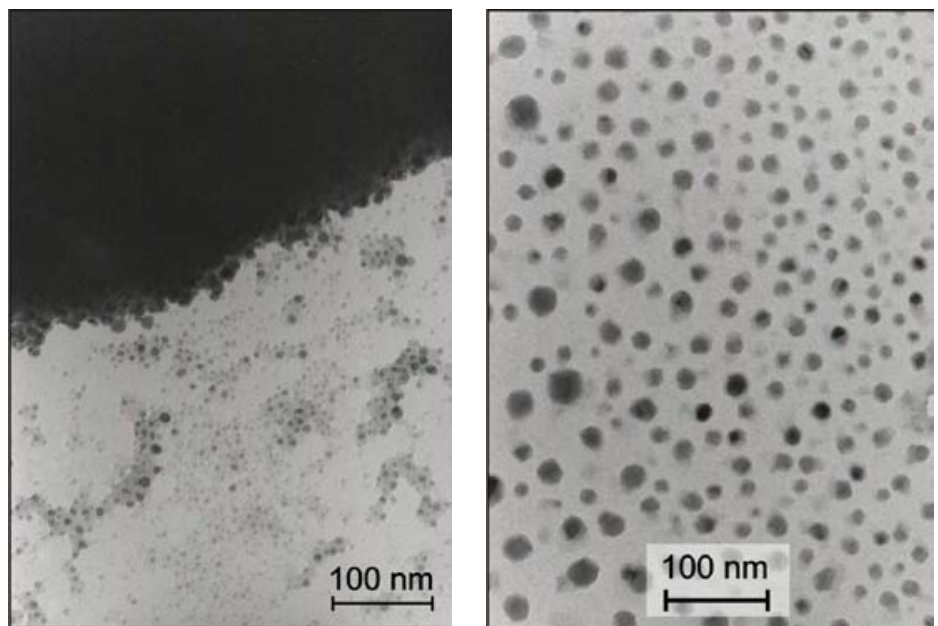

Figura 4.47 - Micrografias das amostra T2Y3A (12h - 540) (à esq.) e T2Y3A (6h - 570) (à dir.), onde foram observadas NPs de chumbo-germânio e chumbo.
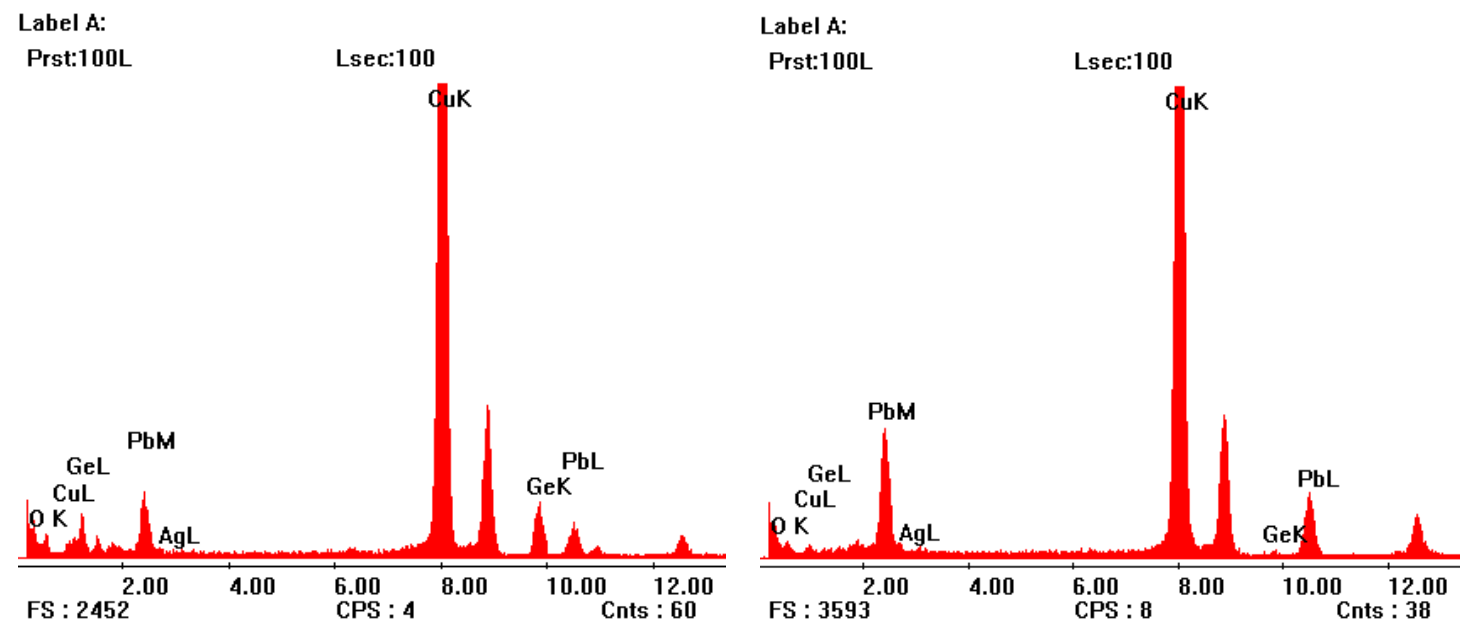

Figura 4.48 - Espectro de EDS das amostra T2Y3A (12h - 540) (à esq.) e T2Y3A (6h - 570) (à dir.), onde foram observadas NPs de chumbo-germânio e chumbo.

\subsubsection{Medidas de Luminescência}

Os espectros de emissão mostrados na Figura 4.49 foram obtidos no LVD, utilizando o mesmo arranjo experimental e parâmetros para as medidas realizadas para as amostras codopadas com $\mathrm{Tm}_{2} \mathrm{O}_{3}$ e $\mathrm{Yb}_{2} \mathrm{O}_{3}$ produzidas em cadinho de alumina-silicato. Podemos observar um aumento considerável da emissão em 480 $\mathrm{nm}$ (transição ${ }^{1} \mathrm{G}_{4} \rightarrow{ }^{3} \mathrm{H}_{6}$ ), que cresce à medida que aumentamos a temperatura de tratamento térmico. O crescimento em função da temperatura se deve inicialmente ao aumento da concentração das NPs de prata que, por possuírem banda de RPS 
na região entre 420 e $550 \mathrm{~nm}$, interagem com esta transição, de forma a proporcionar um aumento do campo local nas proximidades dos íons de $\mathrm{Tm}^{3+}$.

Entretanto, a emissão em $650 \mathrm{~nm}$ (transição ${ }^{1} \mathrm{G}_{4} \rightarrow{ }^{3} \mathrm{~F}_{4}$ ) sofreu menor interferência das NPs, já que a probabilidade desta transição é baixa e não ressonante com a banda de RPS da prata, quando estas possuem tamanho médio compreendido entre 2 e $60 \mathrm{~nm}$, como visto na Figura 4.45. O aumento desta luminescência e da emissão em $800 \mathrm{~nm}$ (transição ${ }^{3} \mathrm{H}_{4} \rightarrow{ }^{3} \mathrm{H}_{6}$ ) é atribuído à presença de NPs maiores do que $60 \mathrm{~nm}$, onde a RPS da prata pode ocorrer em comprimentos de onda maiores, isto é, nas regiões vermelha e infravermelha do espectro eletromagnético, como explicado no item 2.4. O aumento observado para estas emissões é consideravelmente baixo devido à baixa concentração das NPs maiores. À medida que aumentamos a temperatura de tratamento térmico, obtemos um aumento da concentração destas NPs, e assim, um aumento da luminescência em 650 e $800 \mathrm{~nm}$.

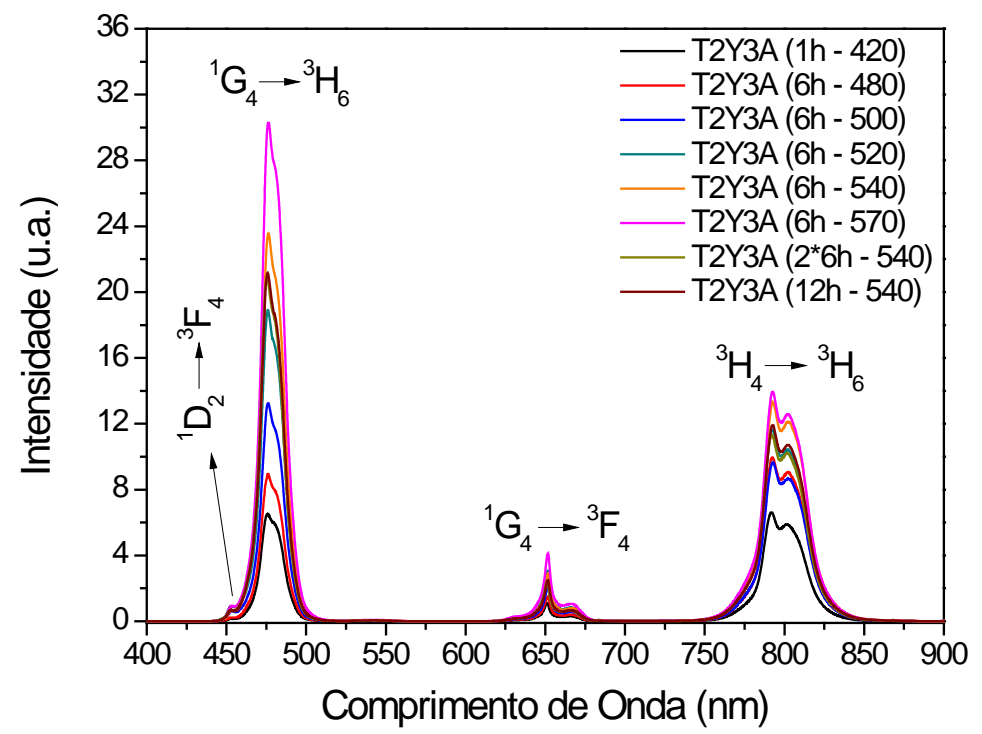

Figura 4.49 - Espectro de emissão das amostras T2Y3A, tratadas em diferentes temperaturas.

Com o intuito de verificar a interferência das NPs no processo de CA dos íons $\mathrm{Tm}^{3+}$, foram realizados testes de variação da intensidade de luminescência em função da potência do laser. Como pode ser visto na Figura 4.50, a quantidades de fótons envolvidos no processo de CA para cada emissão se manteve próxima das obtidas para a amostra T2Y3A (60h - 420) (Figura 4.22), mostrando assim que o aumento da luminescência ocorre provavelmente pelo aumento do campo local, como visto no item 2.4 . 


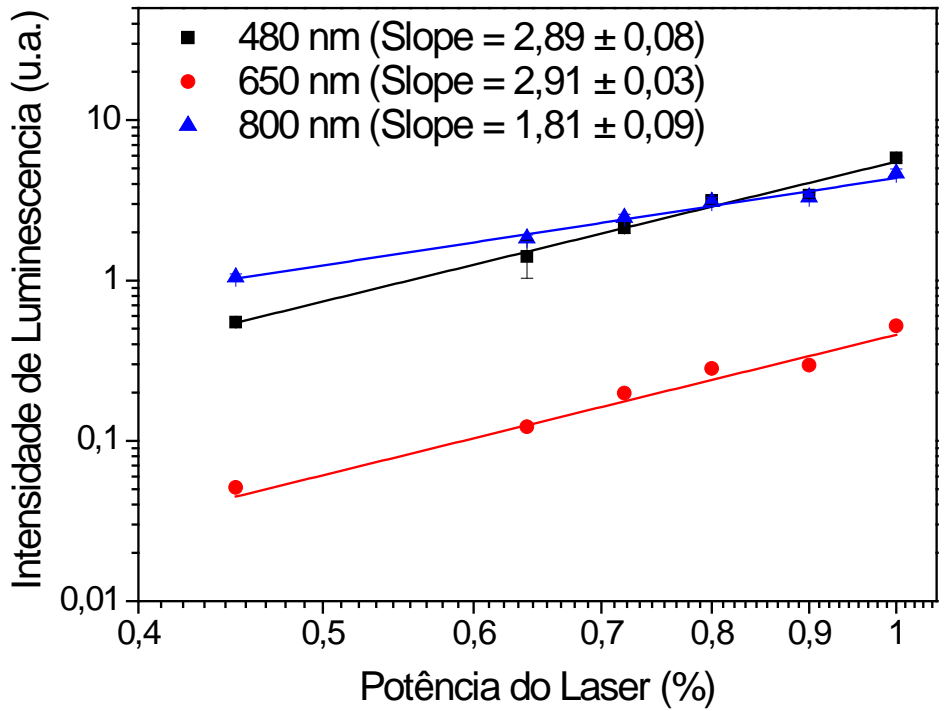

Figura 4.50 - Intensidade de luminescência em função da potência do laser para a amostra T2Y3A $(6 h-570)$.

Considerando os espectros obtidos para as amostras produzidas em cadinho de alumina-silicato, e comparando-os aos espectros obtidos para a as amostras T2Y3A produzidas em cadinho de alumina pura (Figura 4.51), observamos que as amostras produzidas no primeiro cadinho, contendo NPs de prata, apresentavam intensidades de luminescência inferiores a amostra T3Y. Entretanto, após obtermos uma nucleação de NPs de prata mais eficiente, a partir do aumento da temperatura de tratamento térmico, obtivemos intensidades de luminescência, em $480 \mathrm{~nm}$, superiores a da amostra T3Y, para tratamentos a 540 e $570{ }^{\circ} \mathrm{C}$ (Figura 4.49).

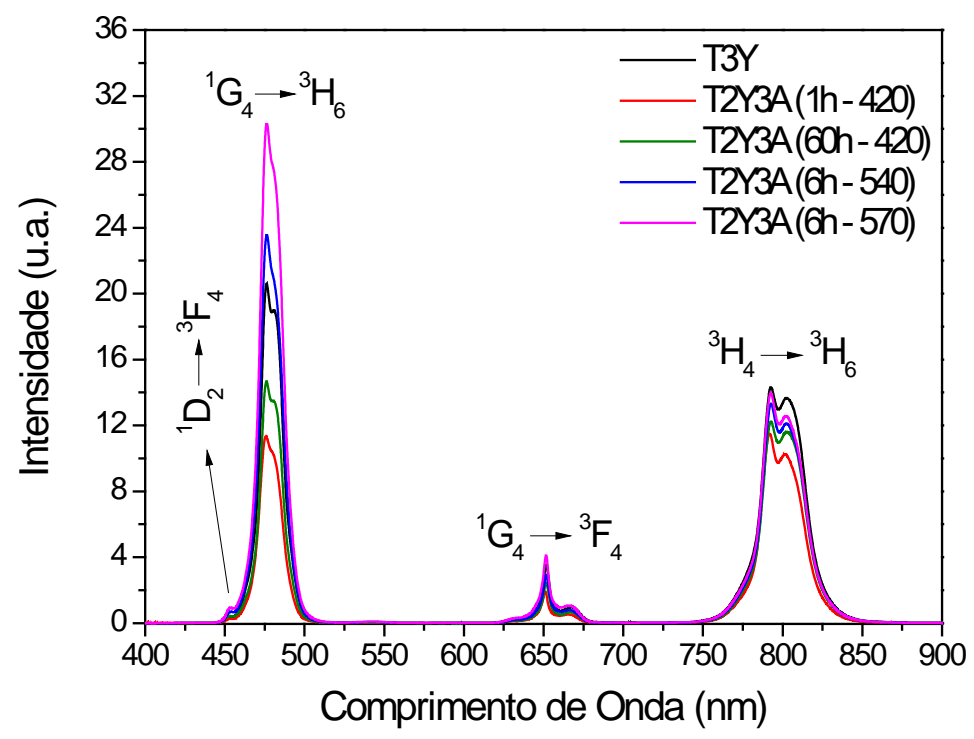

Figura 4.51 - Espectro de emissão comparando as amostras produzidas em cadinho de $\mathrm{Al}_{2} \mathrm{O}_{3}-\mathrm{SiO}_{2} \mathrm{e}$ em cadinho de $\mathrm{Al}_{2} \mathrm{O}_{3}$, tratadas por diferentes tempos e temperaturas. 


\subsection{CONSIDERAÇÕES FINAIS}

Considerando os métodos de nucleação de NPs elencados neste trabalho, serão apresentados na Tabela 4.1 os resultados obtidos para a determinação do número de fótons absorvidos, destacando em cada caso o cadinho utilizado, bem como o tipo de tratamento térmico empregado.

Tabela 4.1 - Resumo dos resultados referentes a determinação do número de fótons absorvidos $(n)$ nas emissões relativas ao processo de conversão ascendente das amostras estudas neste trabalho.

\begin{tabular}{ccccc}
\hline Amostra & $\begin{array}{c}\text { Comprimento de } \\
\text { Onda da Emissão } \\
(\mathbf{n m})\end{array}$ & $\boldsymbol{n}$ & Cadinho Usado & Tipo de Tratamento Térmico \\
\hline $\begin{array}{c}\mathrm{T} 2 \mathrm{Y} 3 \mathrm{~A} \\
(60 \mathrm{~h}-420)\end{array}$ & 480 & 3,32 & & Figura 3.3 \\
& 650 & 3,32 & $\mathrm{Al}_{2} \mathrm{O}_{3}-\mathrm{SiO}_{2}$ & \\
\hline $\mathrm{T} 5 \mathrm{~A}$ & 800 & 2,18 & & Figura 3.4 \\
$(24 \mathrm{~h}-420)$ & 455 & 4,29 & & \\
\hline & 480 & 3,32 & $\mathrm{Al}_{2} \mathrm{O}_{3}$ & Figura 3.5 \\
\hline T2Y3A & 650 & 3,28 & & \\
$(6 \mathrm{~h}-570)$ & 480 & 2,89 & & \\
& 650 & 2,91 & $\mathrm{Al}_{2} \mathrm{O}_{3}$ & \\
\hline
\end{tabular}

Para os casos em que o valor de $n$ é superior a 3 (emissões em 480 e 650 $\mathrm{nm}$ ), superior a 2 (emissão em $800 \mathrm{~nm}$ ) e superior 4 (emissão em $455 \mathrm{~nm}$ ), podemos dizer que houve a participação de outros processos além do que foi apresentado no item 2.3.2, tais como, efeitos térmicos por bombeio e por geração de fônon. Nesses casos, apesar da existência destes outros processos, podemos afirmar que, majoritariamente, os íons $\mathrm{Tm}^{3+}$ absorveram 3, 2 e 4 fótons, em cada caso anteriormente apontado.

No caso da amostra T2Y3A (6h - 570), os valores de $n$ são inferiores aos previstos teoricamente. Isto ocorre, pois as medidas podem ter sido realizadas em regime de saturação da emissão; tal fenômeno pode ser decorrente também da interferência da nucleação da NPs no processo de conversão ascendente. Ressaltase ainda que foi nesta amostra que observamos a maior aumento na luminescência, conforme mostrado na Figura 4.51. 


\section{CONCLUSÕES E PERSPECTIVAS}

Amostras do sistema GP codopadas com os óxidos de TRs $\mathrm{Tm}_{2} \mathrm{O}_{3}$ e $\mathrm{Yb}_{2} \mathrm{O}_{3}$ mostraram grande eficiência nos processos de $\mathrm{CA}$ envolvidos. Devido à baixa concentração de $\mathrm{Tm}_{2} \mathrm{O}_{3}$ utilizada, a CA se deu predominantemente pela AEE por TE dos íons $\mathrm{Yb}^{3+}$ para os íons $\mathrm{Tm}^{3+}$. Através do estudo da concentração de $\mathrm{Yb}_{2} \mathrm{O}_{3} \mathrm{em}$ função da intensidade de emissão, conseguimos determinar que para as emissões em $\approx 480 \mathrm{~nm}$ e $\approx 650 \mathrm{~nm}$ são envolvidos 3 íons $\mathrm{Yb}^{3+}$ para cada íon $\mathrm{Tm}^{3+}$. Para a emissão em $\approx 800 \mathrm{~nm}$ são envolvidos 2 íons $\mathrm{Yb}^{3+}$ para cada íon $\mathrm{Tm}^{3+}$. A eficiência dos íons $\mathrm{Yb}^{3+}$ no processo de TE para os íons $\mathrm{Tm}^{3+}$ pode ser observada a partir do aumento considerável da emissão em $\approx 480 \mathrm{~nm}$, que passou a ser superior a da emissão em $\approx 800 \mathrm{~nm}$.

Foram preparadas amostras somente com $\mathrm{Tm}_{2} \mathrm{O}_{3}$, nas quais pudemos observar que as emissões são menos intensas do que as das amostras codopadas.

Com relação às amostras preparadas com NPs de prata, observamos maior interferência nas emissões das amostras preparadas somente com $\mathrm{Tm}_{2} \mathrm{O}_{3}$, em relação às amostras tratadas à $420^{\circ} \mathrm{C}$ preparadas com $\mathrm{Tm}_{2} \mathrm{O}_{3}$ e $\mathrm{Yb}_{2} \mathrm{O}_{3}$ e $\mathrm{AgNO}_{3}$. Observou-se também que as amostras codopadas e sem NPs apresentaram maiores luminescências do que as mesmas preparadas com $\mathrm{AgNO}_{3}$.

Com relação aos diferentes tratamentos térmicos utilizados para a nucleação, podemos concluir que nos tratamentos contínuos há maior tendência para a formação de aglomerados que coalescem formando agregados. Para os tratamentos não contínuos observamos a tendência de fragmentação das NPs à medida que aumentamos o tempo de tratamento. No caso das amostras tratadas em diferentes temperaturas observamos um aumento considerável da luminescência a medida que aumentamos a temperatura, assim como o surgimento da banda de RPS da prata.

Vimos, através destes métodos, que a melhor forma de obter uma alta concentração de NPs de prata é por meio da utilização de temperaturas mais elevadas e uso de pequenos intervalos, para o tratamento térmico.

No caso da matriz estudada neste trabalho, isto foi observado para temperaturas acima de $500^{\circ} \mathrm{C}$, para as quais há mudanças na banda de absorção dos PS da prata. Para as temperaturas no intervalo de 500 e $520^{\circ} \mathrm{C}$ observamos a 
formação de uma única banda, e para as superiores, a formação de duas bandas de RPS. Cabe acrescentar que o aumento da temperatura (superiores a $540{ }^{\circ} \mathrm{C}$ ) proporcionou a formação de NPs maiores e, consequentemente, a diminuição da concentração e o aumento da distribuição de tamanho destas, evidenciado pela diminuição da intensidade da banda de RPS e pelo seu alargamento, respectivamente.

Para os resultados de emissão das amostras codopadas, concluímos que o melhor procedimento para a nucleação das NPs que propicia aumento considerável da luminescência é o que utilizou tratamento térmico em curto intervalo de tempo em temperaturas superiores a $540{ }^{\circ} \mathrm{C}$. Para o caso das amostras preparadas apenas com $\mathrm{Tm}_{2} \mathrm{O}_{3}$, notamos a tendência de maiores luminescências para as amostra que foram tratadas descontinuamente. A inovação e contribuição do trabalho em questão estão na utilização, pela primeira vez, de tratamentos térmicos realizados acima da $T_{g}$ (temperatura de transição vítrea) e no fracionamento das NPs devido aos curtos intervalos de tempo de tratamento. Tais fenômenos não foram reportados na literatura até o momento para os vidros de germanato com NPs de prata.

Os vidros de germanato apresentam características bastante promissoras para a nucleação de NPs metálicas e nanoestruturas. Dentre as matrizes estudadas pelo grupo, o sistema binário GP já foi consagrado com várias publicações acerca da nucleação de NPs metálicas de vários elementos, tais como, ouro, prata e cobre. No estudo envolvido neste trabalho, conseguimos verificar que este sistema é eficiente tanto no processo de nucleação quanto na incorporação dos íons de TRs, viabilizando sua aplicação como dispositivo fotônico e optoeletrônico. 


\section{SUGESTÕES PARA TRABALHOS FUTUROS}

Como sugestões para trabalhos futuros, podemos apresentar:

- Preparar amostras contendo NPs de diversas naturezas e dopadas com diferentes íons de TR, objetivando o estudo da influência das NPs metálicas nas diferentes emissões dos íons de TR;

- Aplicar o método de nucleação apresentado neste trabalho em amostras contendo outros tipos de reagente metálico, verificando assim a influência da mudança do processo no tamanho e forma das NPs obtidas, e a temperatura adequada para a nucleação de NPs de outras espécies;

- Explorar outras formas de tratamento térmico e a influência dos íons de TRs no processo de nucleação das NPs;

- Obter a nucleação das NPs por meio de laser de femtosegundos;

- Estudar as propriedades ópticas não lineares dos vidros;

- Produzir filmes finos vítreos nanoestruturados, utilizando como alvos as matrizes vítreas apresentadas neste trabalho, contendo NPs metálicas, para a produção de guias de onda nanoestruturadas; 


\section{REFERÊNCIAS BIBLIOGRAFICAS}

1. P. N. Prasad, Nanophotonics (Wiley-Interscience, New Jersey, 2004);

2. L. Armelao et al., Coordination Chemistry Reviews, 250 (2006) 1294;

3. Atwater, Harry A., Scientific American, 3 (2007) 38;

4. L. R. P. Kassab, C. B. de Araújo, Germanate and tellurite glasses for photonic applications, in Photonics Research Developments (Nova Science Publishers, New York, 2008) Capítulo 13, 385.

5. V. N. Sigaev et al., Journal of Non-Crystalline Solids, 279 (2001) 136;

6. A. S. Gouveia-Neto et al., Journal of Applied Physics, 94 (2003) 5678;

7. A. Margaryan, M. A. Piliavin, Germanate Glasses: Structure, Spectroscopy, and Properties (Artech House, Norwood, 1993);

8. J. R. Bonar et al., Optics Communications, 141 (1997) 137;

9. M. J. S. Brandão et al., Journal of Applied Physics, 99 (2006) 113525;

10. M. J. F. Digonnet, Rare-Earth Doped Fiber Lasers and Amplifiers (Dekker, New York, 1993);

11. S. L. de Oliveira; L. A. O. Nunes, Investigação espectroscópica de sistemas vítreos dopados com $\mathrm{Tm}^{3+}, \mathrm{Ho}^{3+}$ e $\mathrm{Nd}^{3+}$. Dissertação de mestrado. Instituto de Física de São Carlos, Universidade de São Paulo. São Carlos, 2004;

12. S. Xu et al., Solid State Communications, 133 (2005) 89;

13. P. S. F. Matos, N. U Wetter, Investigação de Lasers de Fluoreto dopados com túlio e bombeados por diodo laser. Tese de doutorado. Instituto de Pesquisas Energéticas e Nucleares, Universidade de São Paulo. São Paulo, 2006;

14. L. R. P. Kassab et al., Applied Physics B: Lasers and Optics, 94 (2009) 239;

15. L. R. P. Kassab et al., Journal of Applied Physics, 105 (2009) 103505;

16. T. A. A. Assumpção et al., Journal of Applied Physics, 106 (2009) 063522;

17. K. J. Rao, Structural Chemistry of Glasses (Elsevier, India, 2002);

18. A. R. Boccaccini et al., Journal of the European Ceramic Society, 21 (2001) 1073;

19. J. Zarzycki, Glasses and the vitreous state (Cambridge University Press, GrãBretanha, 1991); 
20. D. M. da Silva, Produção e caracterização de materiais vítreos de germanato com nanopartículas metálicas e íons de érbio para aplicações em fotônica. Dissertação de Mestrado. Escola Politécnica da Universidade de São Paulo. São Paulo, 2007;

21. H. G. Pfaender, Schott guide to Glass (Cambridge University Press, GrãBretanha, 1996);

22. W. H. Zachariasen, Journal of American Chemical Society, 54 (1932) 3841;

23. V. M. Goldschmidt, Transactions of Faraday Society, 25 (1929) 253;

24. J. C. Lapp, W. H. Dumbaugh, Journal of American Ceramic Society, 75 (1992) 2315;

25. H. Zheng, R. Xu, J. D. Mackenie, Journal of Materials Research Society, 4 (1989) 911;

26. M. Tatsumisago et al., Applied Physics Letters, 55 (1989) 600;

27. L. R. P. Kassab et al., Optics Communications, 269 (2007) 148;

28. M. Piasecki et al., Materials Letters, 61 (2007) 2943;

29. J. S. Wzang et al., Optical Materials, 3 (1994) 187;

30. M. Jackson, Institute of Rock Magnetism - The IRM Quarterly, 3 (2000);

31. Encyclopædia Britannica. Disponível em: http://www.britannica.com/ EBchecked/topic/491579/rare-earth-element/81142/History\#. Acesso: 20 de outubro de 2009;

32. N. G. Connelly et al., Nomenclature of Inorganic Chemistry - IUPAC Recommendations, The Royal Society of Chemistry (2005);

33. O. Laporte e W. F. Meggers, Journal of the Optical Society of America, 11 (1925) 459;

34. W. T. Carnall et al., Journal of Chemical Physics, 90 (1989) 3443;

35. F. H. Jagosich, Estudos espectroscópicos para o desenvolvimento dos meios laser ativos de $\mathrm{Ho}^{3+}$ e $\mathrm{Tm}^{3+}$ no YLF que operam na região de 3 microns. Dissertação de mestrado. Instituto de Pesquisas Energéticas e Nucleares, Universidade de São Paulo. São Paulo, 2000;

36. L. R. P. Kassab et al., Optics Communications, 269 (2007) 356;

37. L. R. P. Kassab et al., Journal of Non-Crystalline Solids, 351 (2005) 3468;

38. C. B. de Araújo et al., Applied Physics Letters, 68 (1996) 602;

39. S. W. Zhao et al., Chalcogenide Letters, 2 (2005) 97; 
40. J. Emsley, Nature's building blocks: an A-Z guide to the elements (Oxford University Press, Nova York, 2001);

41. A. Rapaport et al., Optics Express, 12 (2004) 5215;

42. M. Dulick et al., Journal of Luminescence, 48 (1991) 517.

43. T. Hebert et al., Applied Physics Letters, 60 (1992) 2592;

44. A. Diening et al., Journal of Applied Physics, 84 (1998) 5900;

45. E. Hunter e J. H. Fendler, Advanced Materials, 16 (2004) 1685;

46. H. Hofmeister et al., Applied Physics Letters, 70 (1997) 1694;

47. G. Fu et al., Applied Physics Letters, 83 (2003) 36;

48. S. Qu et al., Applied Physics Letters, 84 (2004) 2046;

49. A. Podlipensky et al., Journal of Physical Chemistry B, 108 (2004) 17699;

50. Y. Hamanaka et al., Applied Physics Letters, 75 (1999) 1712;

51. S. Qu et al., Chemical Physics Letter, 368 (2003) 352;

52. L. Yang et al., Applied Physics Letters, 78 (2001) 102;

53. A. Abdolvand, Modification Of Optical And Structural Properties Of Glass Containing Silver Nanoparticles Via Dc Electric Field And Moderately Elevated Temperatures. Dissertação de Doutorado. ULB Sachsen-Anhalt. Alemanha, 2006;

54. T. Hayakawa, S.T. Selvan, M. Nogami, Applied Physics Letters, 74 (1999) 1513;

55. L. S. Bonifácio, Processos de agregação e fusão de nanopartículas de ouro: uma abordagem química. Instituto de Química, Universidade de São Paulo, 2008.

56. V. K. Lamer, Transactions of the Faraday Society, 48 (1952) 410;

57. T. R. da Rocha, Nanopartículas metálicas anisotrópicas: mecanismos de formação e aplicações ópticas. Dissertação de Doutorado. Universidade Estadual de Campinas, Instituto de Física "Gleb Wataghin". Campinas - SP, 2008;

58. J.J. Mock et al., Journal of Chemical Physics, 116 (2002) 6755;

59. J. Zhang et al. Journal of Crystal Growth, 310 (2008) 234;

60. M. Mattarelli et al., Physics Review B, 75 (2007) 125102;

61. A. Chiasera et al., Optical Materials, 27 (2005) 1743;

62. F. Stellacci et al., Advanced Materials, 14 (2002) 194;

63. S. K. Mahapatra et al., Nanotechnology, 18 (2007) 135602; 
64. N. H. Ma et al., Materials Letters, 63 (2009) 151;

65. A. P. Nacharov et al., Glass Physics and Chemistry, 34 (2008) 693;

66. A. M. B. Silva, et al., Journal of Physics and Chemistry of Solids, 68 (2007) 729.

67. P.F. James, Physics and Chemistry of Glasses, 15 (1974) 95;

68. J. Deubener et al., Journal of Non-Crystalline Solids 163 (1993) 1;

69. J. Sánchez et al., IV Pricit (Nanotecnología en Espanha) - Plan Regional de Ciência y Tecnologia de la Comunidad de Madrid, (2005);

70. G. Kellermann, Nanoagregados em matrizes vítreas. Dissertação de Doutorado. Instituto de Física "Gleb Wataghin". Universidade Estadual de Campinas. Campinas - SP, 2003;

71. G. C. Hadijapanayis and R. W. Siegel. Nanophase materials: synthesis, properties and applications. Kluwer Academic Publishers, (1994);

72. L. Brus. IEEE Journal of Quantum Electron, QE-22 (1986) 1909;

73. S. Schmitt-Rink et al., Physics Review B, 35 (1987) 8113;

74. M. L. Steigerwald and L. Brus. Annual Review of Material Science, 19 (1989) 471;

75. P. Mazzoldi and G. C. Rhighini. Insulating Materials for Optoeletronics. World Scientific, Singapoure, (1995);

76. F. Hache et al., Physics Review B; 38 (1988) 7990;

77. F. Gonella and P. Mazzoldi. Handbook of Nanostructured Materials and Nanotechnology, (4), Academic. New York, (2000);

78. K. Ushida et al., Journal of the Optical Society of America B, 11 (1994) 1236;

79. H. Itogawa et al., Journal of Non-Crystalline Solids, 210 (1997) 95;

80. L. P. Naranjo et al., Applied Physics Letters, 87 (2005) 241914;

81. D. M. da Silva et al., Applied Physics Letters, 90 (2007) 081913;

82. L. A. Gómez et al. Applied Physics Letters, 92 (2008) 141916;

83. T. Lutz et al., Journal of Alloys and Compounds. 262 (1997) 438;

84. O. A. Yeshchenko et al., Materials Science and Engineering.137 (2007) 247;

85. L. R. P. Kassab et al., Applied Physics B: Lasers and Optics, 94 (2009) 239;

86. F. A. Bomfim et al., Journal of Non-Crystalline Solids, 354 (2008) 4755;

87. L. R. P. Kassab et al., Applied Physics Letters, 94 (2009) 101912;

88. H. Zhang et al., Optics Express, 14 (2006) 4826;

89. J. Liu et al., Optics Communications. 253 (2005) 315; 
90. V. D. D. Cacho, Caracterização de materiais vítreos de germanato dopados com itérbio para uso em circuitos optoeletrônicos. Dissertação de Mestrado. Escola Politécnica da Universidade de São Paulo. São Paulo, 2005;

91. F. A. Bomfim, Produção e Caracterização de Vidros de Óxidos de Metais Pesados Dopadas Com Terras-raras e Nanopartículas Metálicas. Dissertação de Mestrado. Instituto de Pesquisas Energéticas e Nucleares, Universidade de São Paulo. São Paulo, 2009.

92. T. A. A. de Assumpção, Caracterização de amostras de germanato dopadas com Túlio. Trabalho de Conclusão de Curso, FATEC - SP, São Paulo, SP, 2007. 


\section{APÊNDICE A - PARTICIPAÇÕES EM CONFERÊNCIAS E PUBLICAÇÕES}

\section{PUBLICAÇÕES EM PERIÓDICOS}

- $\quad$ T. A. A. de Assumpção, D. M. da Silva, L. R. P. Kassab, J. R. Martinelli, C. B. de Araújo - Influence of the temperature on the nucleation of silver nanoparticles in $\mathrm{Tm}^{3+} / \mathrm{Yb}^{3+}$ codoped PbO-GeO2 glasses. Aprovada publicação no Journal of Non-Crystalline Solids;

- $\quad$ T. A. A. de Assumpção, D. M. da Silva, L. R. P. Kassab, C. B. de Araújo - Frequency upconversion luminescence from $\mathrm{Yb}^{+3}-\mathrm{Tm}^{+3}$ codoped $\mathrm{PbO}-\mathrm{GeO}_{2}$ glasses containing silver nanoparticles. Journal of Applied Physics, 106 (2009) 063522;

- $\quad$ L. R. P. Kassab, R. A. Pinto, D. M. da Silva, T. A. A. de Assumpção, C. B. de Araujo Enhanced luminescence of $\mathrm{Tb}^{3+} / \mathrm{Eu}^{3+}$ doped tellurium oxide glass containing silver nanostructures. Journal of Applied Physics, 105 (2009) 103505;

- L. F. Freitas, T. A. A. de Assumpção, R. A. Pinto, L. R. P. Kassab - Produção e caracterização de amostras vítreas de telureto codopadas com íons de terras-raras e nanopartículas de prata. Boletim Técnico da Faculdade de Tecnologia de São Paulo, 26 (2009) 16;

\section{APRESENTAÇÕES EM CONGRESSOS}

- T. A. A. de Assumpção, D. M. da Silva, L. R. P. Kassab, C. B. de Araújo - Influence of the annealing on the nucleation of Ag nanoparticles in Tm/Yb doped PbO-GeO2 glasses. XII International Conference on the Physics of Non-Crystalline Solids \& 9th International Symposium on Crystallization in Glasses and Liquids, Foz do Iguaçu - PR, 2009. Anunciado oralmente e apresentado em forma de pôster em 2009;

- $\quad$ T. A. A. de Assumpção, L. R. P. Kassab, R. M. B. Diniz, A. S. L. Gomes, C. B. de Araújo. Influence of the heat-treatment on the nucleation of silver nanoparticles in Tm3+ doped $\mathrm{PbO}-\mathrm{GeO} 2$ glasses. International Workshop On Nanophotonics and Biophotonics Recife - PE, 2009. Apresentado na forma de pôster em 2009;

- L. F. Freitas, T. A. A. de Assumpção, R. A. Pinto, D. M. da Silva, L. R. P. Kassab. Produção de vidros de telureto dopados com $\mathrm{Tm}^{3+}$ para aplicações com dispositivos para gravação de dados. $10^{\circ}$ Simpósio de Iniciação Científica e Tecnológica - São Paulo, 2008. Apresentado em forma de pôster em 2008; 